\title{
العدالة التظظيمية في إطار إدراكات العاملين (دراسة ميدانية)
}

الباحثة طيف

$$
\begin{aligned}
& \text { م. د. ناظم جواد الزيدي } \\
& \text { نوري عبد الحميد } \\
& \text { جامعة بغداد/ كلية الادارة و الاقتصاد } \\
& \text { قسم ادارة الاعمال }
\end{aligned}
$$

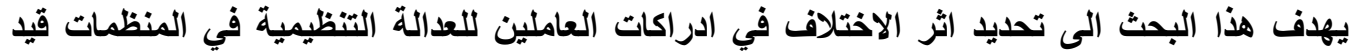

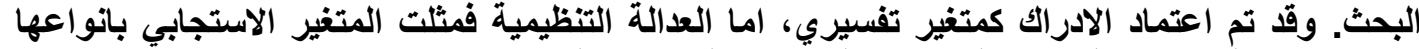

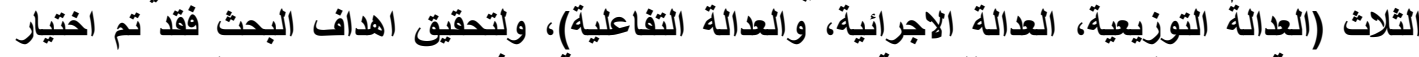

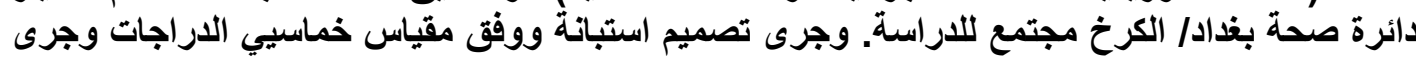

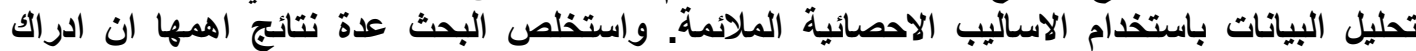

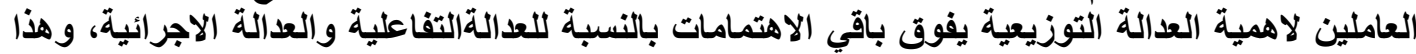

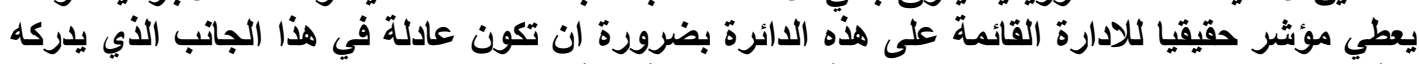

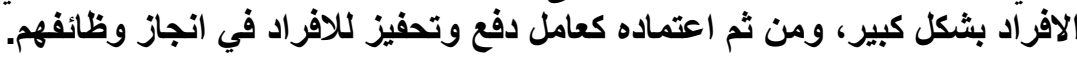

\section{مشكلة البحث}

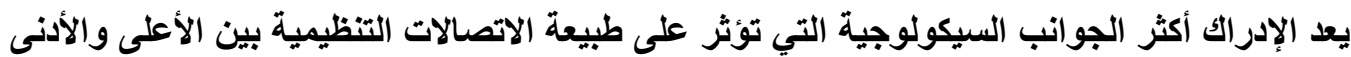

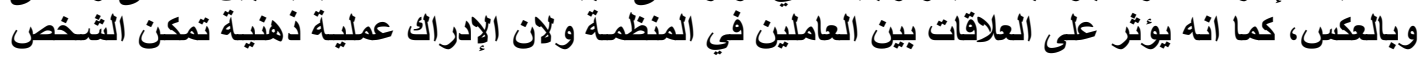

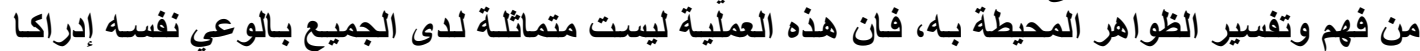

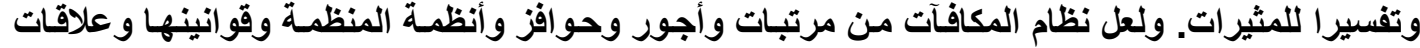

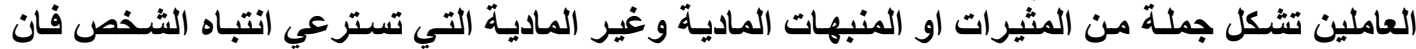

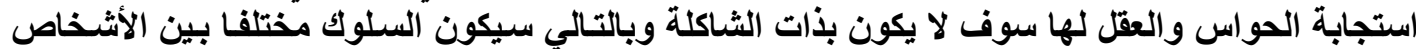

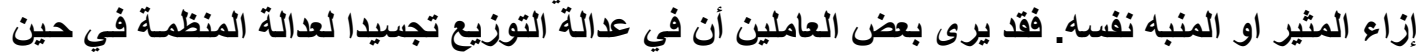

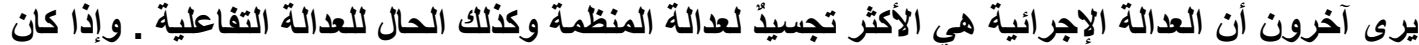

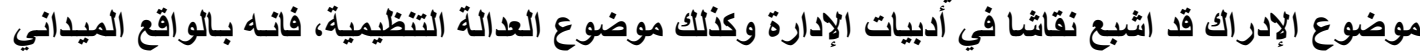

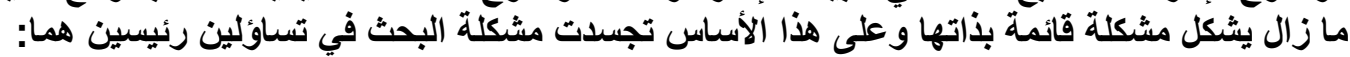

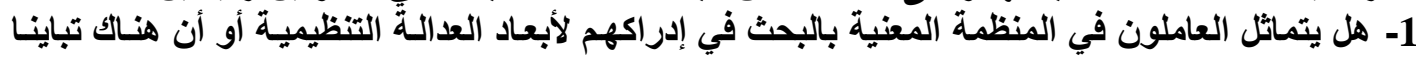

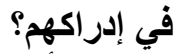

2- هل "هناك تأثير لادراكات العاملين على أبعاد العدالة التنظيمية؟ وأي الأبعاد أكثر استجابة لايهه؟ وكيف

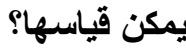

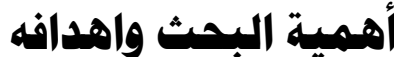

فرضيات البحث

القرضيات الرئيسية للار الئة

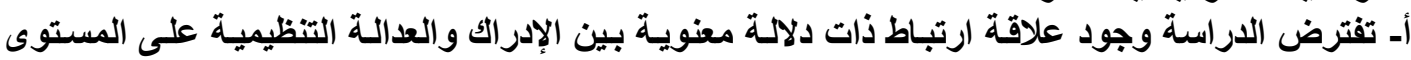

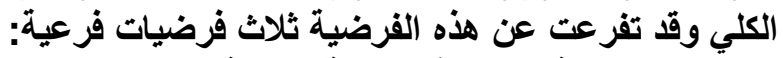

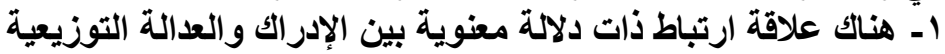

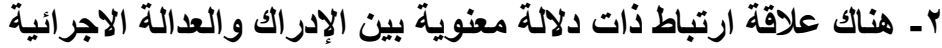

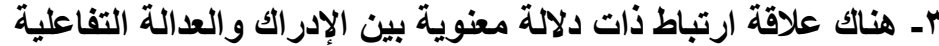

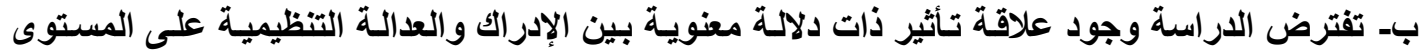
الكلي.

وقد تفرعت عن هذه الفرضية الرئيسة الفرضيات الفرعية آلاتية:

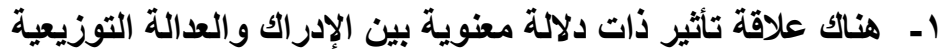

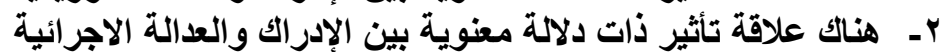

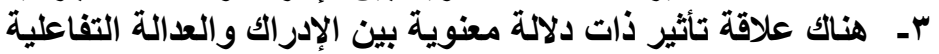




\section{همتهمع وعينة البهث}

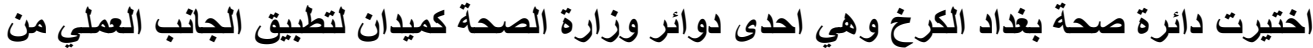

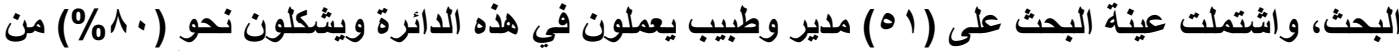

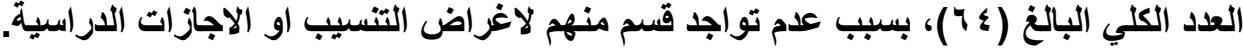

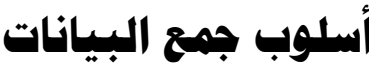

تم جمع البيانات بالاعتماد على مصدرين هما:

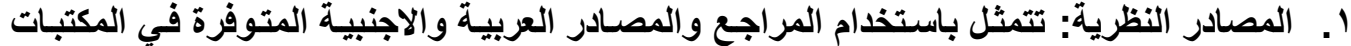

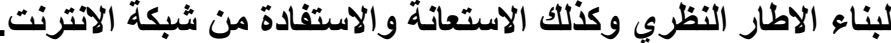

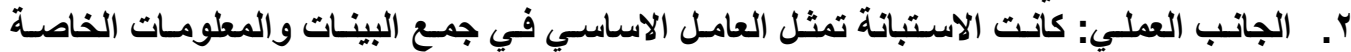

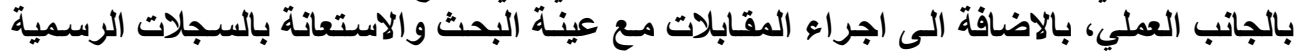

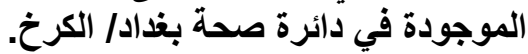

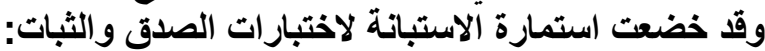

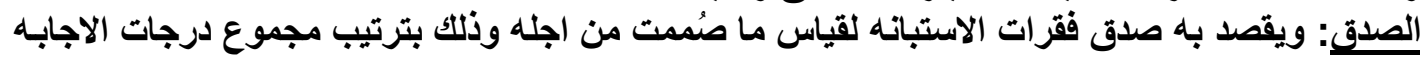

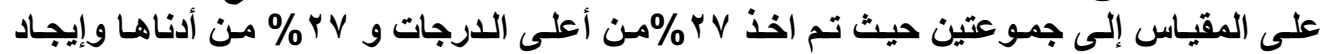

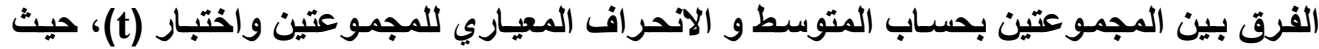

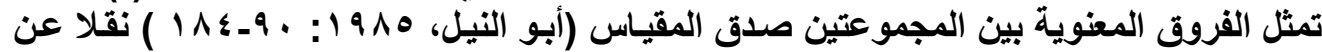

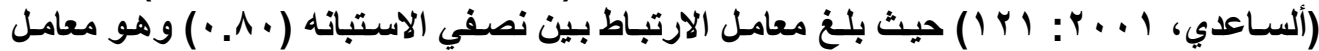

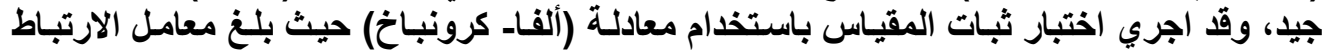

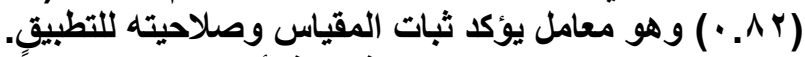

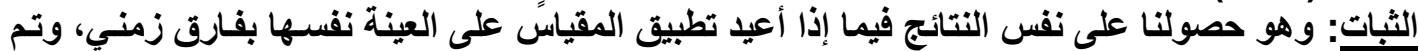

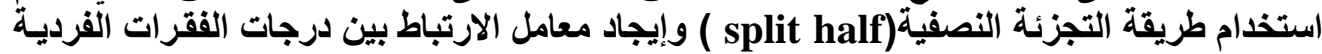

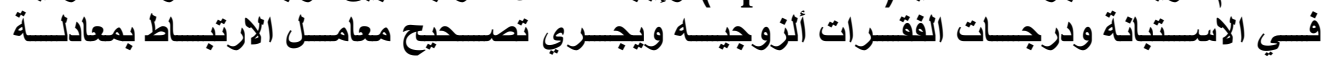

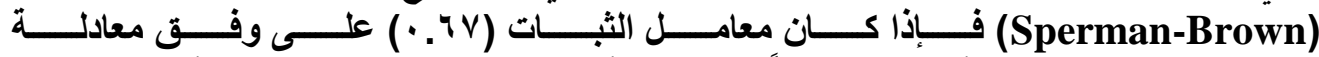

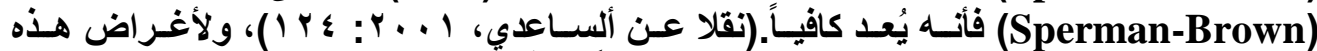

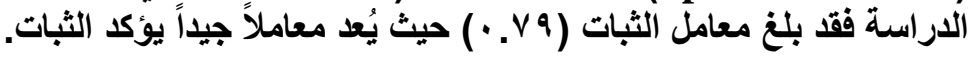

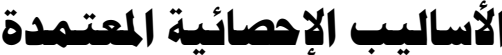

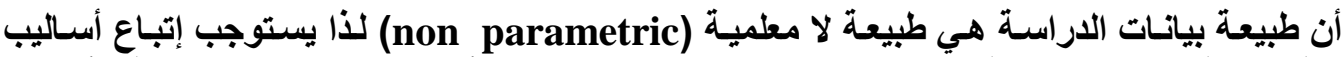
إحصائية ملائمة لتحليل ومعالجة البيانات واختبار البيانات وعلى هذا الأساس فقل اعتمدت الباحثة الأساليب

1- النسبة المئوية (percentage): لعرض البيانات المتعلقة باختيار عينة البحث ووصفها.

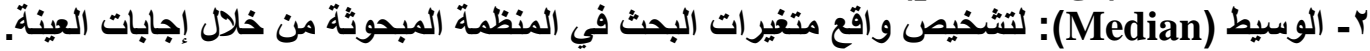
r- آ- المدى (range)

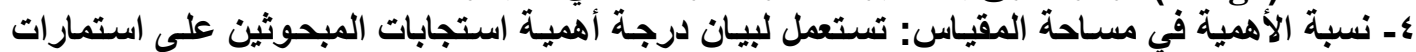

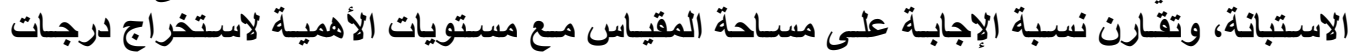

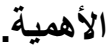

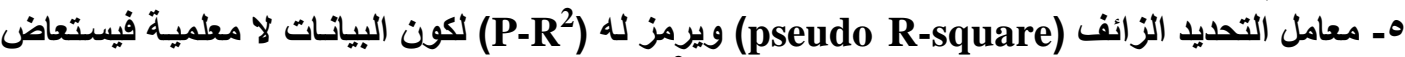

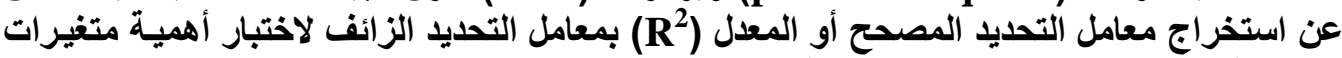

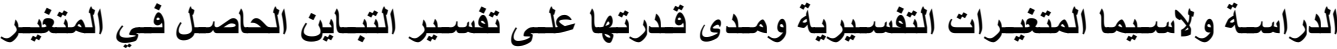

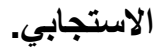

T- معامل الارتباط كندال: هو معامل ارتباط لا معلمي يستخدم لتشخيص العلاقة بين متغيرين أو أكثر آخذا

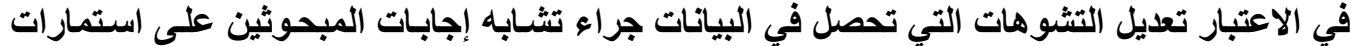

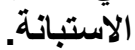

V- اختبار(T test ) (T) (T) لاختبار معنوية معامل الارتباط كندال.

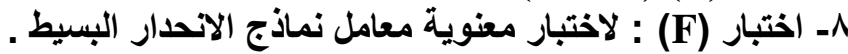

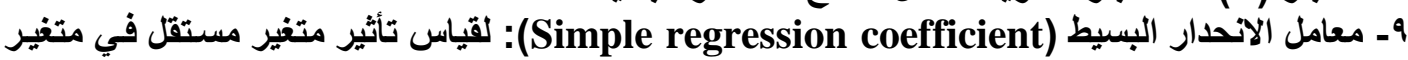
وقد تمت الاستعانة بالبرنامج الإحصائي الجاهز (SPSS.14) لمعالجة البيانات واستخراج النتائج. 


\section{Perception الإدراك}

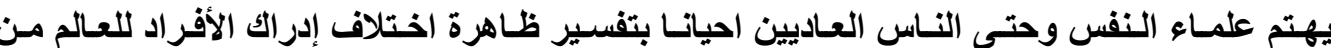

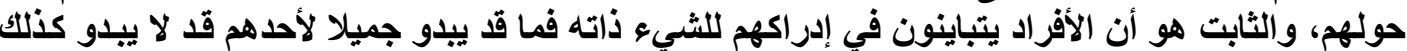

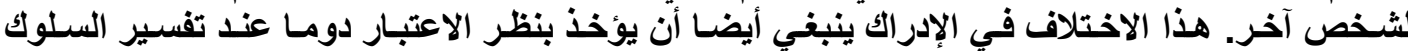
التظظيمي للعاملين في المنظمات.

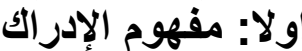

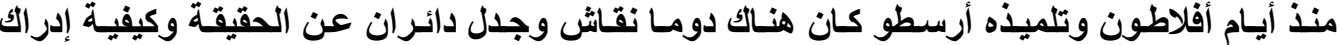

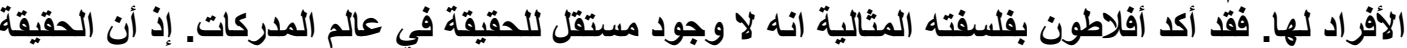

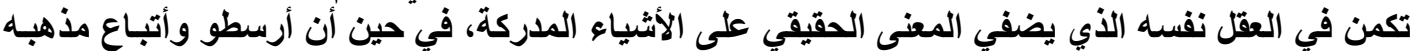

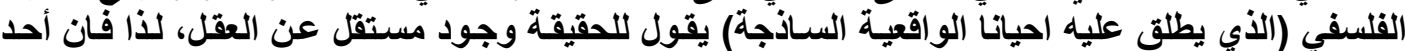

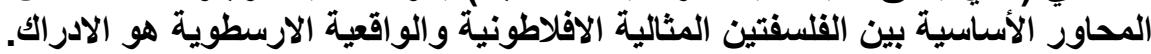

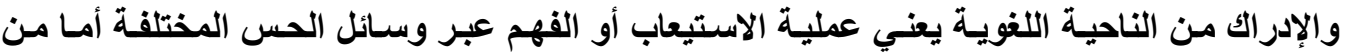

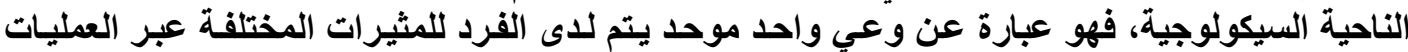

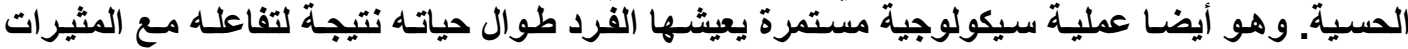

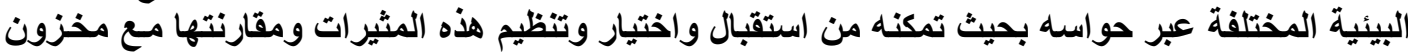

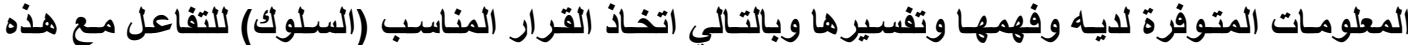

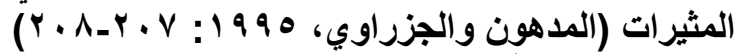

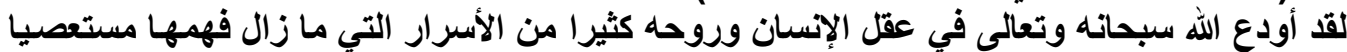

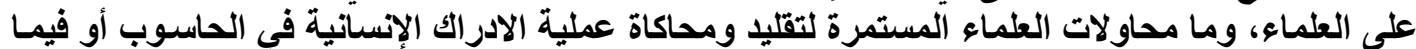

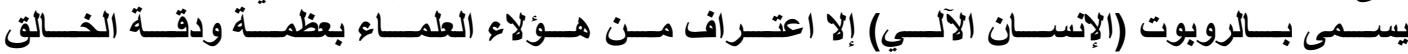

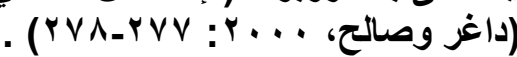

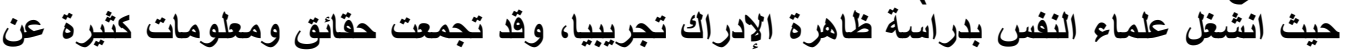

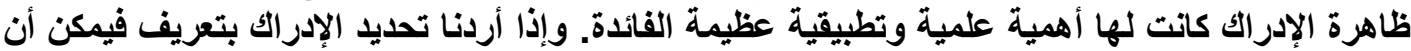

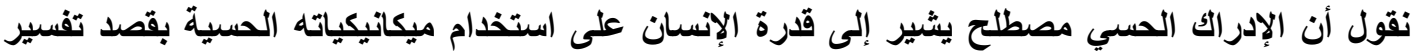

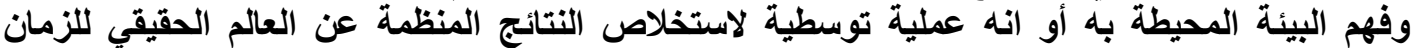

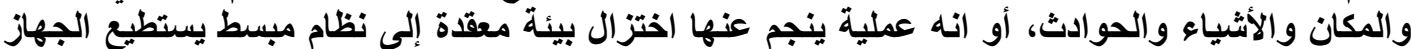

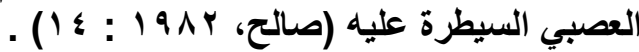
وقً عرف Kreitner (1992) الإدرالك على انه عملية ذهنية ومعرفية تمكنتا من فهم وتفسير ما

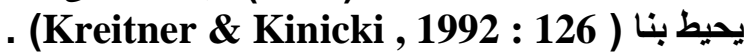

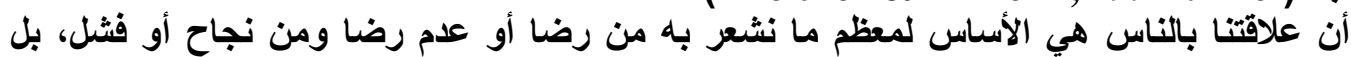

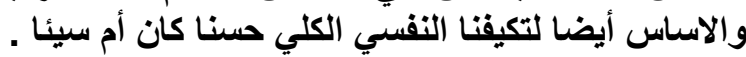

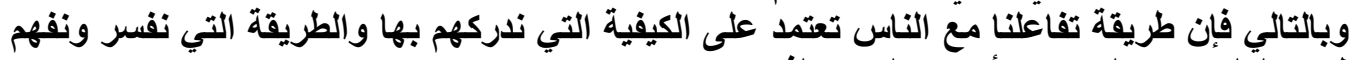

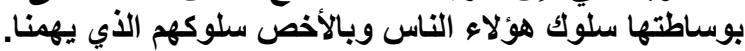

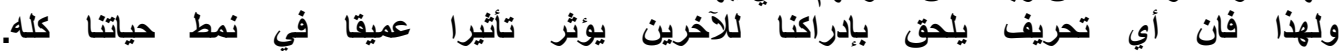

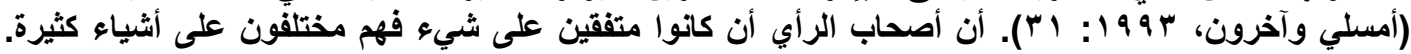

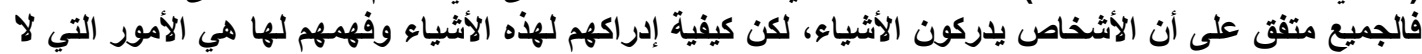
تزال موضع خلاف بين جمهرة أصحاب الرأي والئن والمفكرين الإداريين.

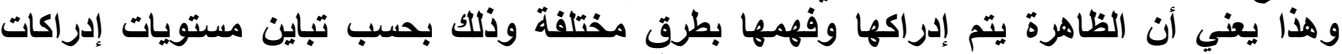

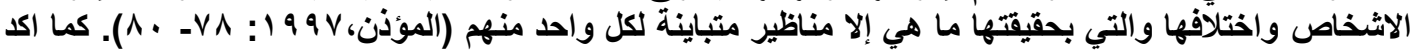

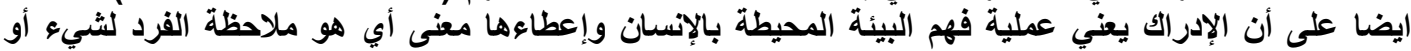

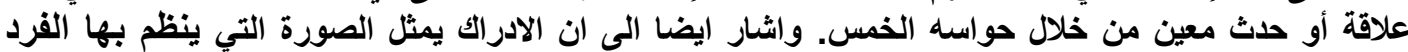

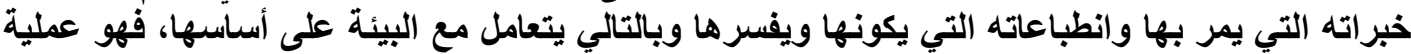

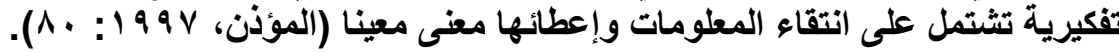


والإدراك هو الطريقة لتكوين انطباعات حول الذات وحول الآخرين وحول تجارب الحياة اليومية كما

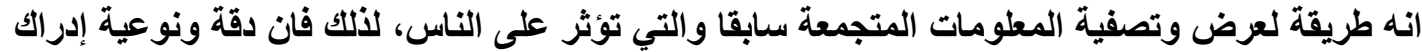

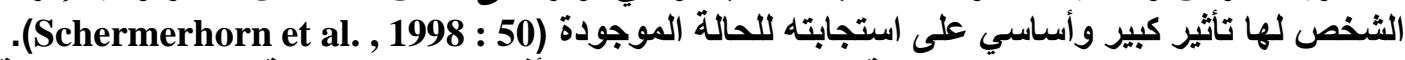

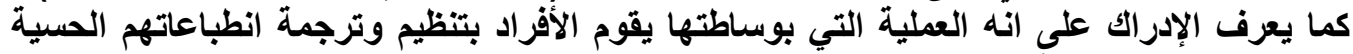

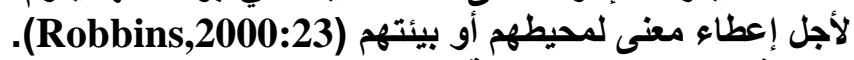

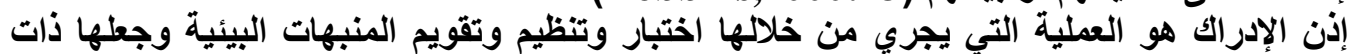

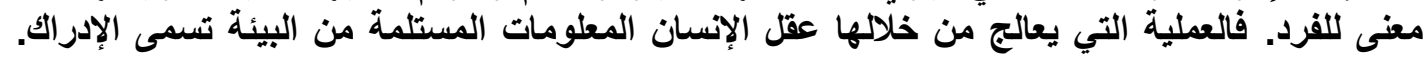

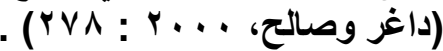

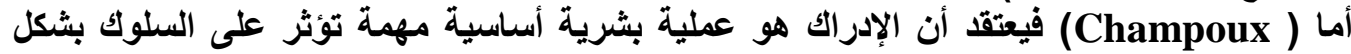

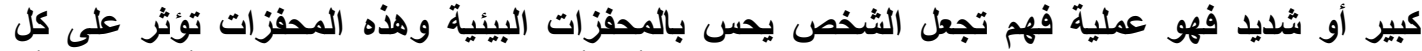

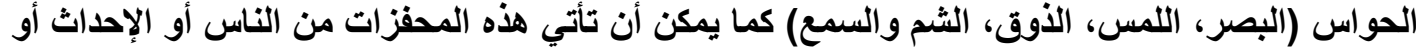

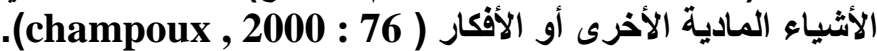

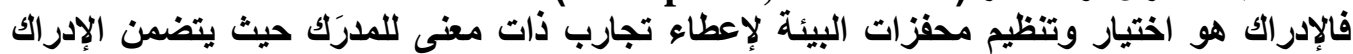

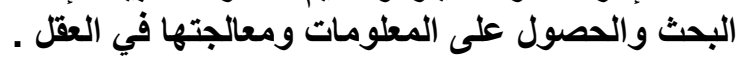

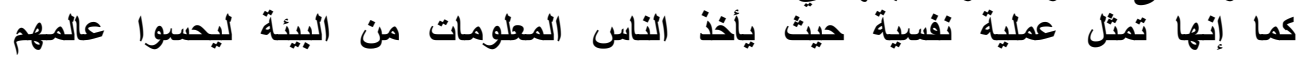

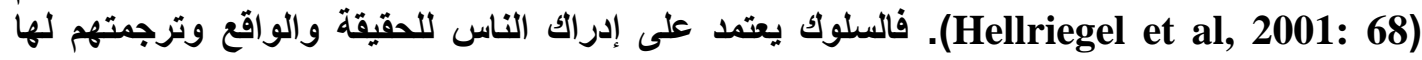
.(Hersey et al.,2001:209 )

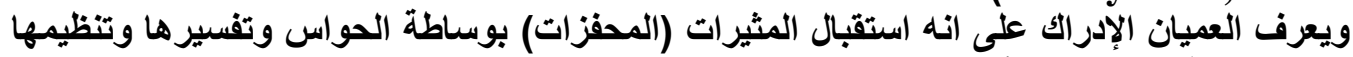

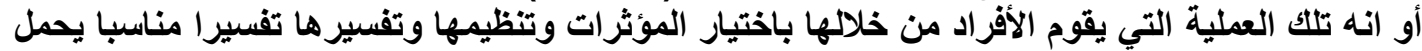

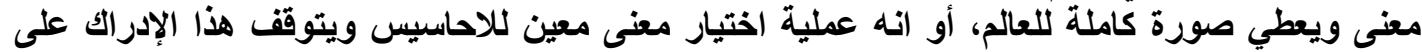

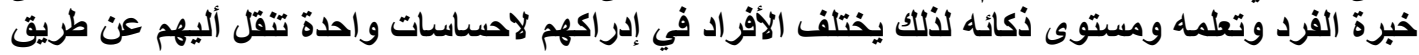

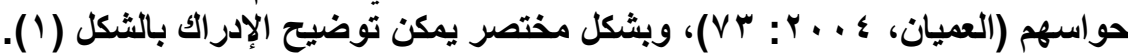
شكل (1) - الادر الك الأر

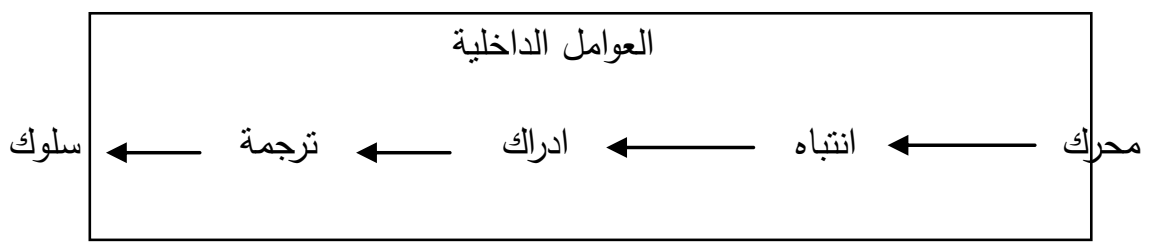

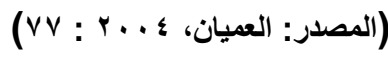

وبسبب تثنب المفهوم الادراكي واختلاف الأفراد وتنوعهم واعتماد الإدراك بشكل رئيسي على البعد

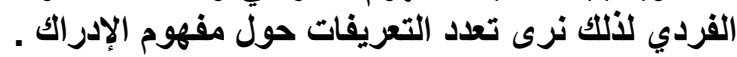

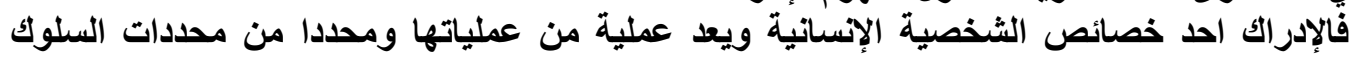

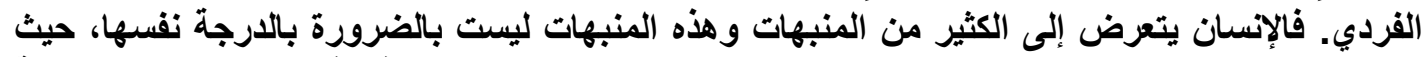

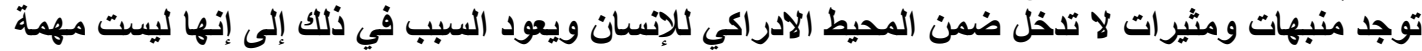

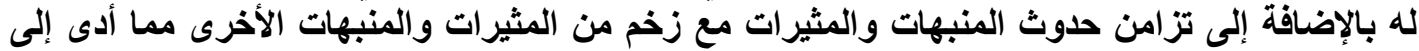

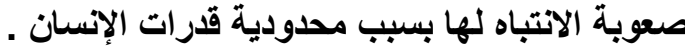

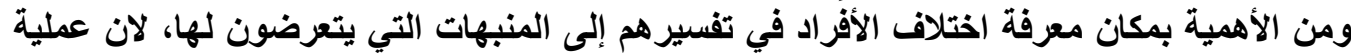

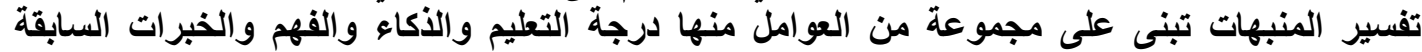

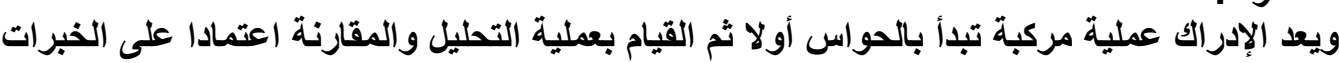
والحفظ للقرد .

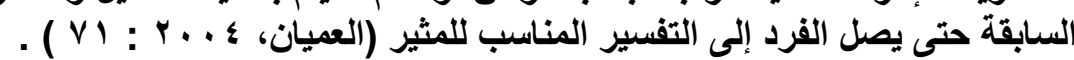




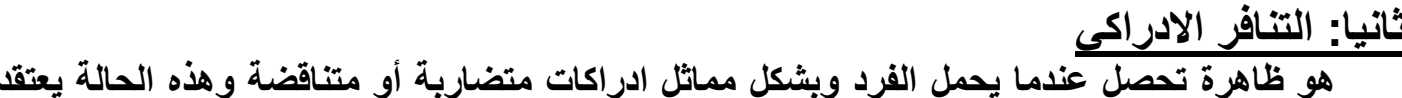

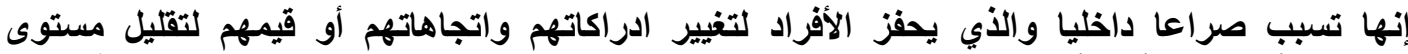

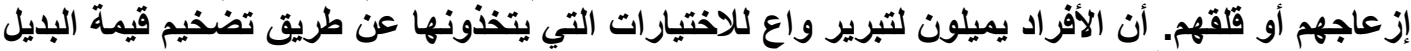

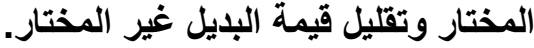

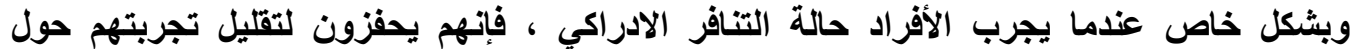

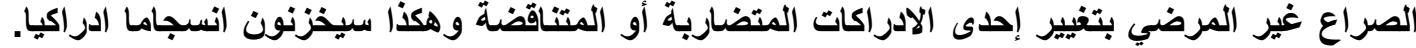

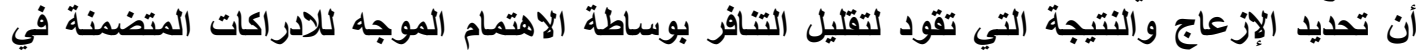

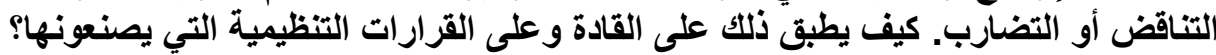

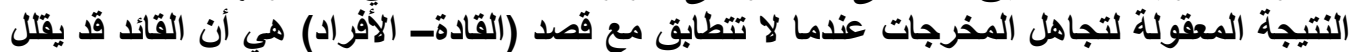

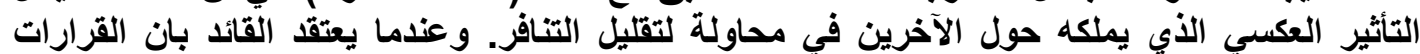

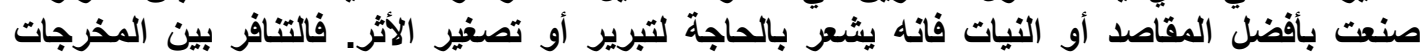

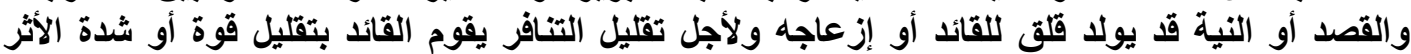

العكسي. (Eberlin \& Tatum,2008:4-5)

ثالثا: العملية الادر اكية وخصائصها ومكوناتها

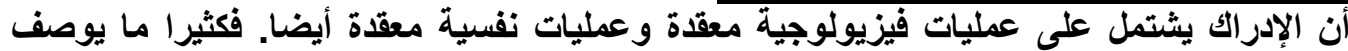

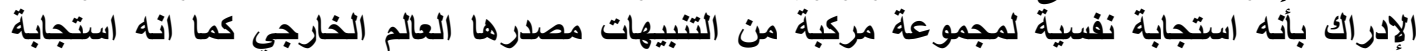

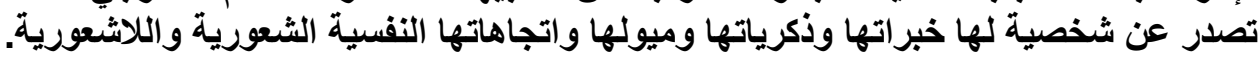

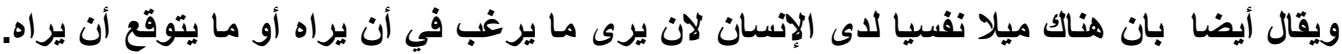

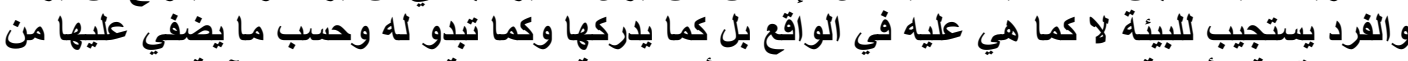

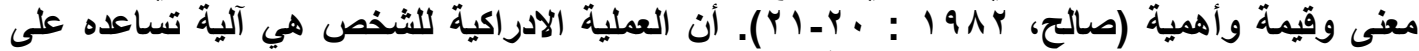

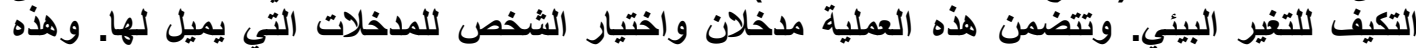

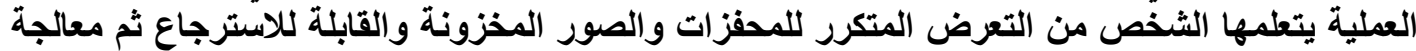

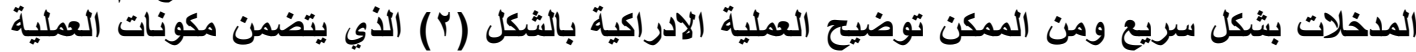

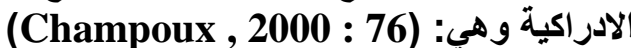

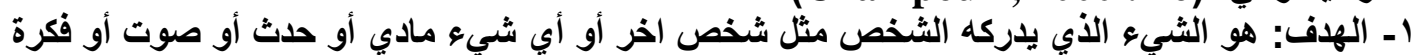

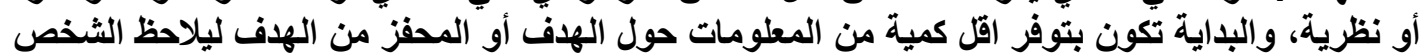
r - حد التنبو: هوده النقطة التي عندها يلاحظ الشخص ذلتك الشيء الثتغير في بيئته .

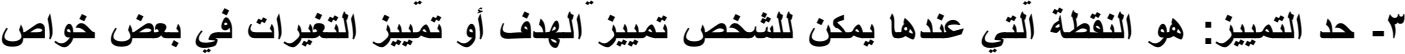

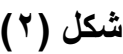

مكونات العملية الادر اكية

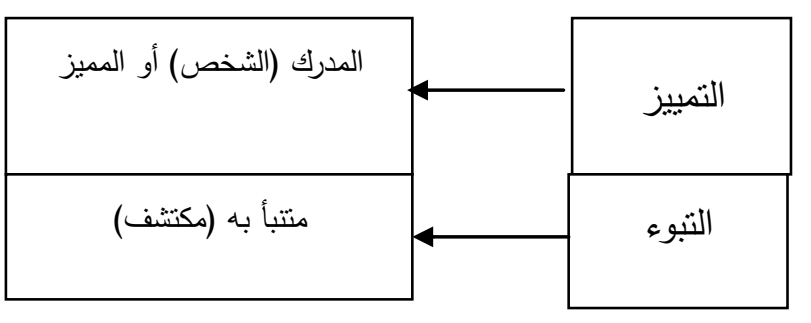

(Source: Champoux , 2000: 77)

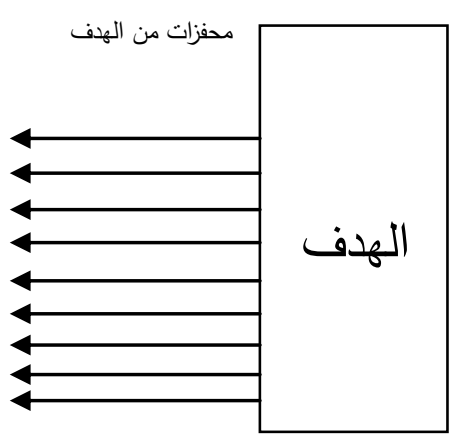

وقد بين Luthans (1973) أن العملية الادراكية أكثر تعقيدا من الإحساس وتتضمن تفاعلات معقدة

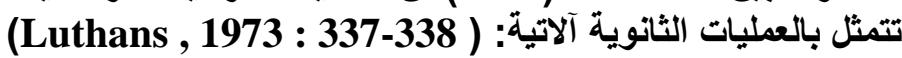


اـ المحفزات: عندما يبدأ الإدراثك يتواجه الثخص مئه مع المحفزات وهذه المواجهة قد تكون مع محفز حسي

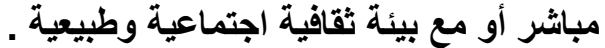

r - التسجيل: الأي يحصل خلال العملية الثانوية وهي ظاهرة التهية تسجيل ميكانيكية فسلجية (حسية وعصبية).

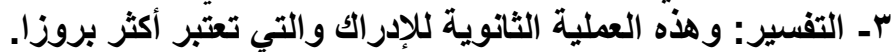

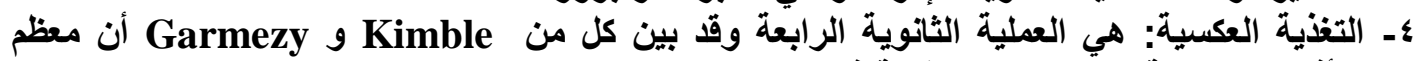

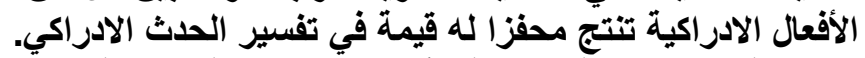

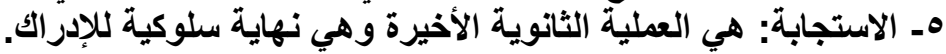

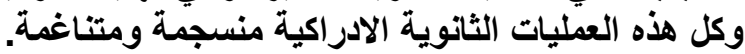

رابعا: مراحل العملية الاداركية

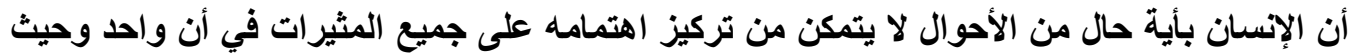

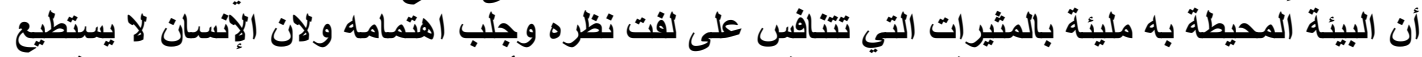

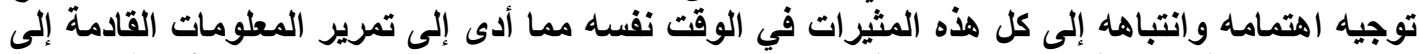

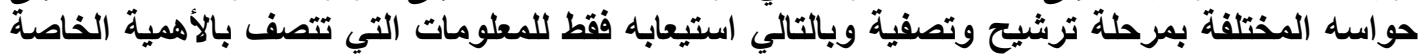

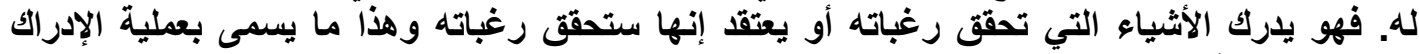

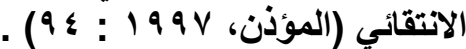
وتمر العملية الادراكية بمراحل عدة يمكن ادراجها في جدول (1)، وكما تم وصفها من قبل الباحثين.

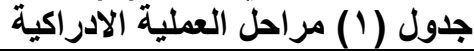

\begin{tabular}{|c|c|}
\hline مراحل العملية الادراكية & الباحث \\
\hline 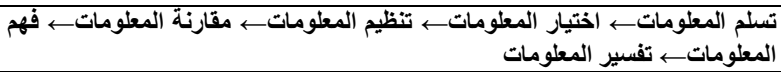 & 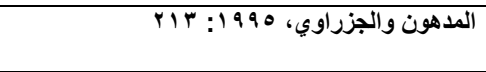 \\
\hline 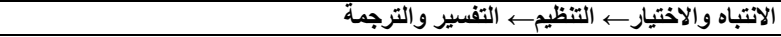 & Schermerhorn et al., 1998:52 \\
\hline الاختيارـ التنظيم؟ التقويم او التفسير & 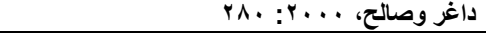 \\
\hline 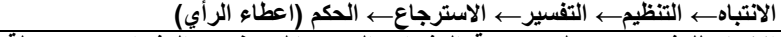 & Daft \& Noe, 2001: 129 \\
\hline تحديذ السلوك او الاستجابه المناسبة المثيرات الى رسائل (تفسير المثيرات)ـ مرحلة & 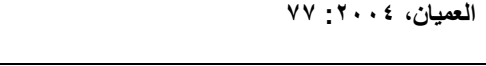 \\
\hline
\end{tabular}

فعندما ينتبه شخص ما إلى احد المثيرات فان كل خطوة من عملية الإدراك تزود بالتفذية العكسية

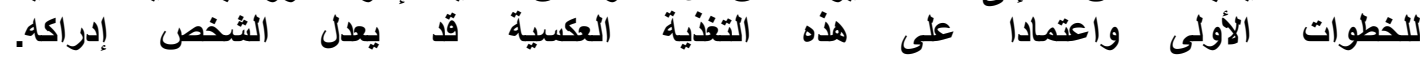

خامسا: العو امل المؤثرة في الإدرالك الكي

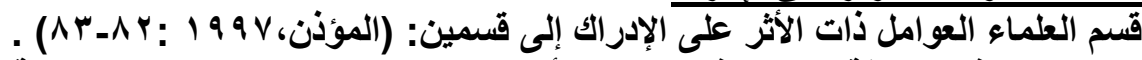

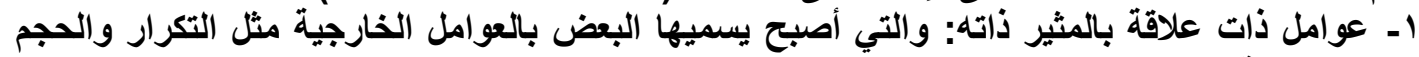

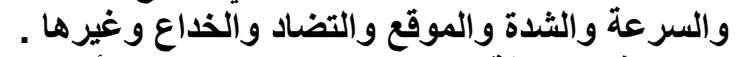

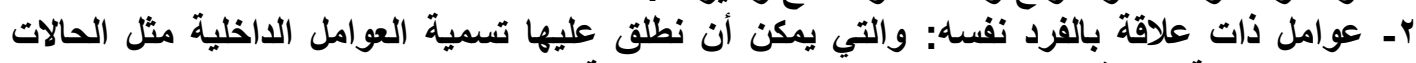

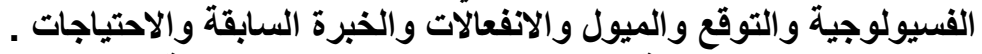

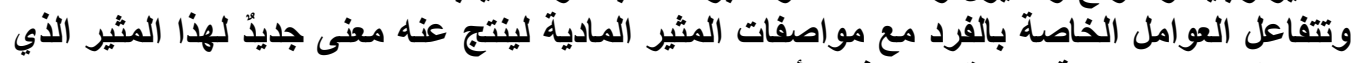

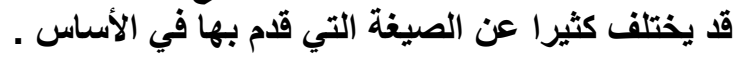

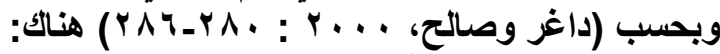

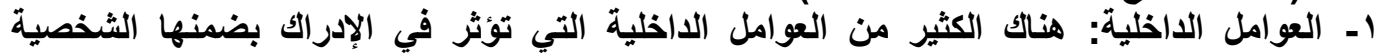

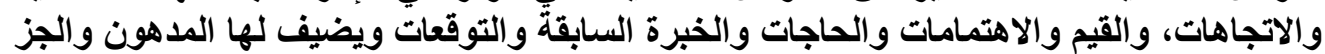

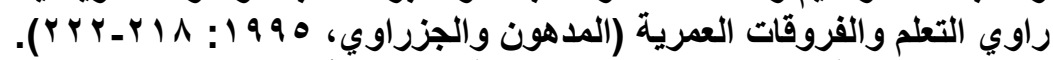

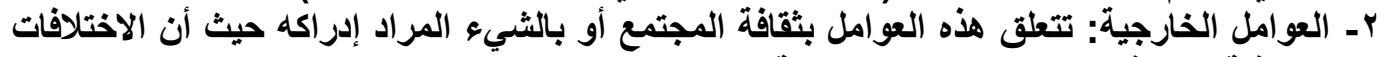

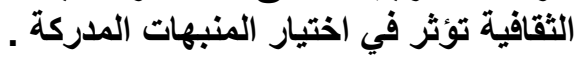
والمجموعة الثانيةّ من العوامل الخارجية التئية تؤثر في الإدراك ترتبط بخصائص المنبه أو المؤثر

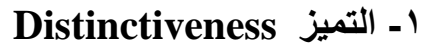

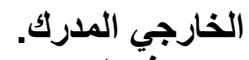

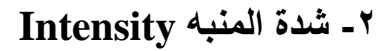

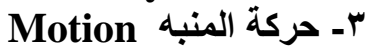

كـ ـ حجم المنبه المنه 
هـ مدى بروز المنبه Salience

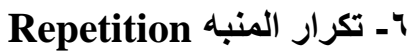

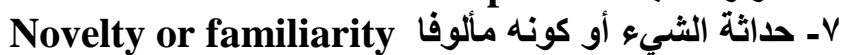

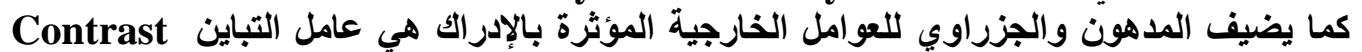

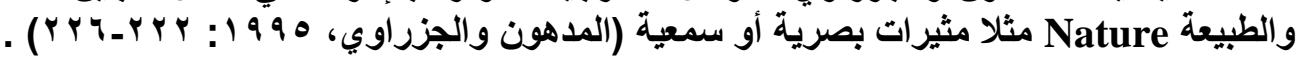

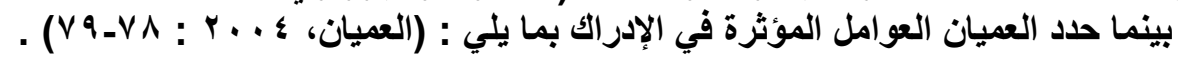
| - 1 سمات الفرد وخصائصه

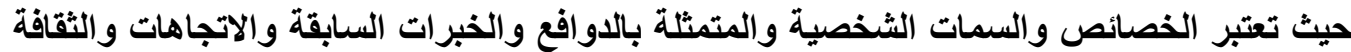
والقيم والعادات من أهم المصادر المؤثرة على الإدراك وتعتبر الحاجات الغير مشبعة والثيرة عند الأفراد عاملا

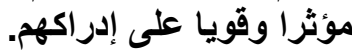

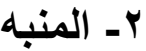

تعد خصائص المنبهات وطبيعتها من العوامل المؤثرة على الإدراك فكلما كان المثير أو المنبه قويا ،

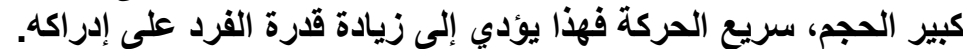

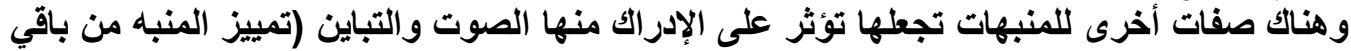

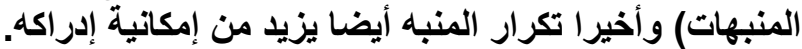

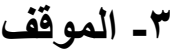

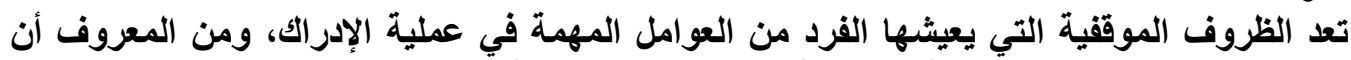

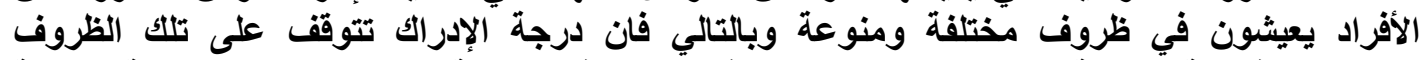

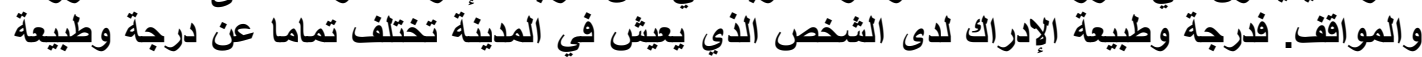

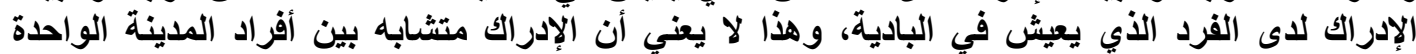

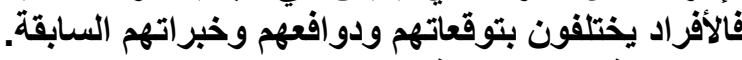
ع - البيئة الاجتماعية

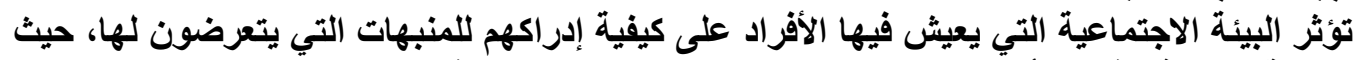

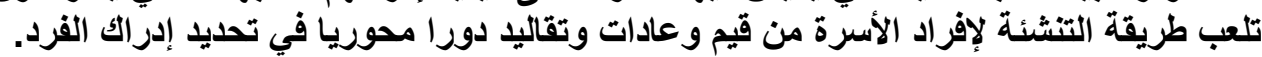

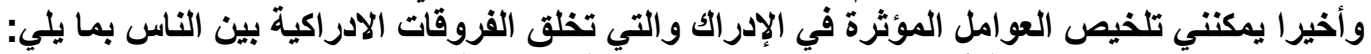

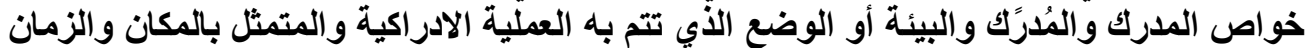

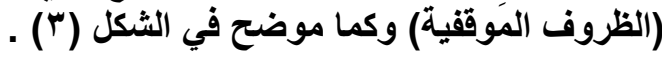
شُكل (r) العوامل المؤثرة في الادراك

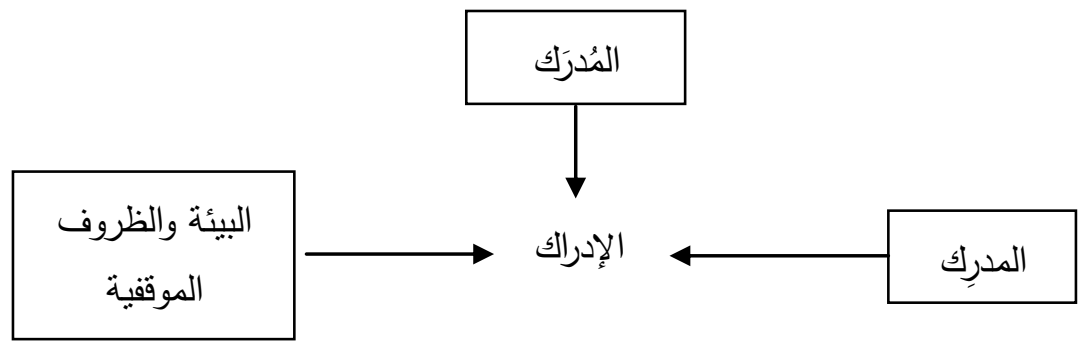

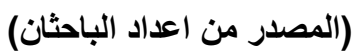




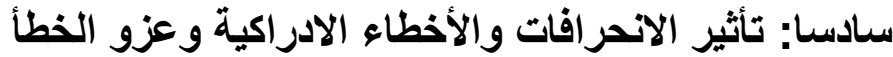

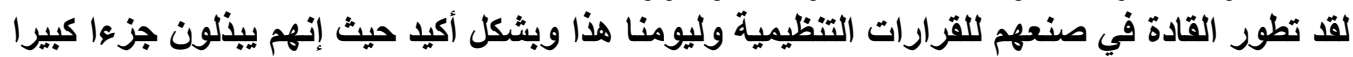

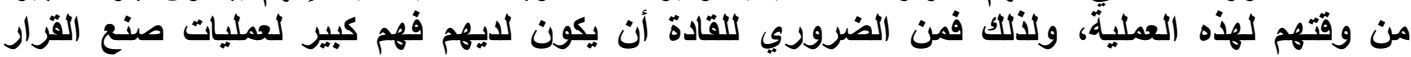

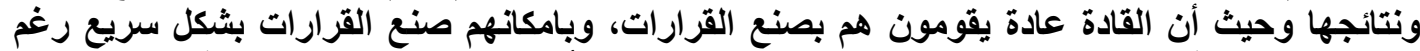

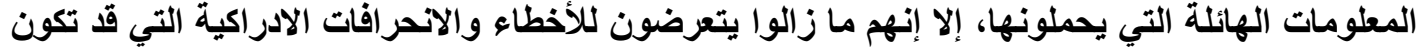

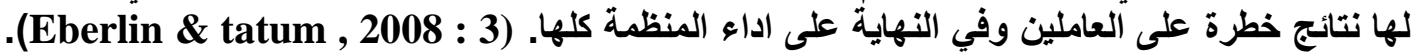
وبين Champoux (2000) أن هناك خطأين ادراكيين هما: أولا- الميل الادراكي

حيث أن الثخص الادي ذا الميل الادراكي حول الهلف يتوقع أن يجد خواص معينة مرتبطة بالهدف

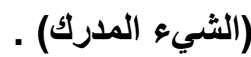
تانيا- الآراء المقولبة

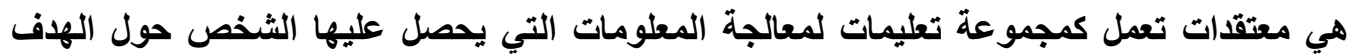

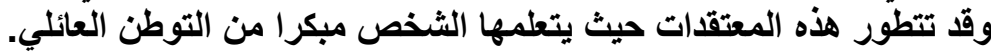

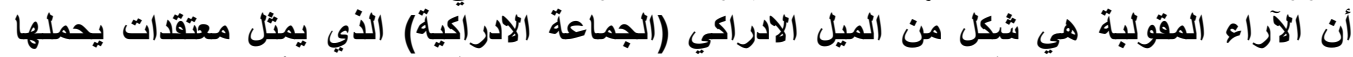

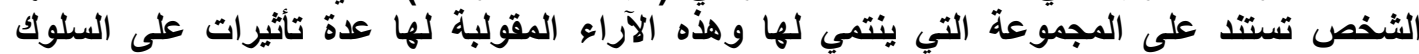

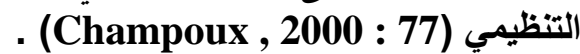

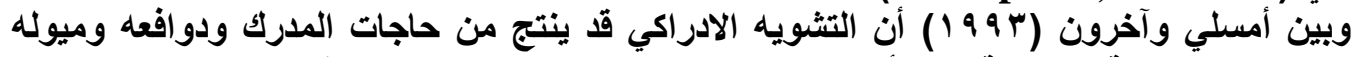

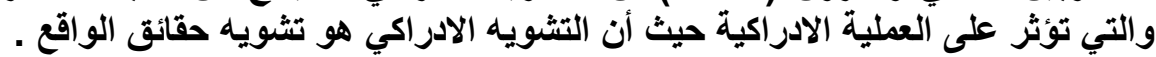

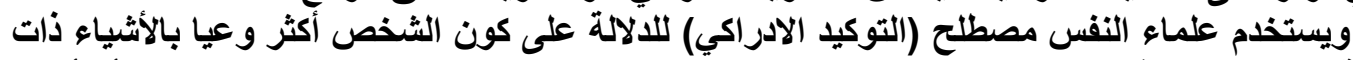

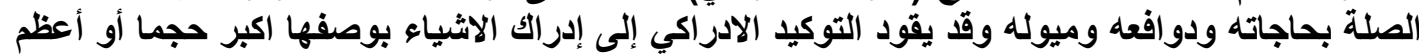

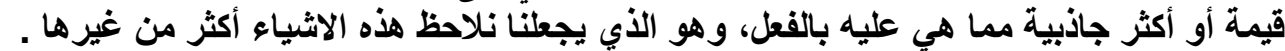

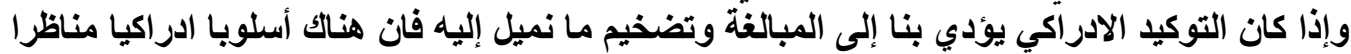

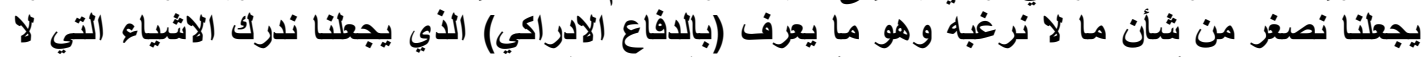

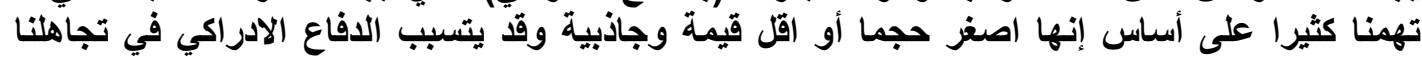

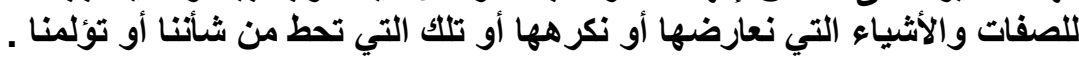

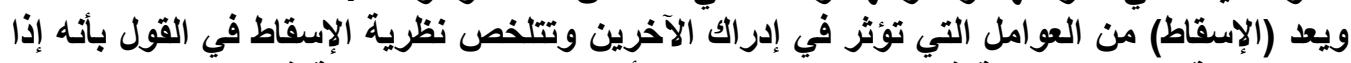

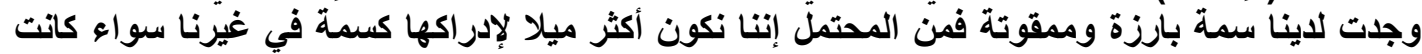

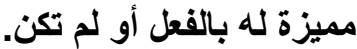

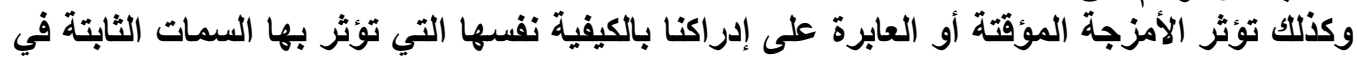

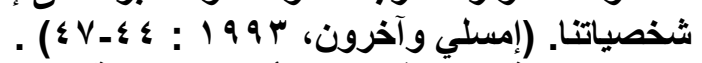

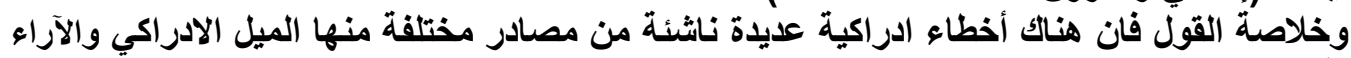

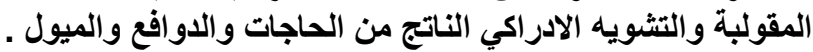

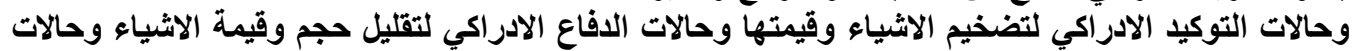

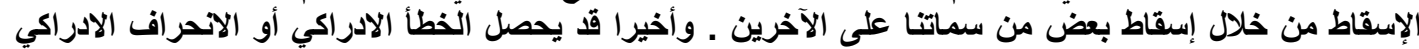
بتأثير الأمزجة المؤقتة.

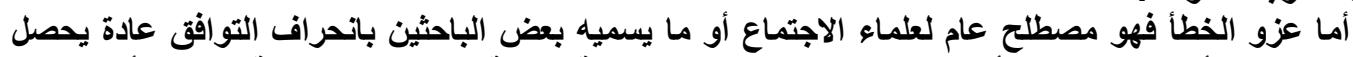

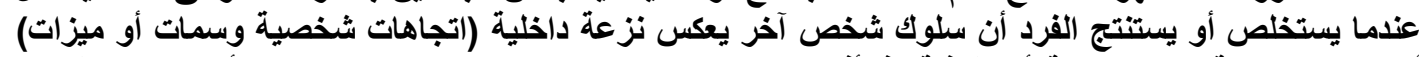

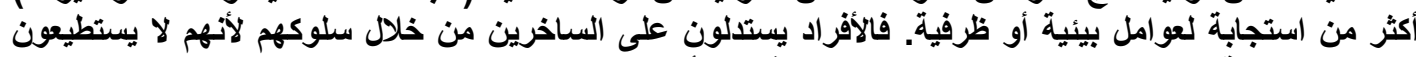

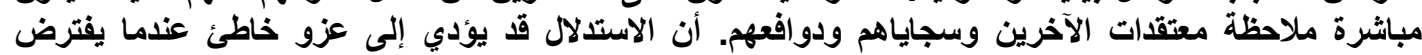

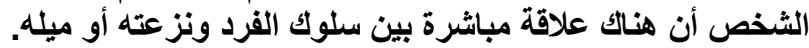

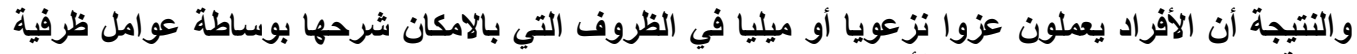

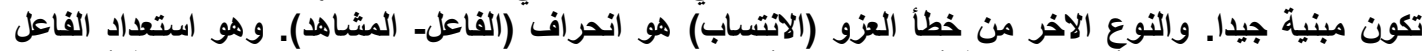

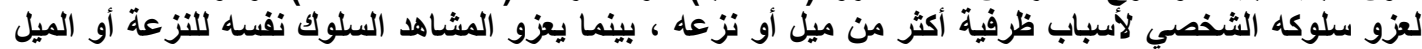

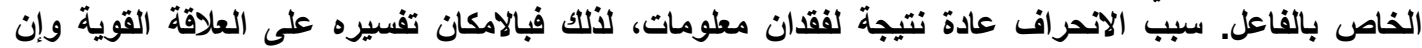

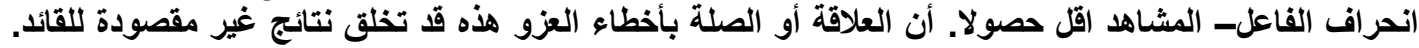

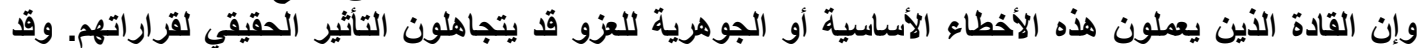

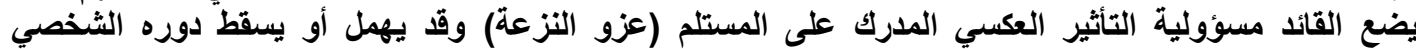

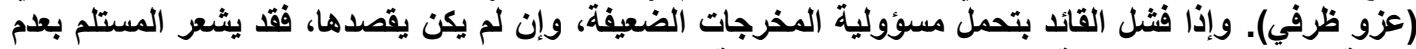

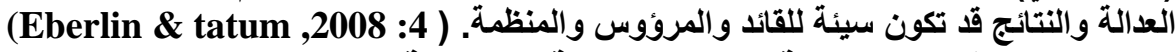
سابعا: الفروقات الادراكية وإدارة العملية الادراكية 


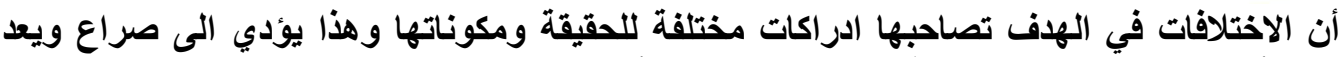

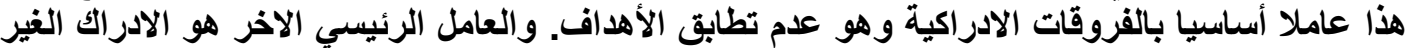

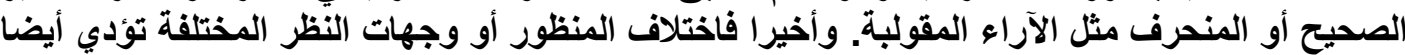

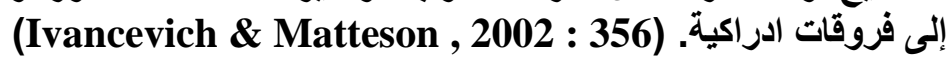

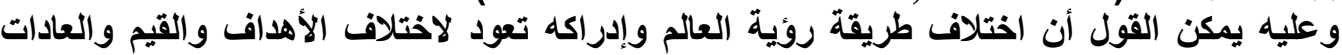

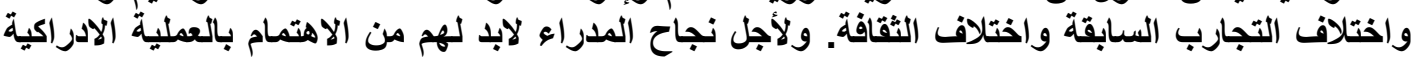

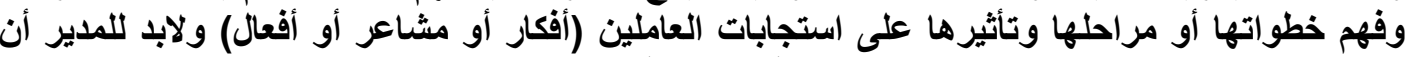

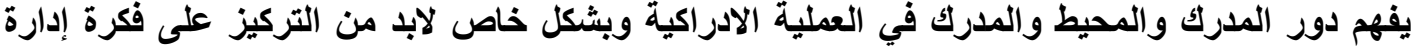

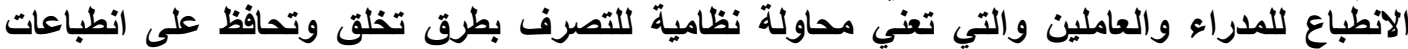
مرغوبة للشخص بعيون الآخرين.

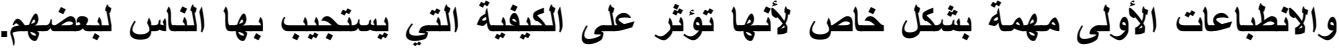

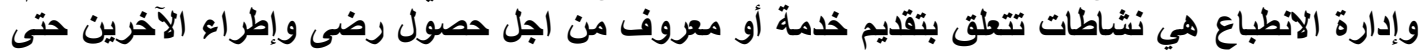

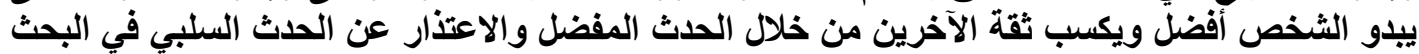

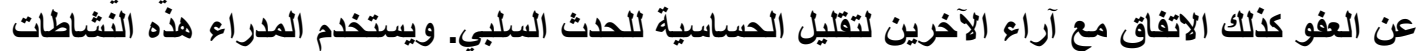

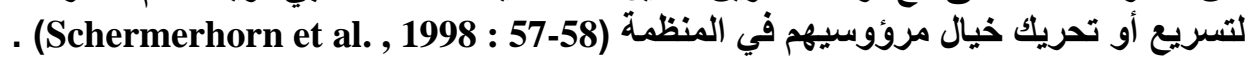

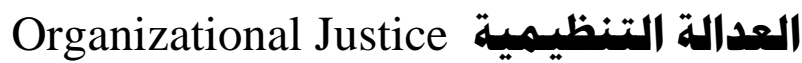

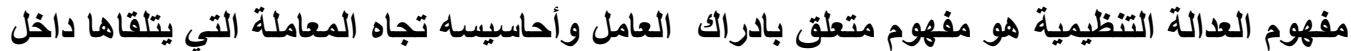

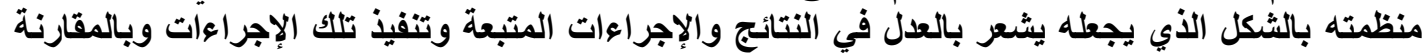

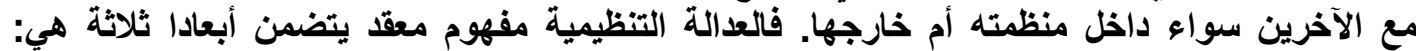

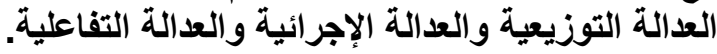

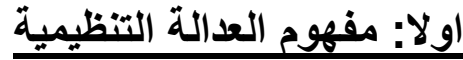
هناك مدى من المنظورات النظرية التي تتناول مفهوم العدالة التظيمية وأهمية الحفاظ على مدركات

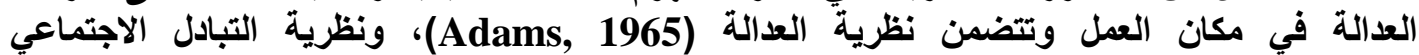
(Homans, 1961)

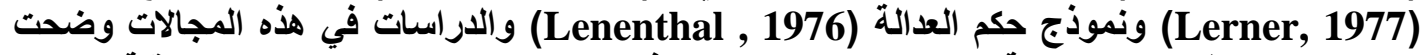
بان مدركات الظلم (عدم العدالة) ريما تؤدي الى نقصان في الداء العماء العمل وضعف جودة العمل وقلة التعاون

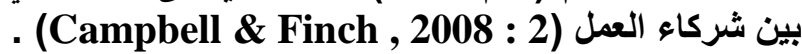

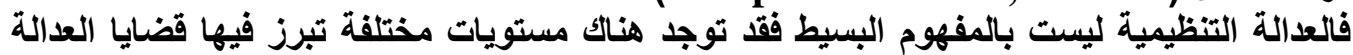

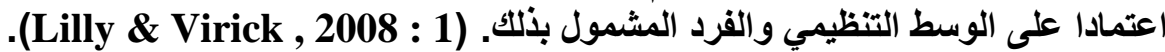

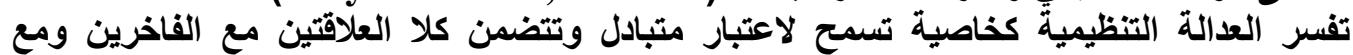

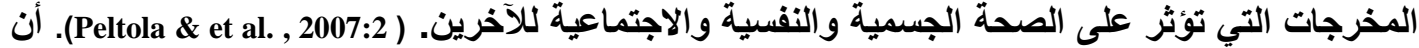

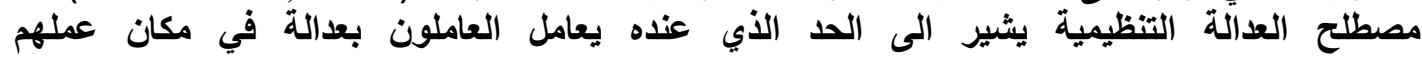
. (Kivimaki et al. , $2003: 2$ )

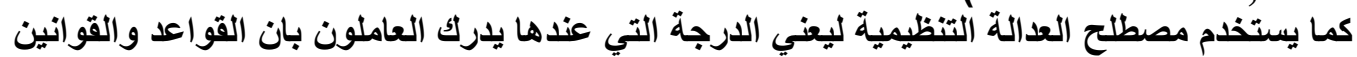

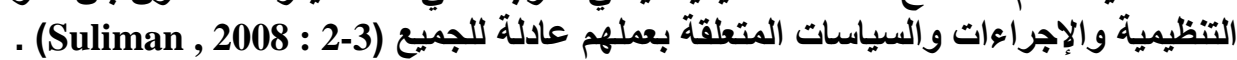

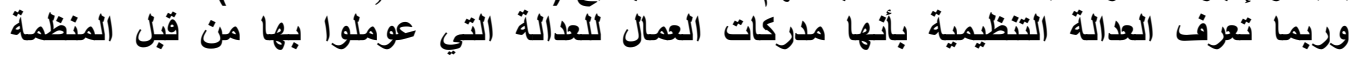

. (Campbell \& Finch , 2008 : 2-3) فالعدالة التظظيمية تصف إدرالك الفرد أو الجماعة لعدالة المعاملة المعلة المتلقاة من المنظمة واستجاباتهم

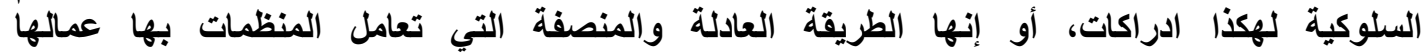
. (Fernandes \& Awamleh, 2008 : 2-3) أن فكرة العدالة تعد السلوك كونه أخلاقيا من خلال عدم التحيز في معاملة الناس (Schermerhorn , Jr. et al. , 1998: 11) والعدالة بالمعنى العام هي إنصاف أي أن كل واحد من أن أصحاب المصالح (ذوي العلاقة) يتعامل

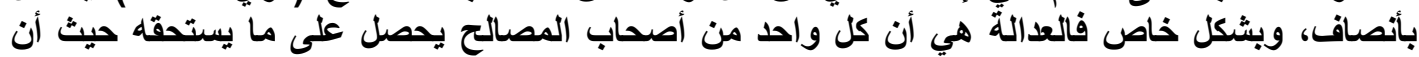

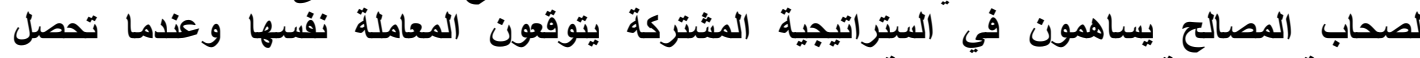

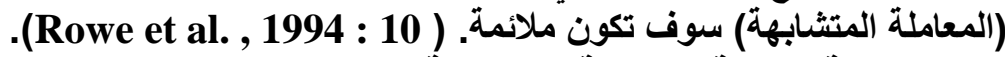

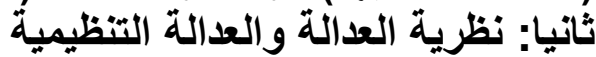


نظرية توفر طريقة لتفسير الاعتقادات التي يحملها شركاء العمل حيث تعتمد هذه النظرية على فكرة

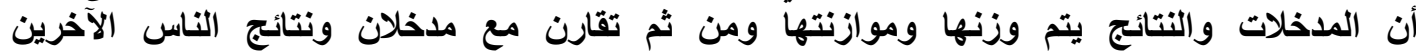
- (Bradley , 2008 : 4)

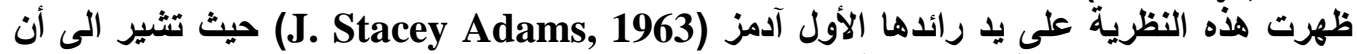

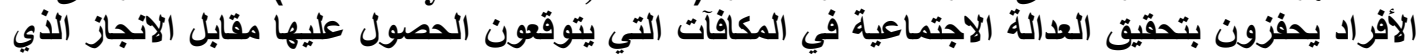

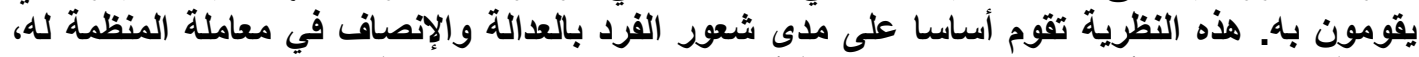

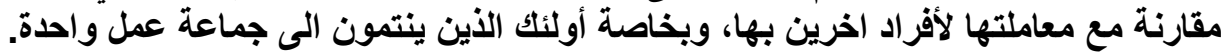

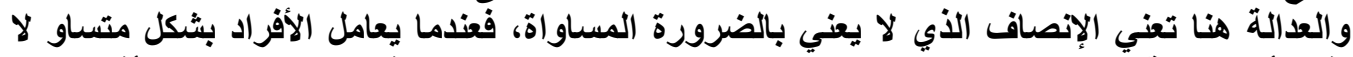
يعني ذلك أن العدالة تحققت لانه قد يتضمن عدم إنصاف بعض العاملين الذين يقومون بعمل أفضل من الأن يقول العلماء أن هذه النظرية (نظرية العدالة) الثتقت من عملية المقارنات الاجتماعية لأنها تمثلها

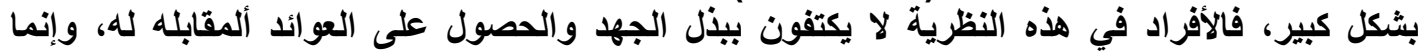

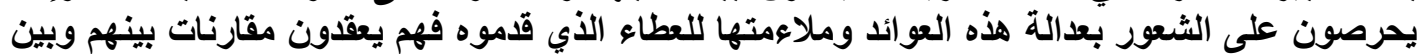

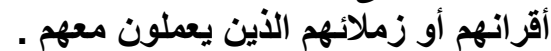

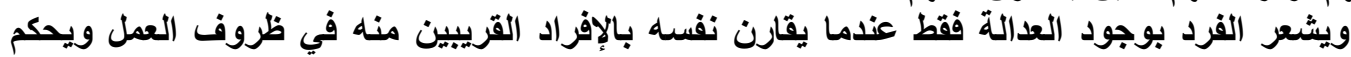

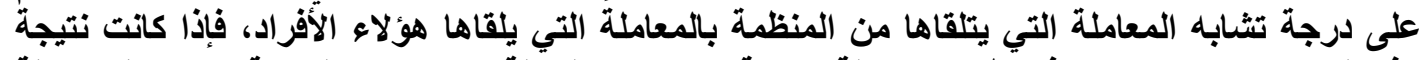

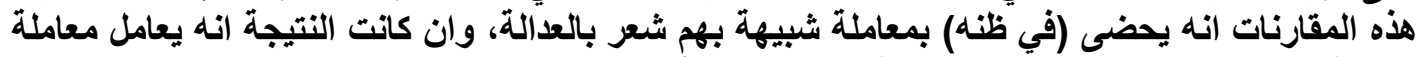

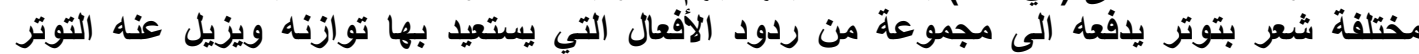

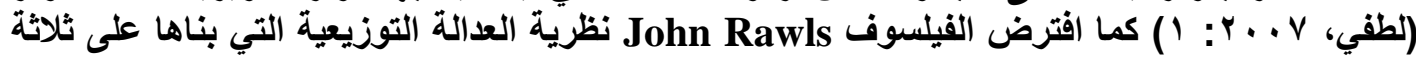

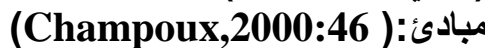

ا- مبأ المساواة في الخيار: الذي يعني أن كل الخيارات الأساسية للشخص يجب أن تساوي خيارات

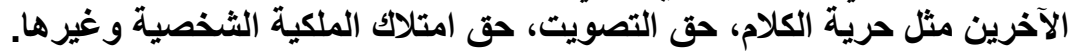

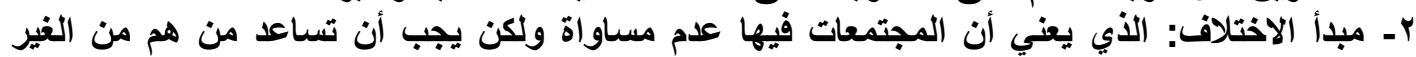

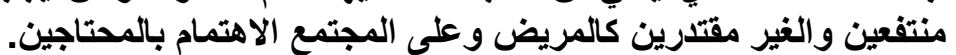

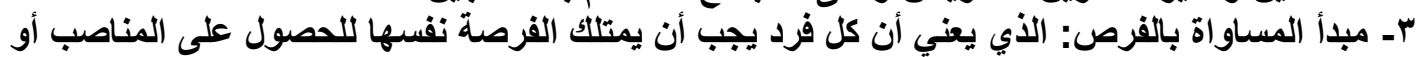

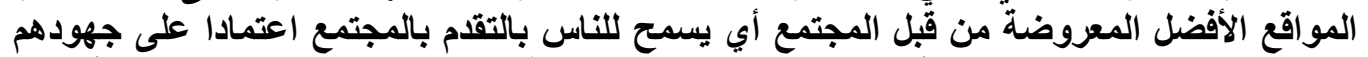

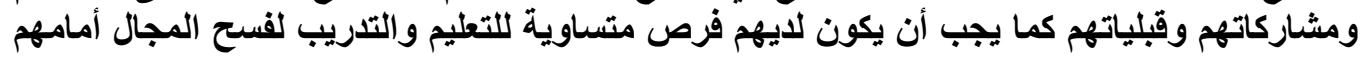

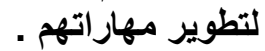

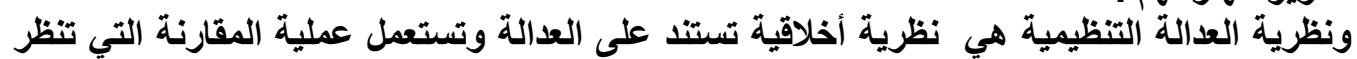
لميزان الفوائد والواجبات الموزعة بين أعضاء المجموعة أو تلك النتيجة من تطبيق القوانين والتقواعد

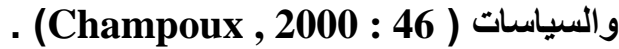
وتركز نظرية العدالة التظيمية على مدركات العدالة في المنظمات من خلال تصنيف وجهات نظر الماتر

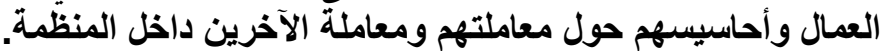

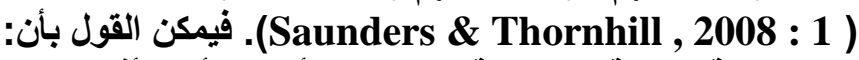

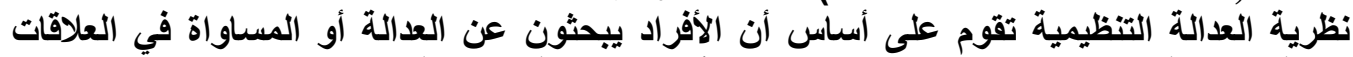

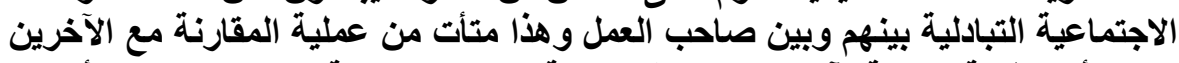

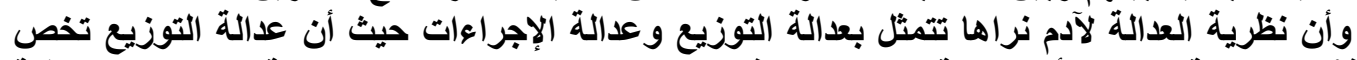

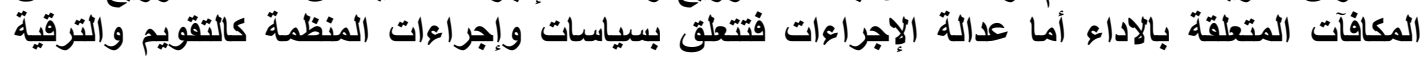

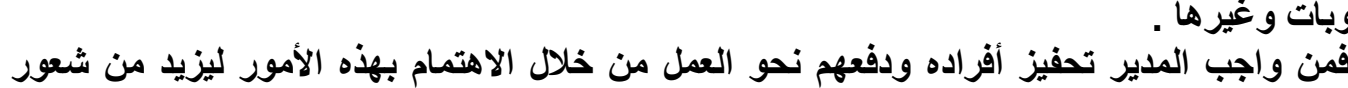

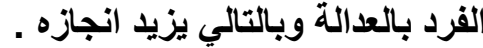


ثثالثا: انواع العدالة التظظيمية (إبعادها)

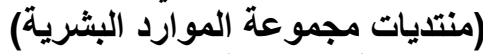

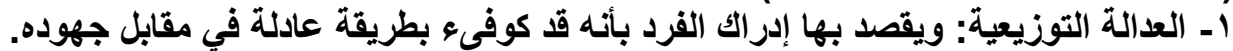

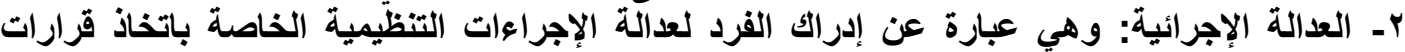

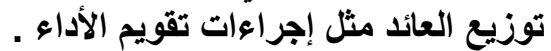

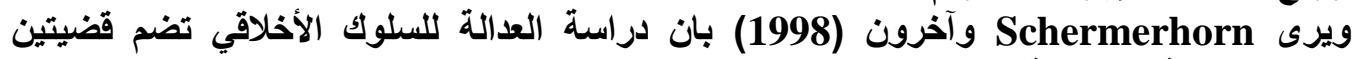
مهمتين هي العدالة الإجرائية التي تخص الإجراءات والقواعد التي تتبع من خلال السياسات التي تطبق

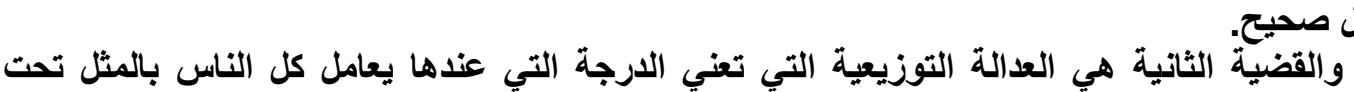

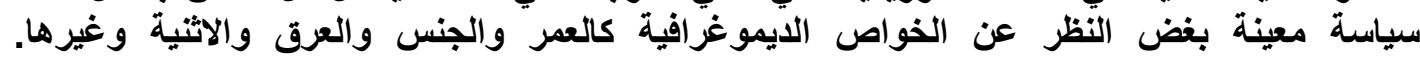

(Schermerhorn et al. , 1998 : 11)

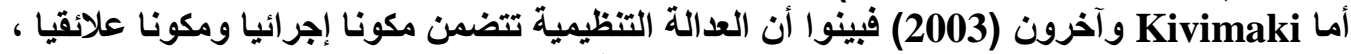

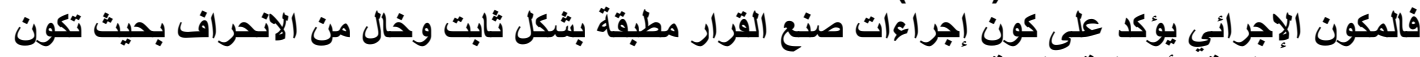

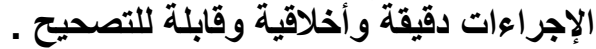

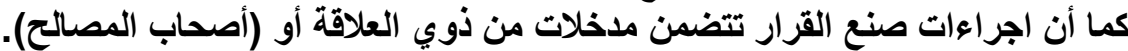

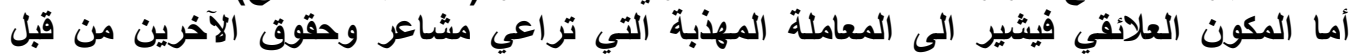

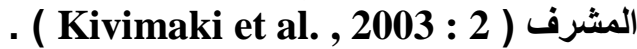

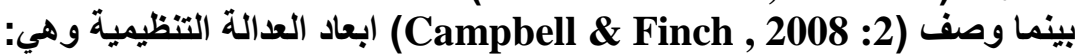

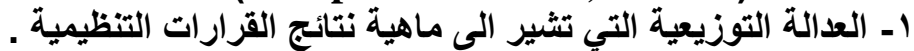

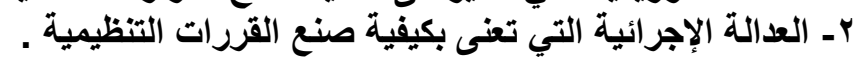

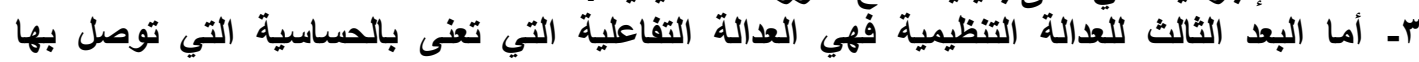

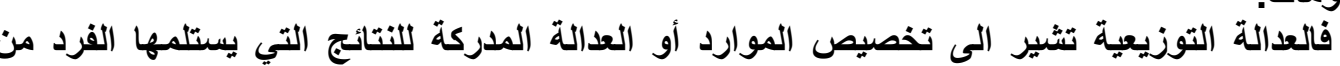

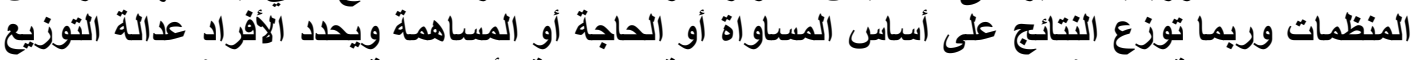

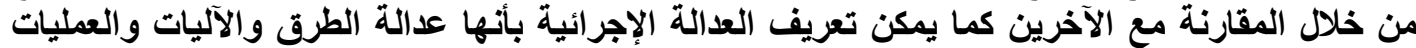
المستخدمة لتحديد النتائج . وقد حد Tyler و Bies خمسة عوامل تؤثر على مدركات العمال للعدالة الإجرائية في المنظمات

(Campbell \& Finch , 2008 : 3 ) هي: 1- الاحترام لوجهات نظر الآخرين .

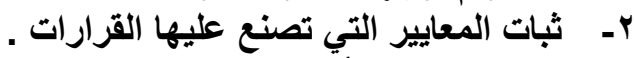

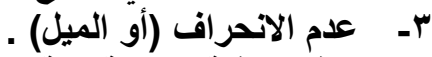
ع- ت توفير تغذية عكسية آنية .

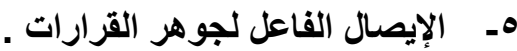
وبصورة الإيصالة فالنة العدالة التنظيمية تثنتمل ثلاثة مركبات مختلفة هي: العدالة التوزيعية والعدالة

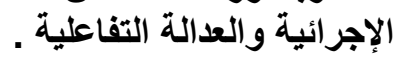

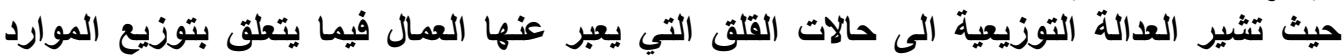

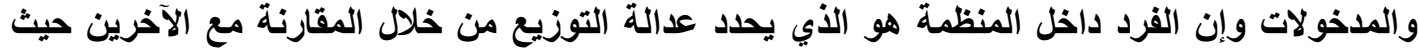

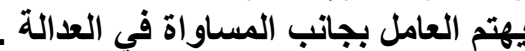

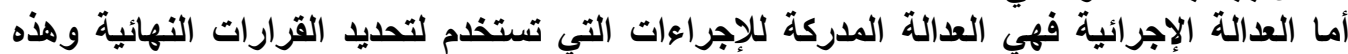

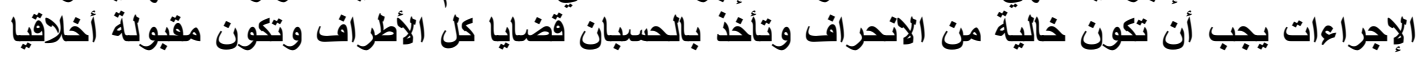

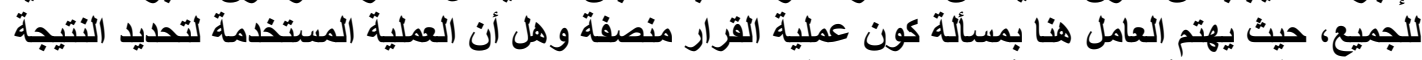

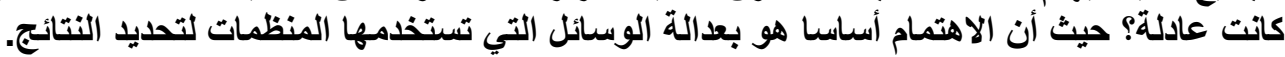

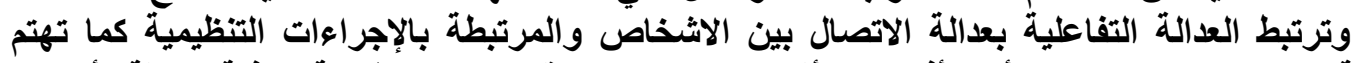

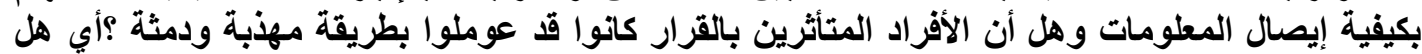

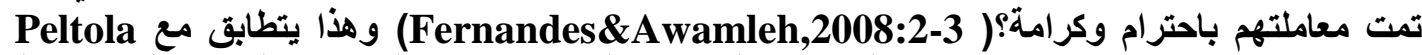
وآخرين (2007) حيث قسم تركيب العدالة التنظيمية الى ثلاثة جوانب (العدالة التوزيعية، العدالة الإجرائية

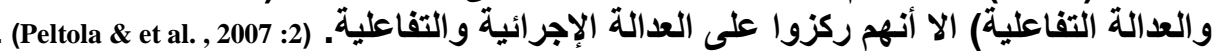

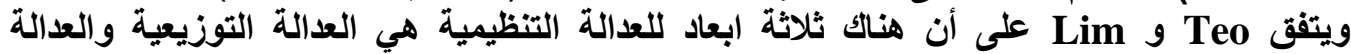
الإجرائية والعدالة التفاعلية وافترض (Dentsch , 1975) أساسين اخرين بالإضافة الى المئية المساواة للحكم 
على عدالة النتائج (أساس المساواة) و (أساس الحاجات) فالمساواة تعنى بالدرجة التي يتلقى فيها الأفراد

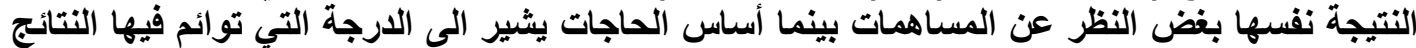

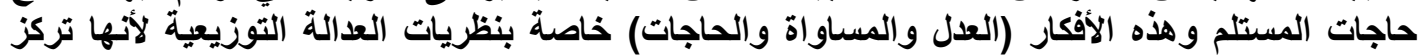

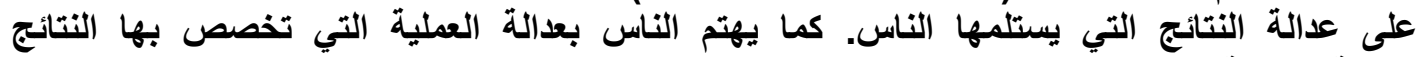
( (عدالة إجرائية). (Teo \& Lim,2008:2). ويؤكد Suliman أن تركيب العدالة التنظيمية ذو طبيعة متعددة الأوجه حيث تتكون من ثلاثة عوامل

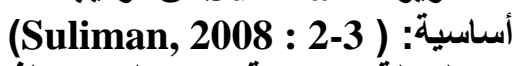

اـ العدالة الإجرائية: وهو المكون الذي يتعلق بعدالة العمليات التي بوساطتها يتم صنع القرارات كما تؤكد

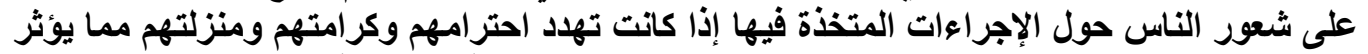

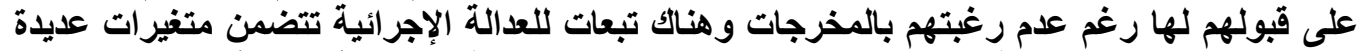

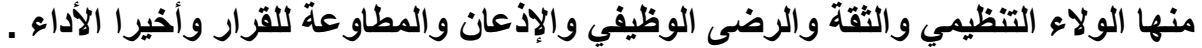

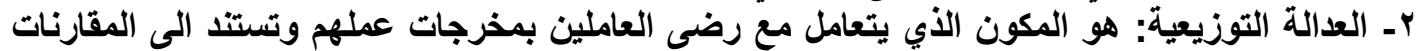

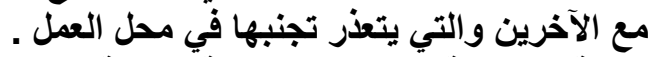

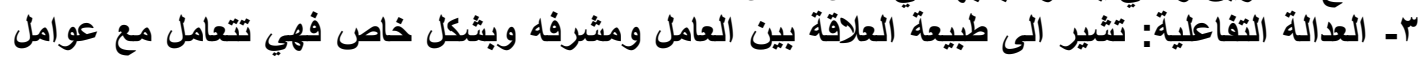

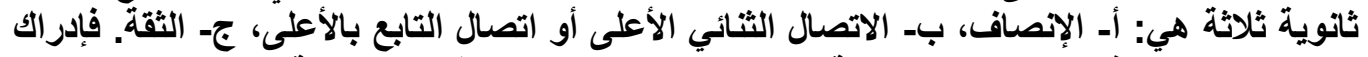

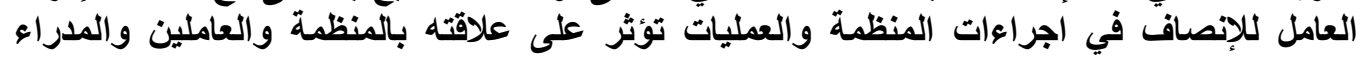

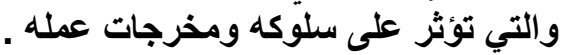

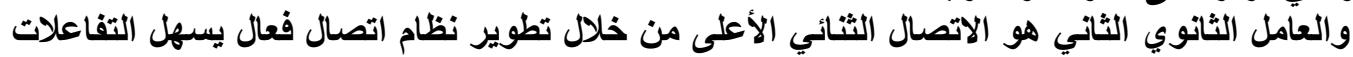

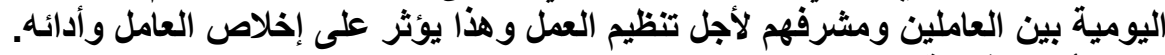

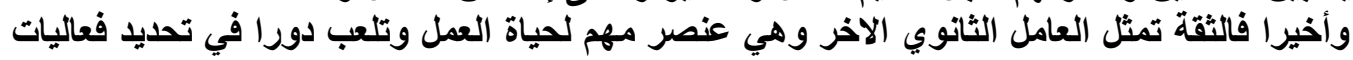
العاملين (-3) : 2008

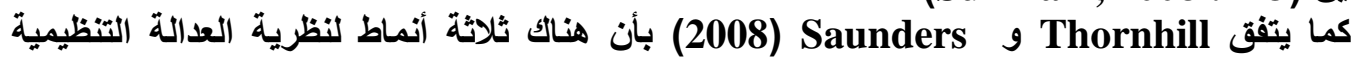

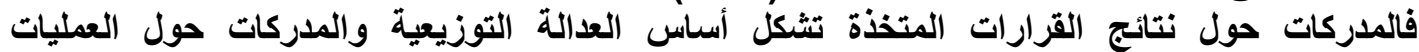

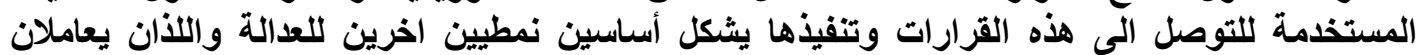

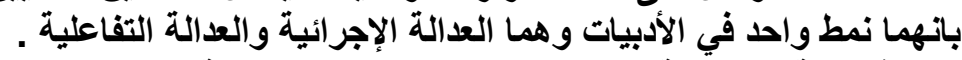

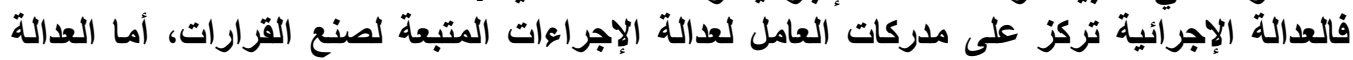

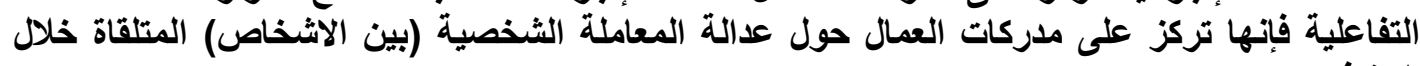

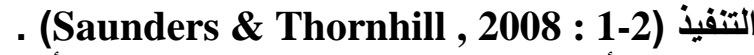
بينما أكد ( Lilly \& Virick) (2008) على أن مفهوم العدالة الإجرائية يصف التمام الفرد بجودة

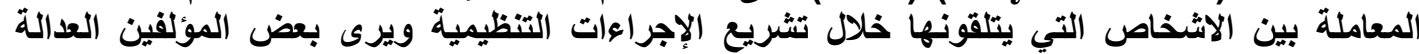

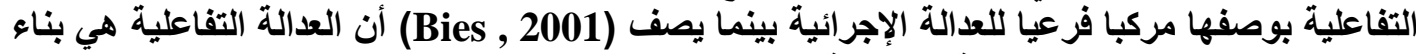
منفصل يختلف مفاهيميا عن العدالة الإجرائية .

(Lilly \& Virick, $2008: 3$ )

بينما صنف Tatum وآخرون (2008) مجالين واسعين للعدالة تسمى عدالة هيكلية وعدالة

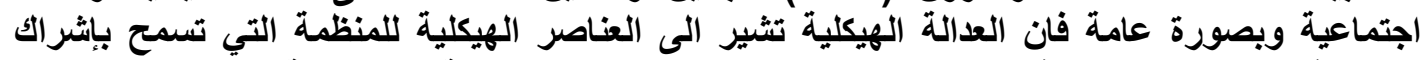

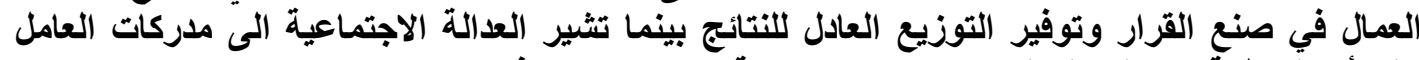

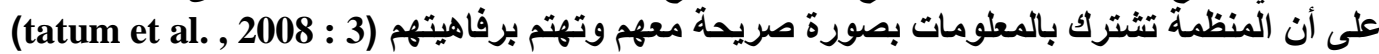

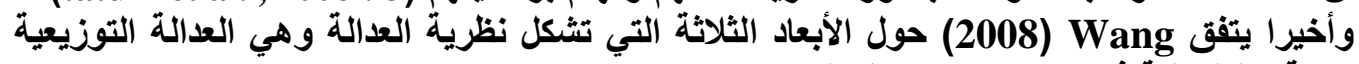

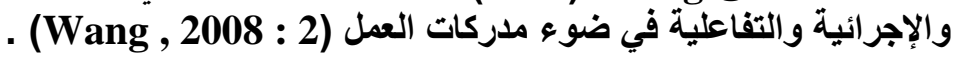


وخلاصة القول أنه بأمكاني تحديد ثلاثة انواع للعدالة التنظيمية وهي :

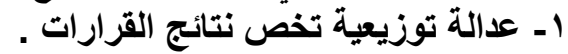

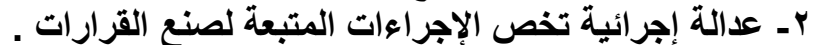

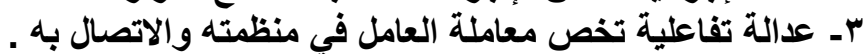

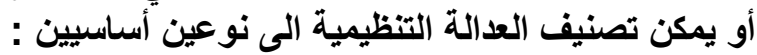

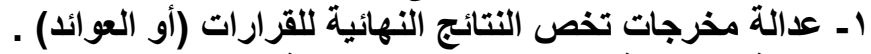

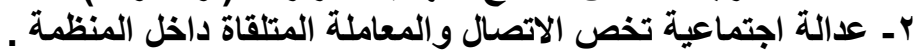

رابعا: اهمية العدالة التنظيمية المبية في القرن الماضي كان هنائك الهتمام كبير بالعدالة التنظيمية كونها بناءا مهما ومجالا بحثيا رئيسيا في

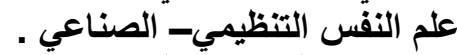

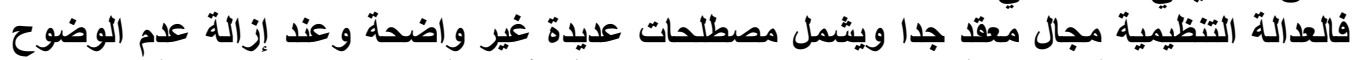

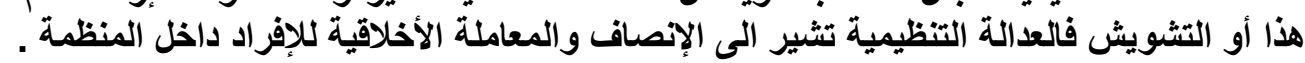

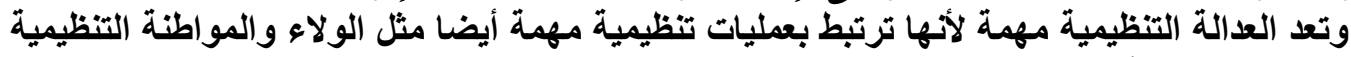

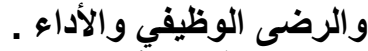

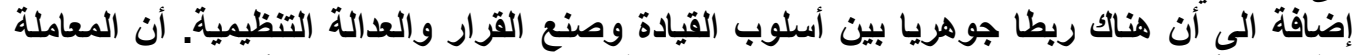

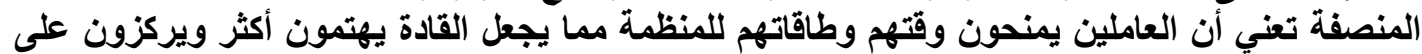

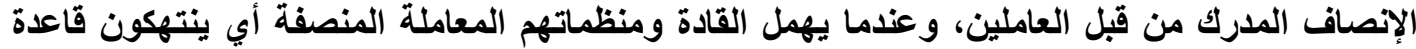

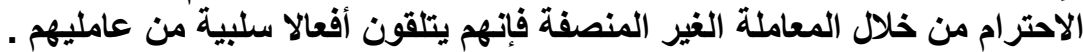

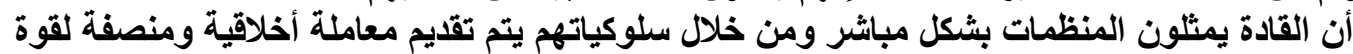

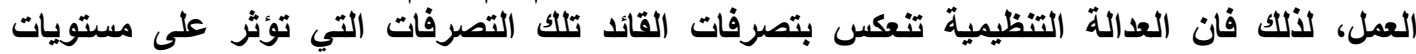
الإنصاف المدرك والعدان العالة المدركة للعاملين.

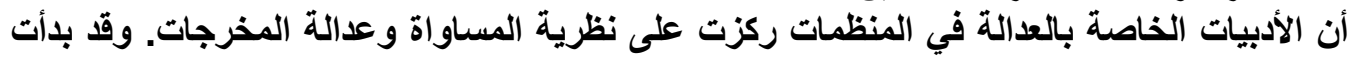

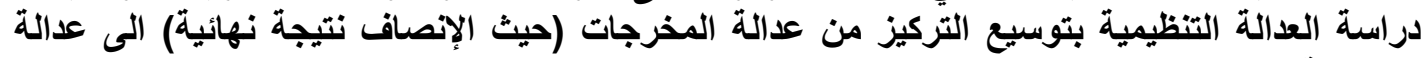

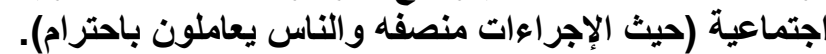

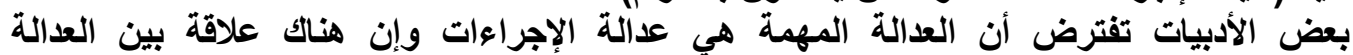

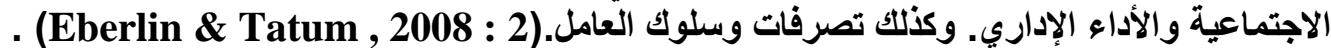

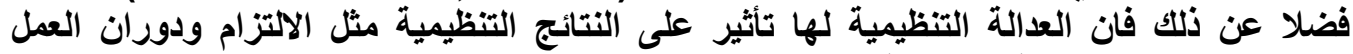

ورضى العمل وسلوك المواطنة التنظيمية وغيرها (Fernand \& Awamleh,2008:2)

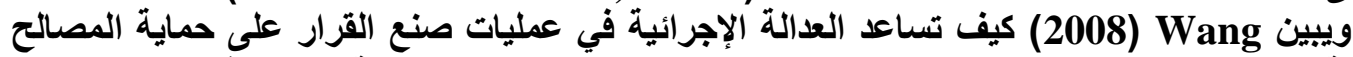

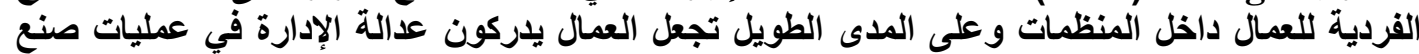

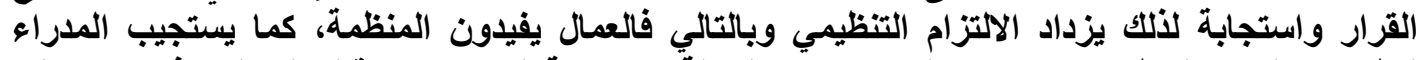

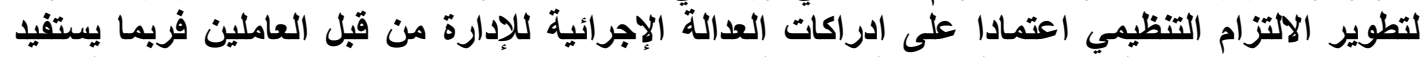

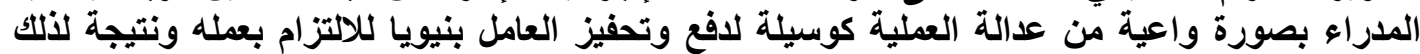
سيشجعون مشاركة العامل في عملية صنع القرار (

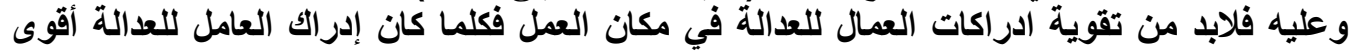

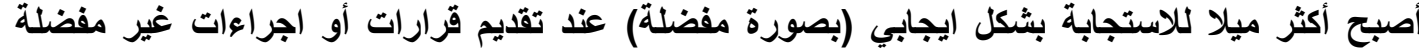

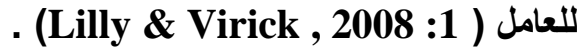

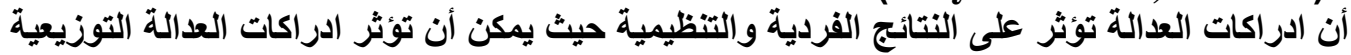

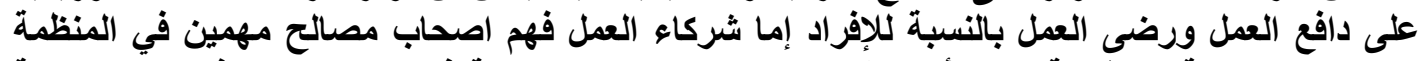

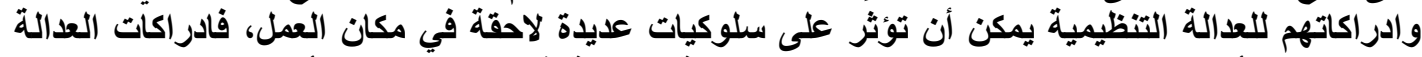

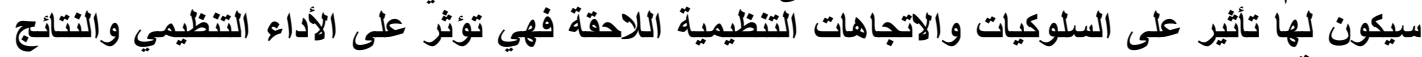

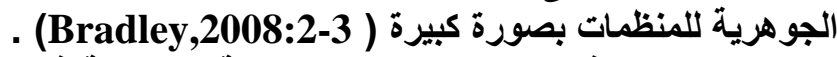

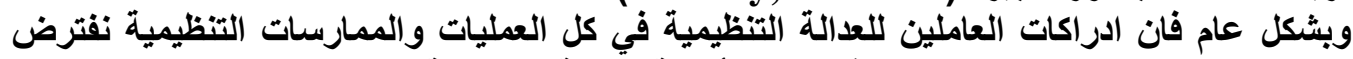
تأثير ها على سلوكهم ومخرجات عملهم وبذلك تكمن أهمية العدالة التنظيمية ـ التئية 
خامسا: ادر اكات العدالة

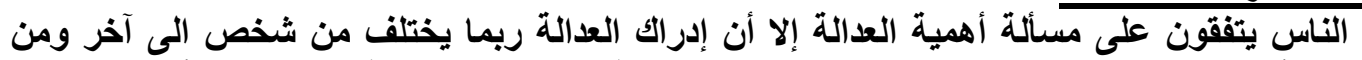

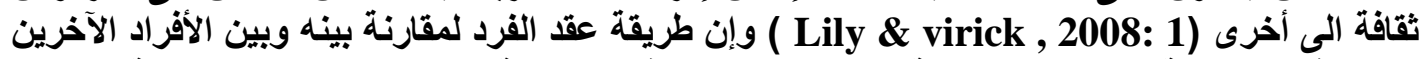

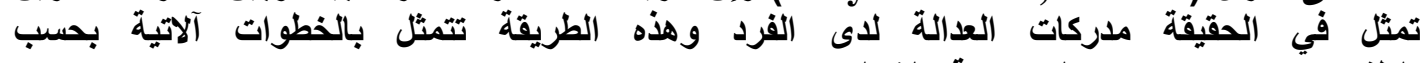

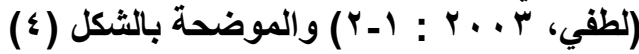

$$
\text { شكل ( }
$$

ادراكات العدالة

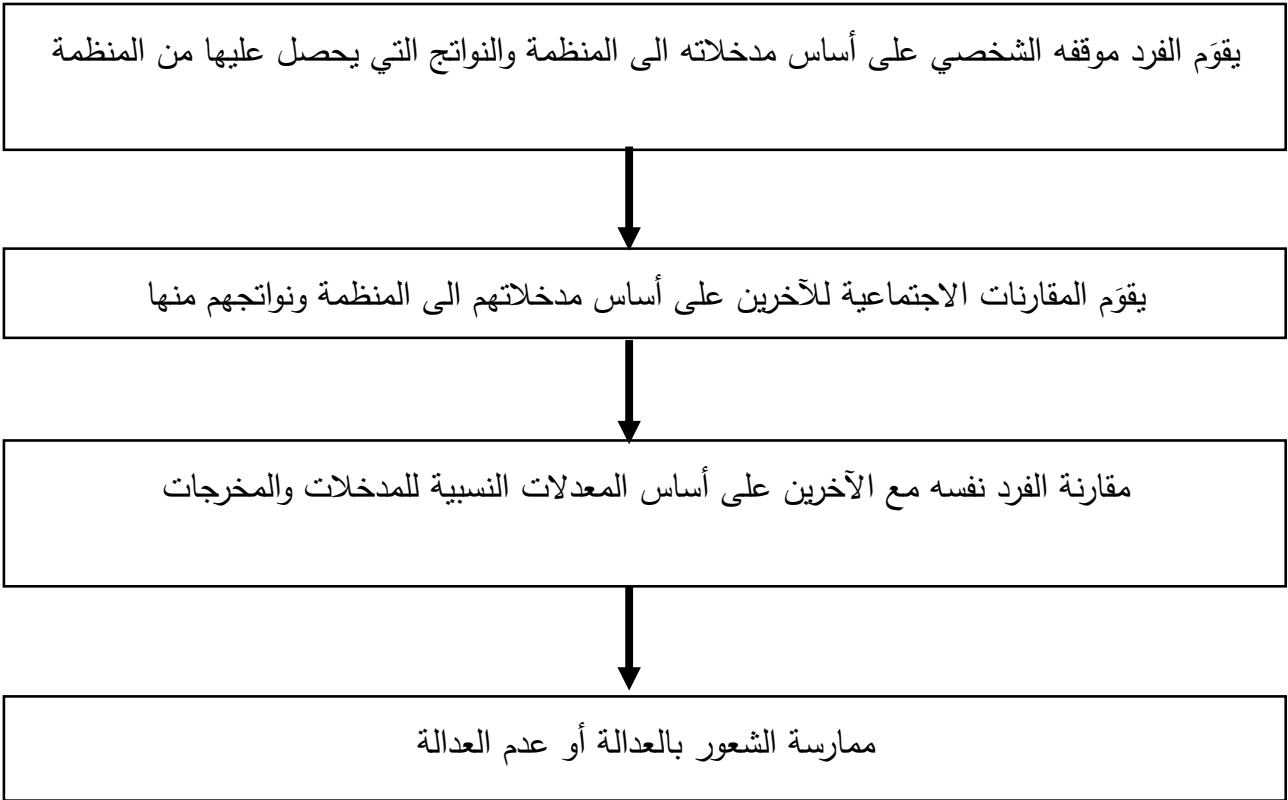

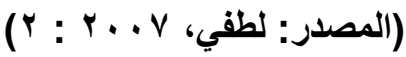

\section{التحليل والاختبار الإحصائي

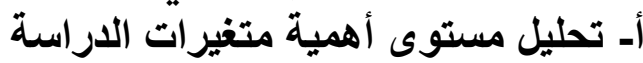

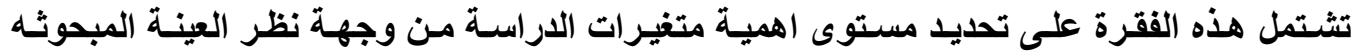
باستخدام التكرارات والنسب المئوية وعن طريق استخراج الوسيط اذ كانت النتائج موضحة في الجدولين

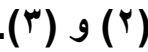

اولا: تحليل مستوى أهمية الإدراك (المتغير التفسيري)

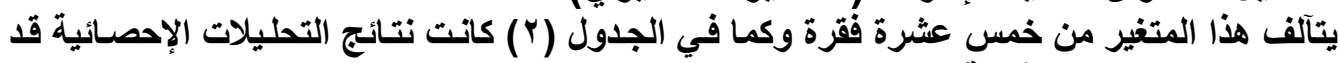
أشرت إزاء كل منها النتائج آلاتية : 
$-53$ 


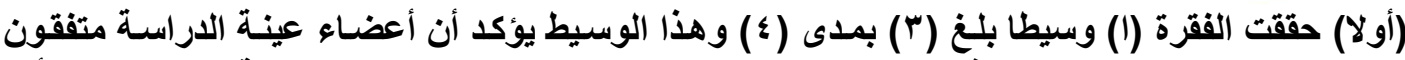

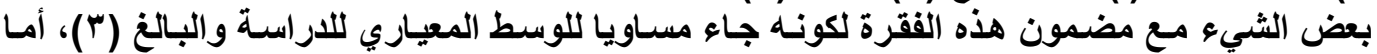

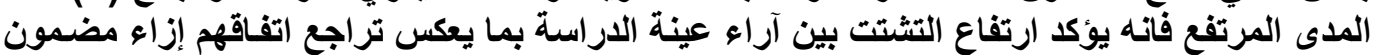

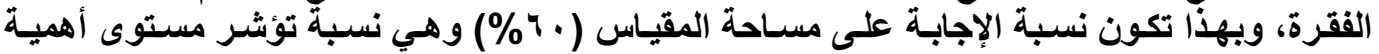

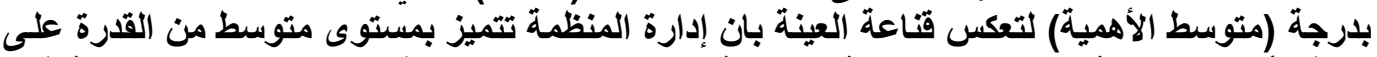

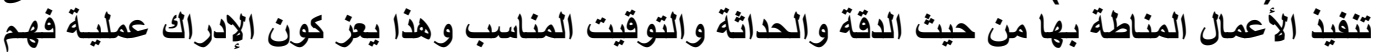
تجعل الثخص يحس بالمحفزات البئية البية.

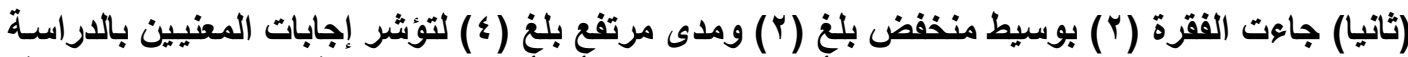

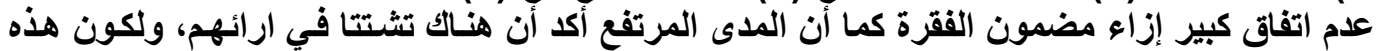

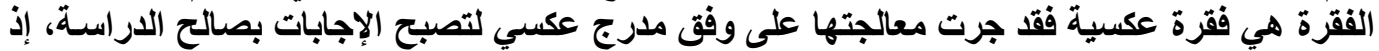

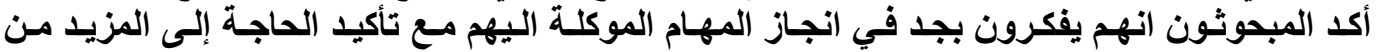

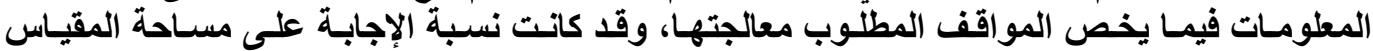

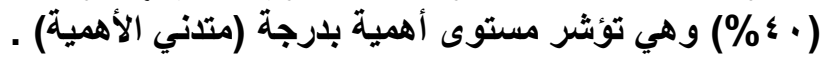

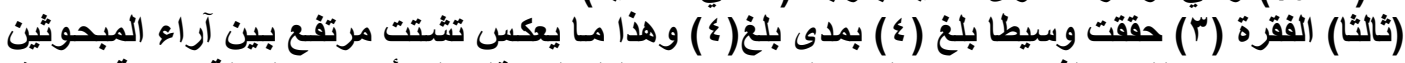

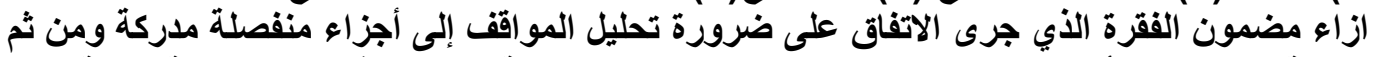

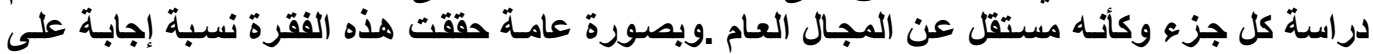

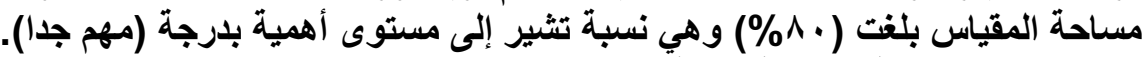

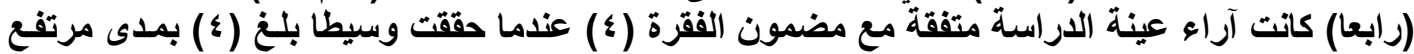

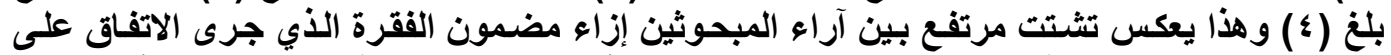

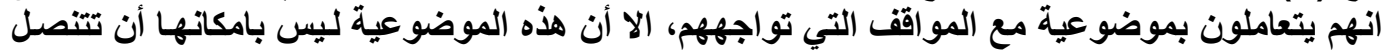

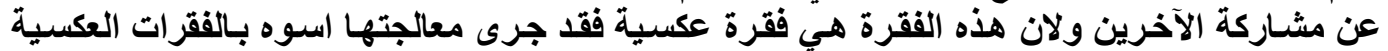

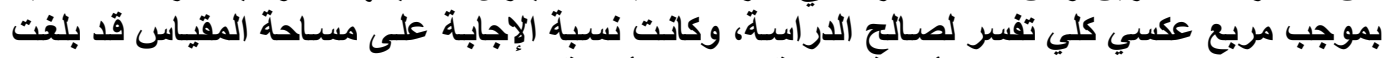

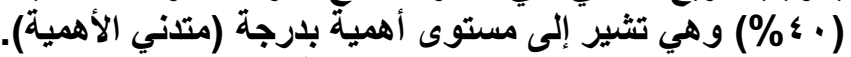

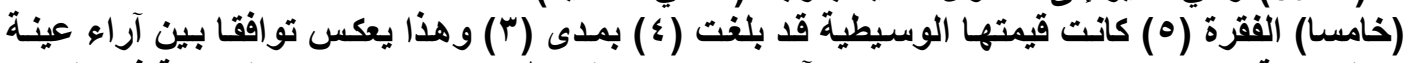

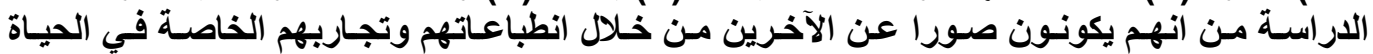

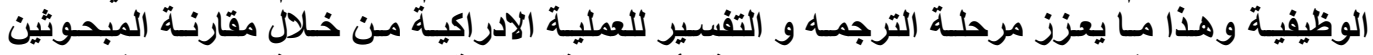

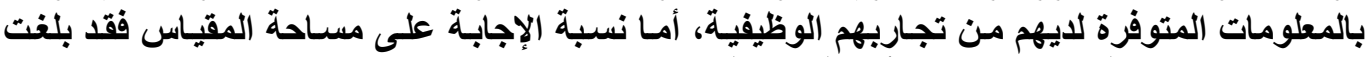

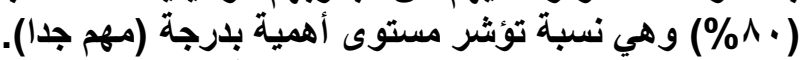

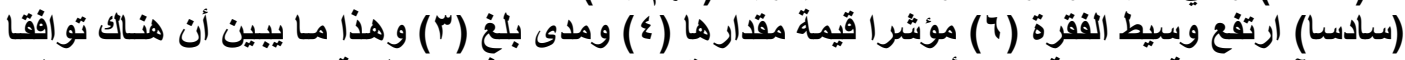

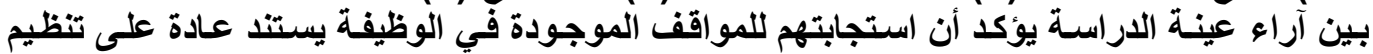

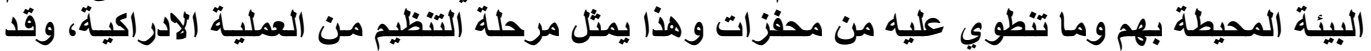

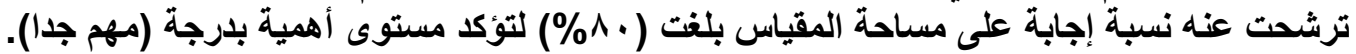

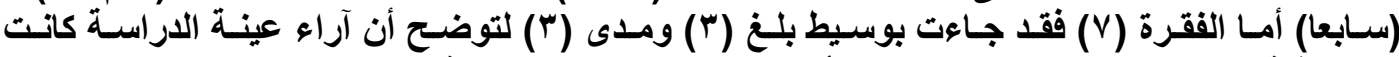

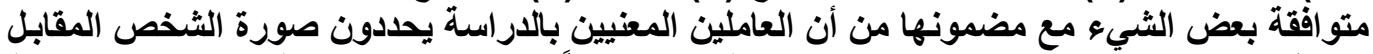

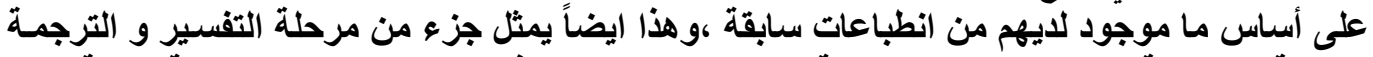

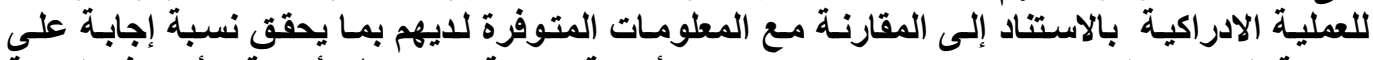

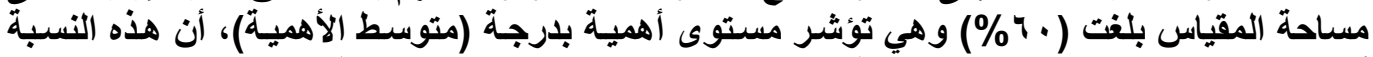

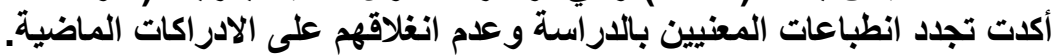

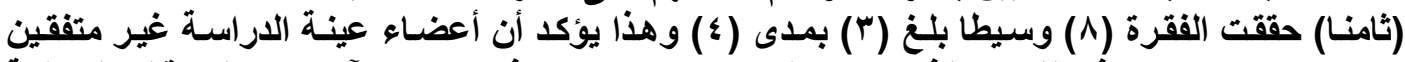

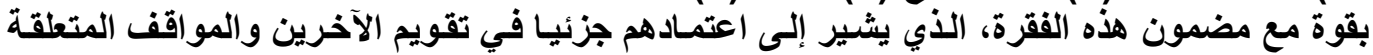

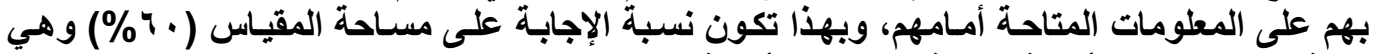

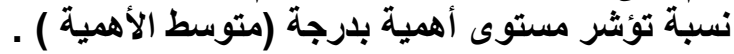

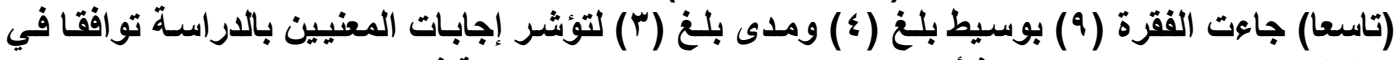

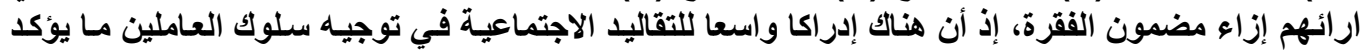

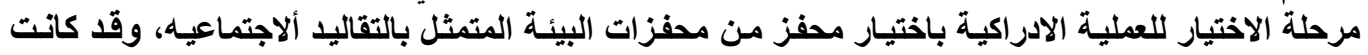

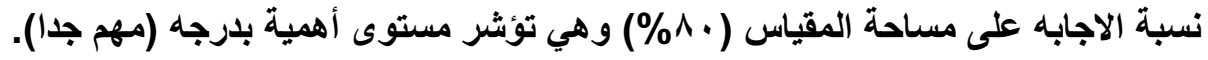




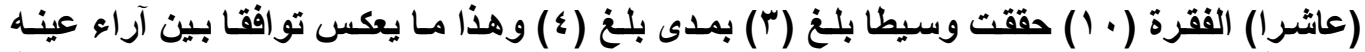

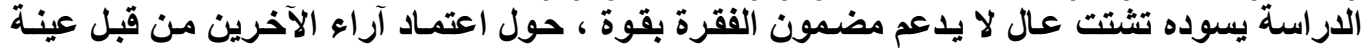

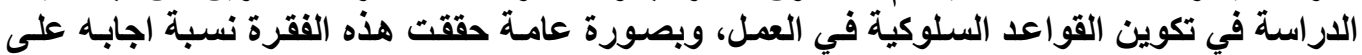

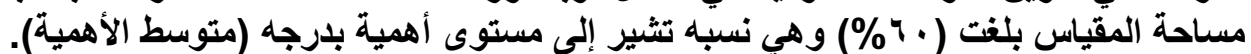

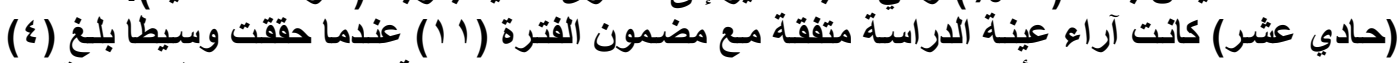

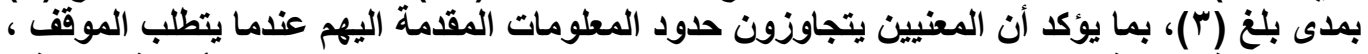

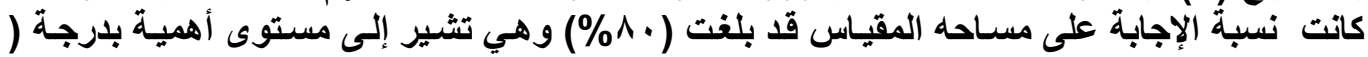

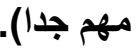

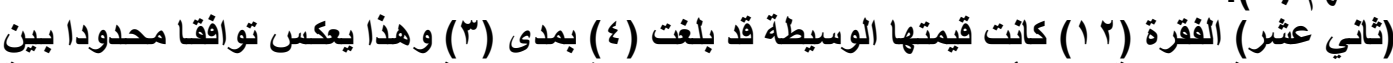

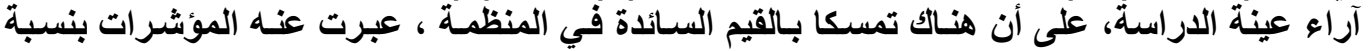

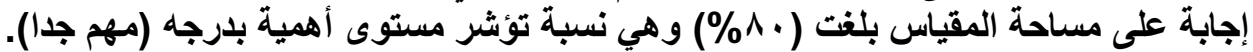

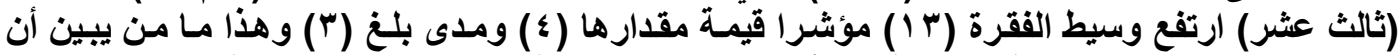

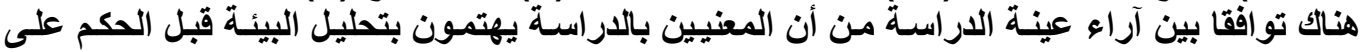

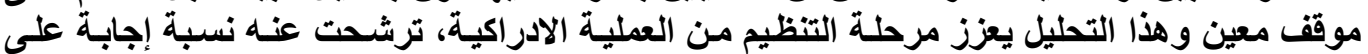

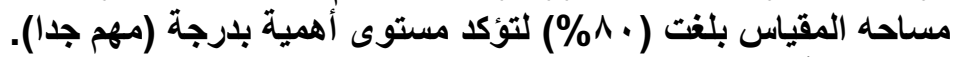

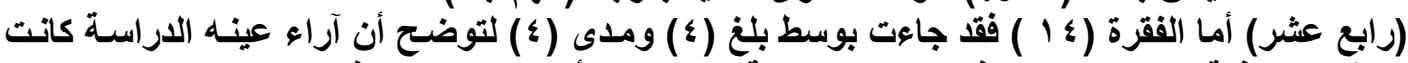

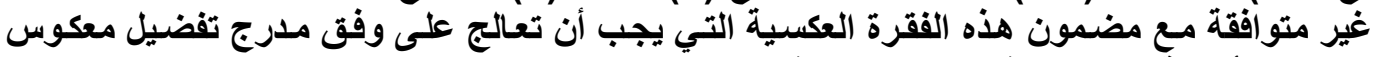

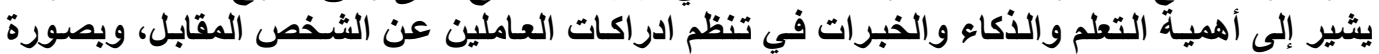

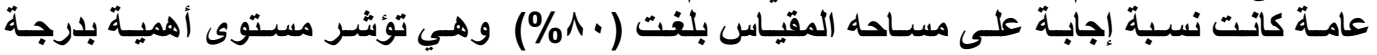

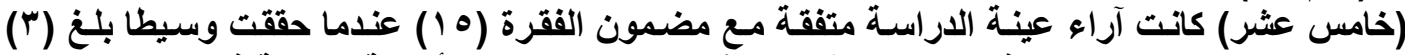

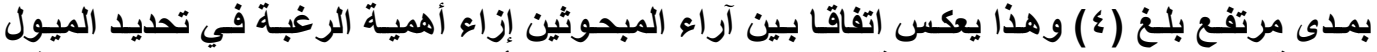

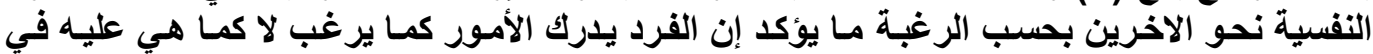

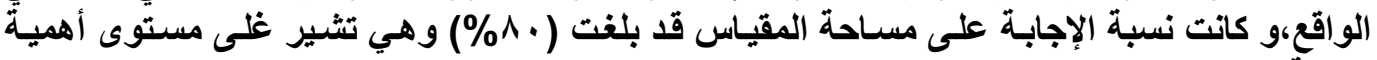

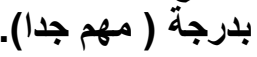

ثاتيا: تحليل مستوى أهمية العدالة التظظيمية (المتغير الاستجابي)

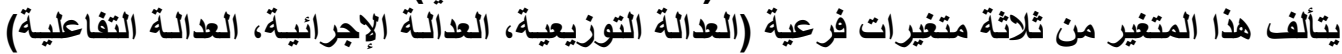

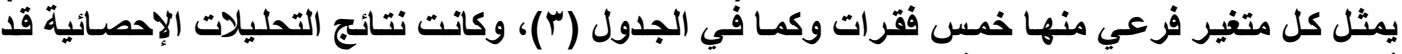

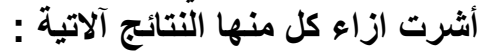

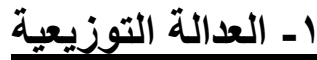

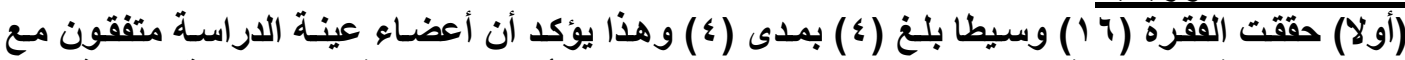

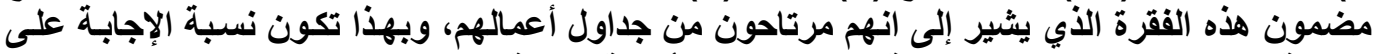

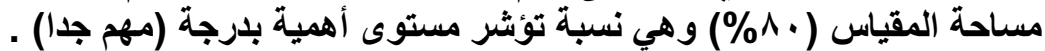

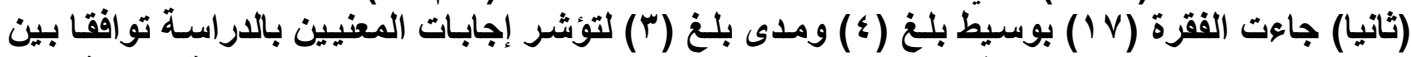

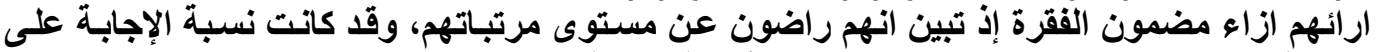

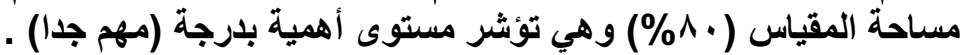

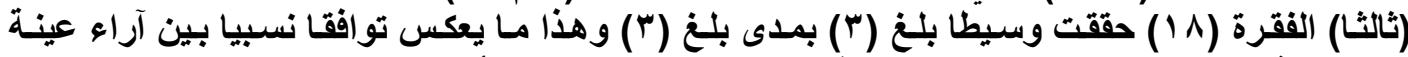

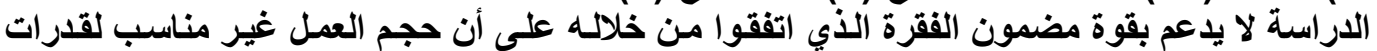

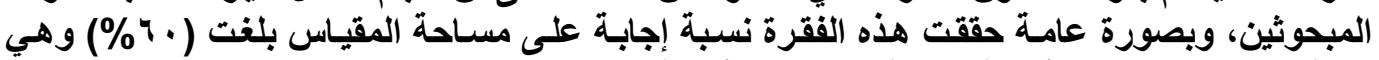

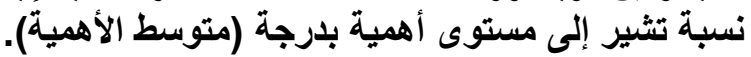

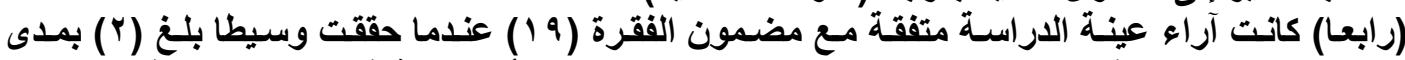

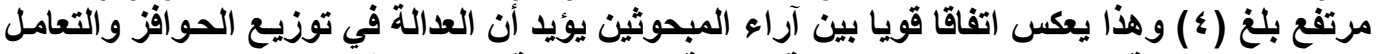

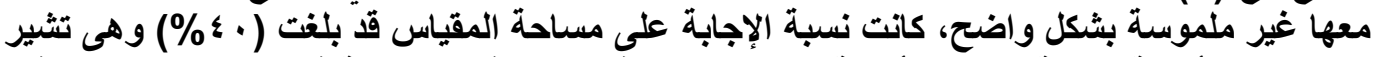

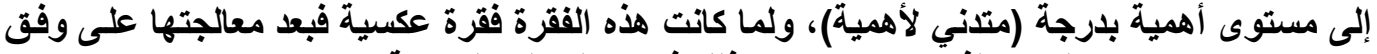

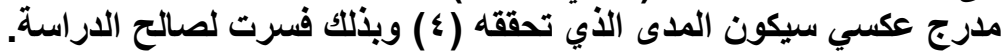




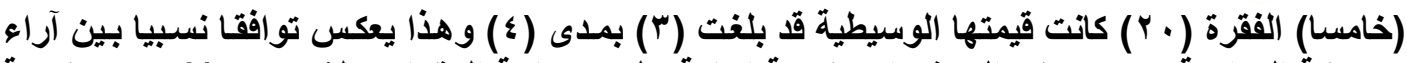

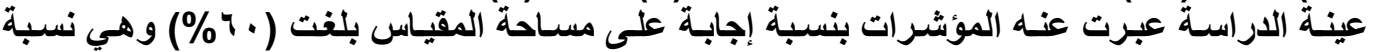

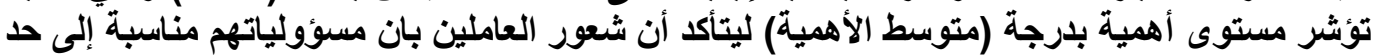

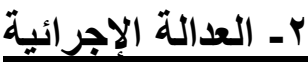

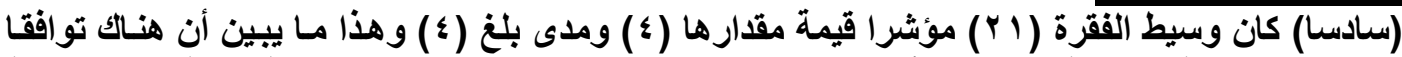

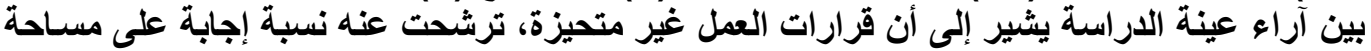

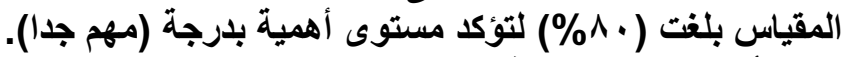

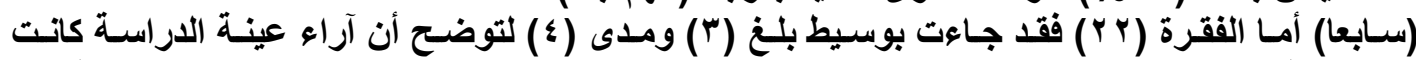

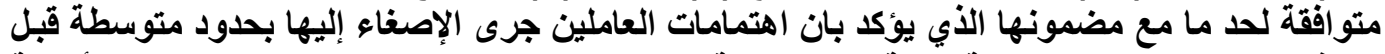

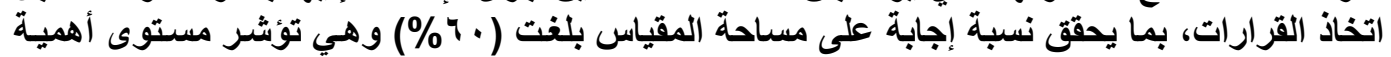

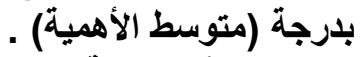

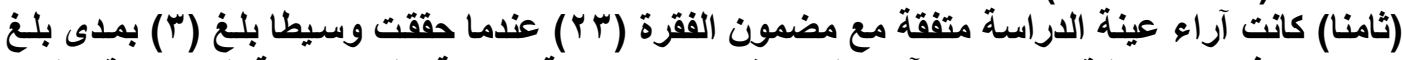

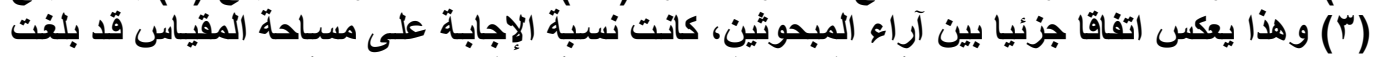

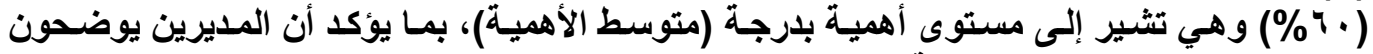

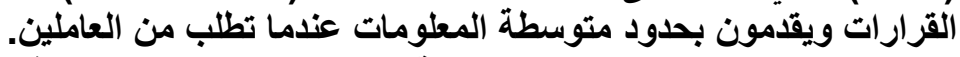

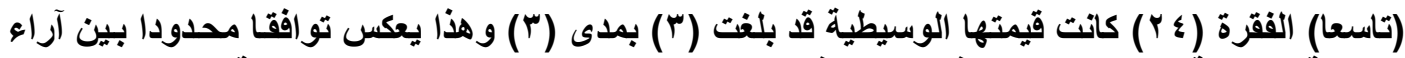

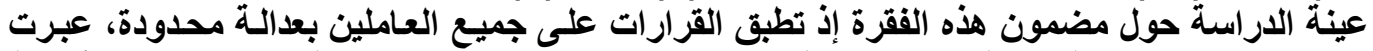

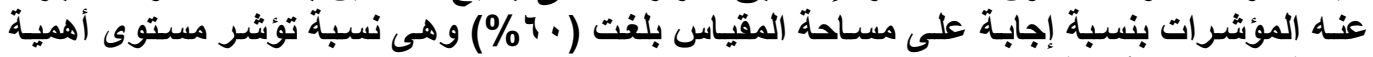
بارجة (متوسط الأهمية).

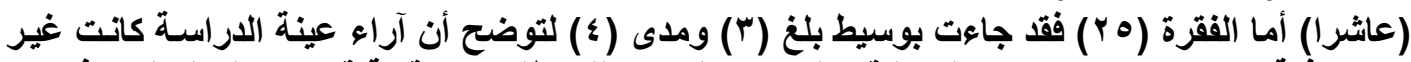

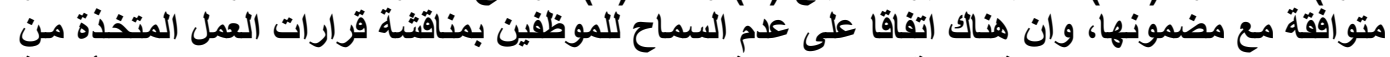

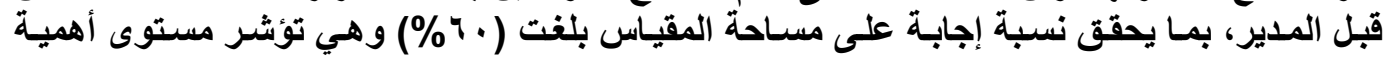

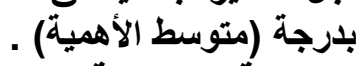
بـ العدالة التفاعلية (مئية

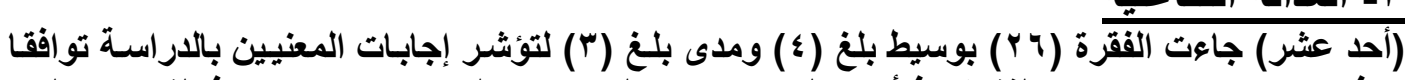

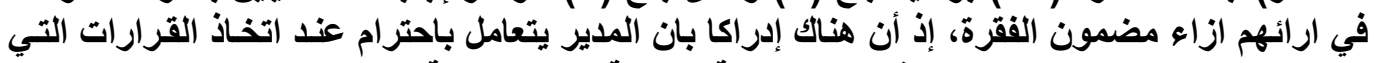

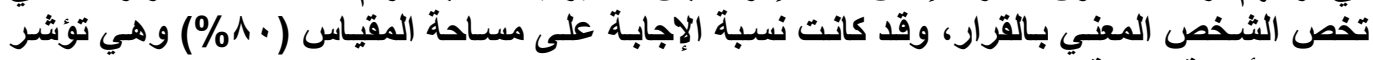

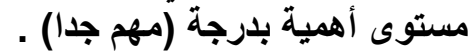

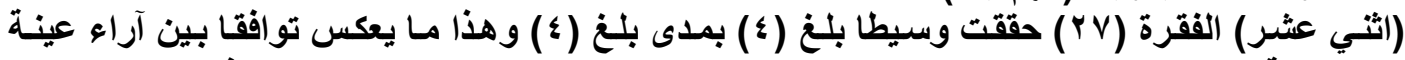

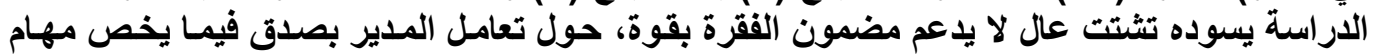

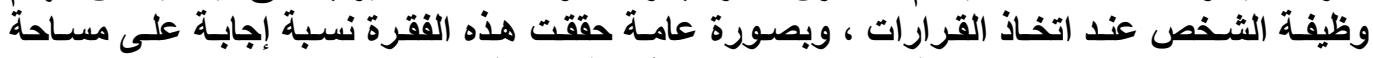

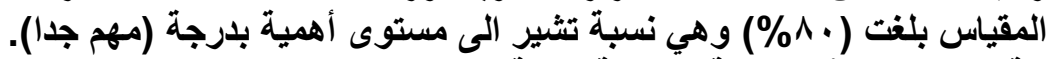

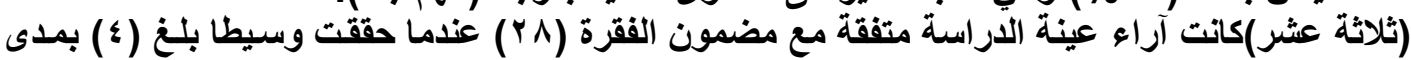

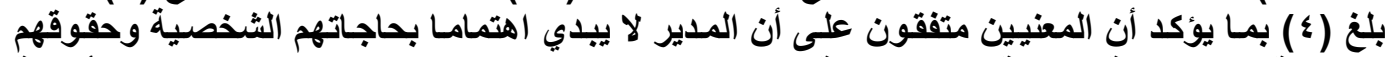

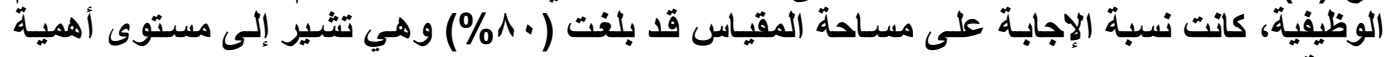
بلدرجة (مهم جدا).

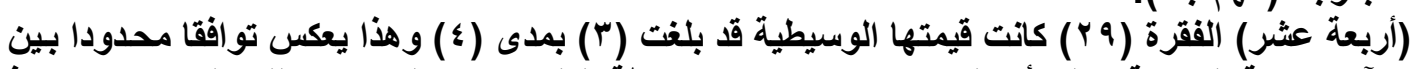

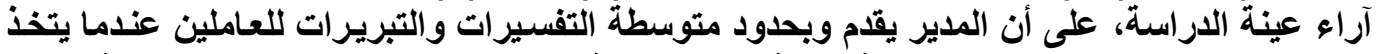

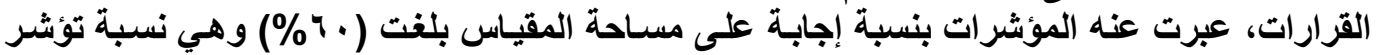
مستوى أهمية بلرجة (متوسط الأهمية).

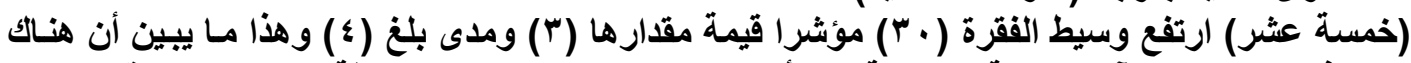

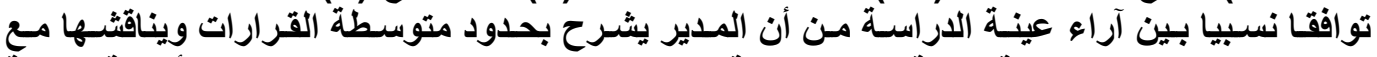

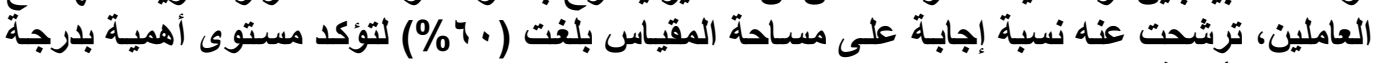


الجدول (؛ ( ) خلاصة بمستوى الأهمية لفقرات الاستبانة

\begin{tabular}{|c|c|c|c|c|c|}
\hline مستوى الأهمية & رقم الفقرة & $ت$ & مستوى الأهمية & رقم الفقرة & ت \\
\hline مهم جدا & 17 & 17 & متوسط الأهمية & 1 & 1 \\
\hline مهم جدا & IV & IV & متدني الأهمية & $r$ & $r$ \\
\hline متوسط الأهمية & 11 & 11 & مهم جذا & $\mu$ & $r$ \\
\hline متدني الأهمية & 19 & 19 & متدني الأهمية & $\varepsilon$ & $\varepsilon$ \\
\hline متوسط الأهمية & $r$. & $r$. & مهم جلا & 0 & 0 \\
\hline مهم جدا & YI & YI & مهرم جلا & 7 & 7 \\
\hline متوسط الأهمبة & Yr & rr & متوسط الأهمية & V & $\mathrm{V}$ \\
\hline متوسط الأهمية & $r r$ & $r r$ & متوسط الأهمية & $\Lambda$ & $\Lambda$ \\
\hline متوسط الأهمية & $r \varepsilon$ & $r \leqslant$ & مهم جدا & 9 & 9 \\
\hline متوسط الأهمبة & ro & ro & متوسط الأهمية & 1. & 1. \\
\hline مهم جدا & ry & $r 7$ & مهم جدا & 11 & 11 \\
\hline مهم جدا & $r V$ & YV & مهم جدا & IT & Ir \\
\hline مهم جدا & YA & $r \wedge$ & مهم جدا & IT & 11 \\
\hline متوسط الأهمية & rq & rq & مهم جدا & $1 \leqslant$ & $1 \varepsilon$ \\
\hline متوسط الأهمية & $r$ & $r$. & متوسط الأهمية & 10 & 10 \\
\hline
\end{tabular}

(المصدر: من إعاد الباحثان بالاعتماد على نتائج الاحصائية)

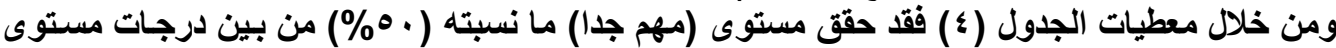

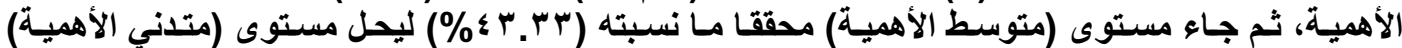

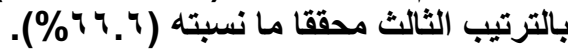

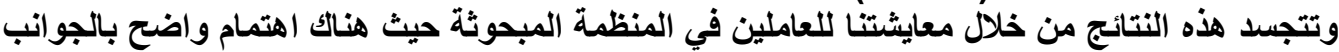

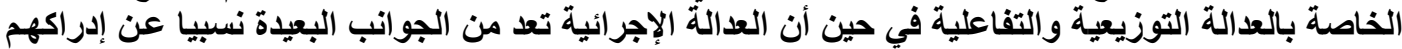

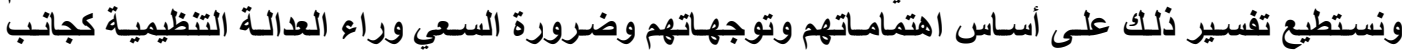
أساسي في المنظمة المبحوثة.

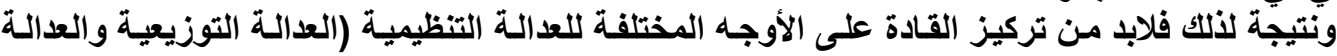
الإجرائية والعدالة التفاعلية).

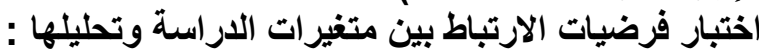

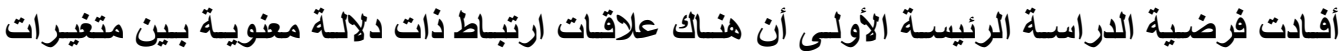

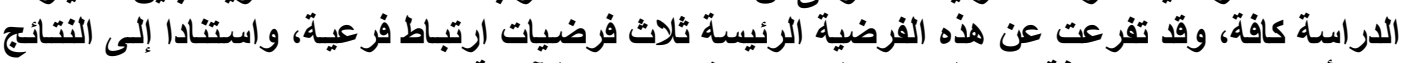

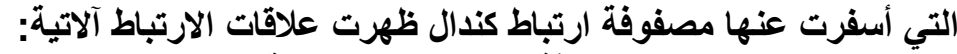

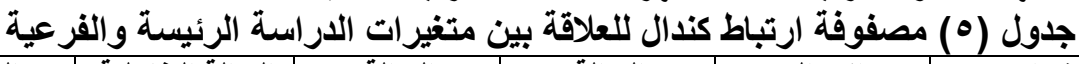

\begin{tabular}{|c|c|c|c|c|c|}
\hline التنظيمية العدالة & العدالةُ التفاعلية & الإجرائية & التوالة & الإدراك & المتغيرات \\
\hline & & & & $T$ & الإلدراك \\
\hline & & & 1 & **. & العدالة التوزيعية \\
\hline & & $T$ &. .11. &. .187 & العدالة الإجرائية \\
\hline & $T$ & **..74. & ${ }^{* *} \cdot . \leqslant \Gamma q$ & **..YI. & العدالة التفاعلية \\
\hline 1 & **.TYT & $* * .01 Y$ & $\star * . \Delta \vee \wedge$ & **.,YभI & العدالة التظظيمية \\
\hline
\end{tabular}

(المصدر: من إعداد الباحثان بالاستفادة من مخرجات الحاسبة الاكترونية)

وفي ضوء ما أسفرت عنه نتائج تحليل علاقات الارتباط يمكن اختبار فرضيات الدراسة الفرعية وكما يأتي:

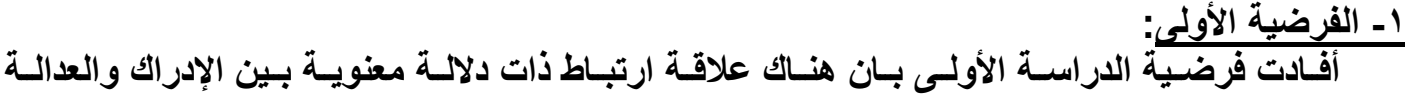

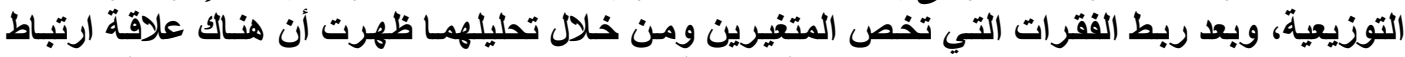

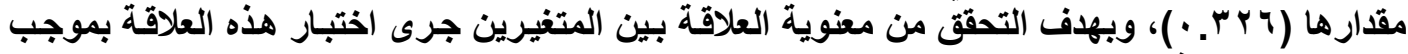
الجدول (T) اختبار علاقة الارتباط بين الإدراك والعدالة التوزيعية

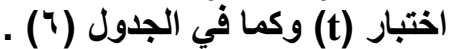

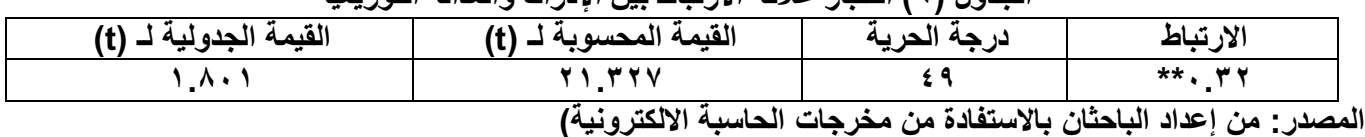

(المصدر: من إعداد الباحثان بالاستفادة من مخرجات الحاسبة الاكترونية)

يتضح من معطيات الجدول (†) أن قيمة (t) المحسوبة هي اكبر من قيمتها الجدولية بمستوى معنوية

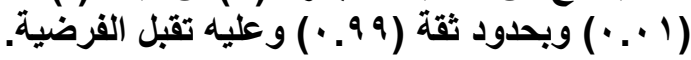




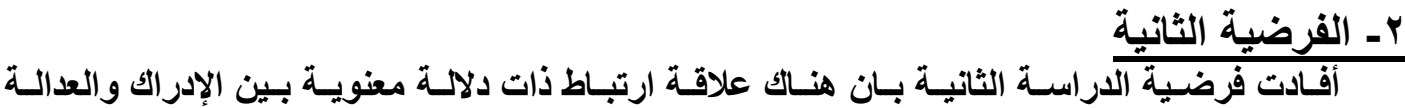

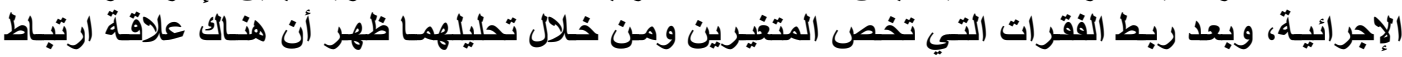

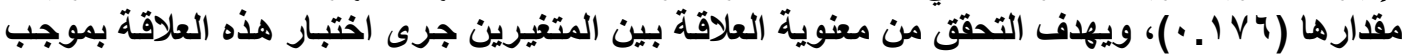

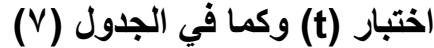
الجدول (V) اختبار علاقة الارتباط بين الإدراك والعدالة الإجرائية

\begin{tabular}{|c|c|c|c|}
\hline القيمة الجدولية لـ (t) & القيمة المحسوبة لـ (t) & درجة الحرية & الارتباط \\
\hline $1 . \wedge .1$ & $1.7 \leqslant V$ & $\leqslant 9$ & $.1 \vee 7$ \\
\hline
\end{tabular}

(المصدر: من إعداد الباحثان بالاستفادة من مخرجات الحاسبة الاكترونية)

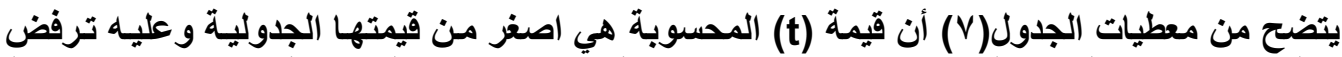

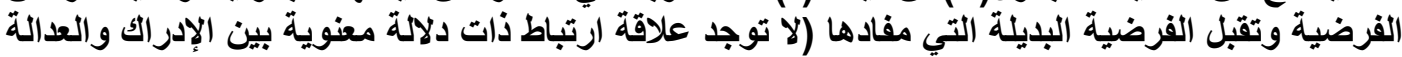

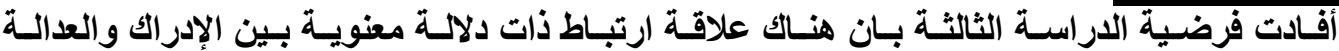

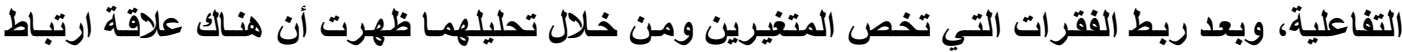

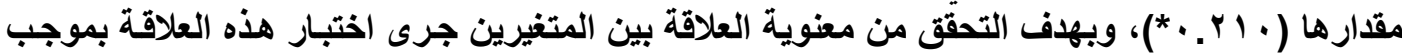

الجدول (^) اختبار علاقة الارتباط بين الإدراك والعدالة التفاعلية

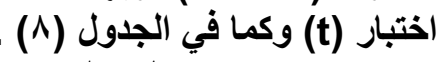

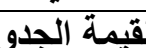

\begin{tabular}{|c|c|c|c|}
\hline القيمة الجدولية لـ (t) & القيمة المحسوبة لـ (t) & درجة الحرية & الارتباط \\
\hline $1 . \wedge \cdot 1$ & r.r.r & $\varepsilon 9$ & $* ., r_{1}$ \\
\hline
\end{tabular}

يتضح من معطيات الجدول (^) أن قيمة (t) المحسوبة هي اكبر من قيمتها الجدولية بمستوى معنوية إناية

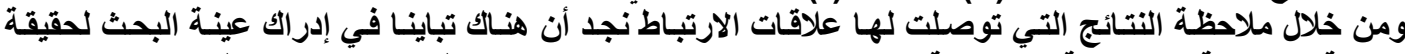

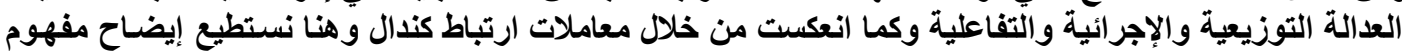

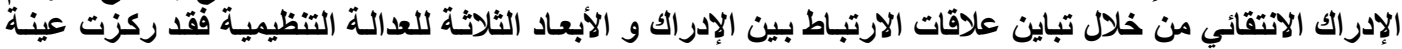

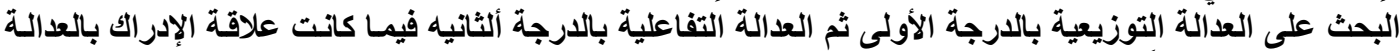

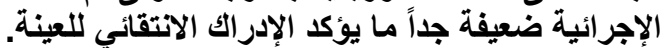

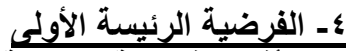

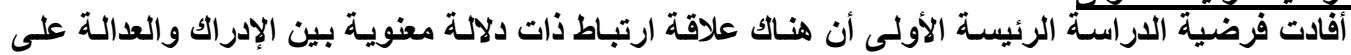

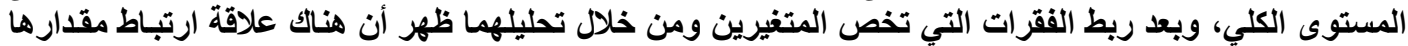

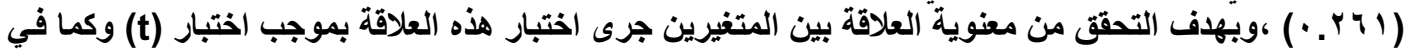

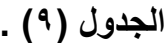
الجدول (9) اختبار علاقة الارتباط بين الإدراك والعدالة على المستوى الكلي

\begin{tabular}{|c|c|c|c|}
\hline القيمة الجذولية لـ (t) & القيمة المحسوبة لـ (t) & درجة الحرية & الارتباط \\
\hline $1 . \wedge \cdot 1$ & TY.YY & $\leqslant 9$ & $* * ., Y 71$ \\
\hline
\end{tabular}

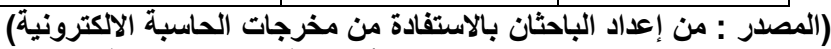

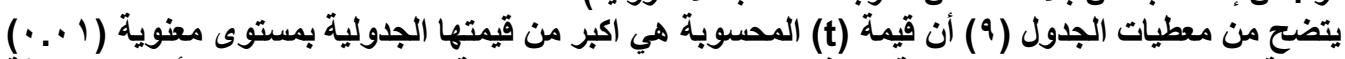

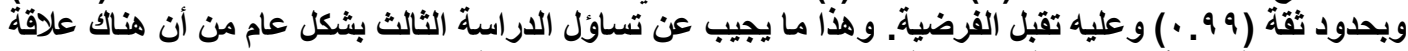

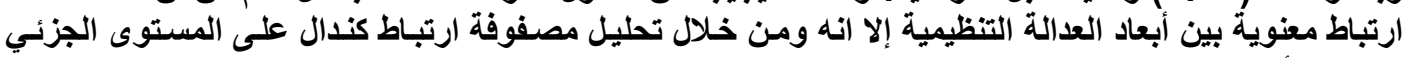

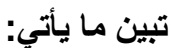

أ- لا توجد علاقة ارتباط ذات دلالة معنوية بين العدالة الإجرائية و العدالة التوزيعية.

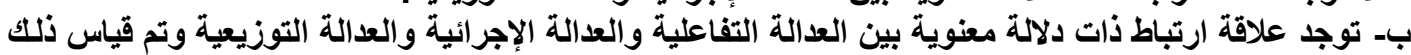

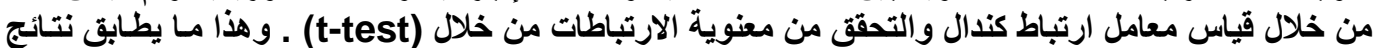

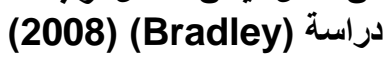

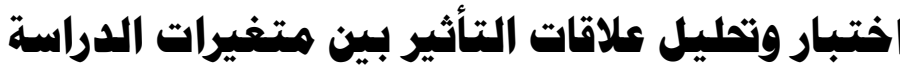

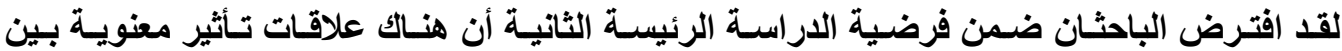

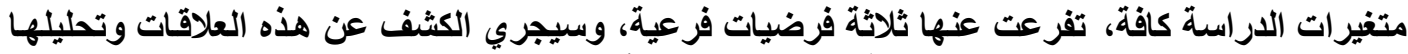

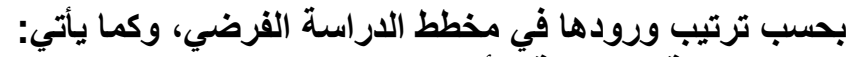
Iـ الفرضية الفرعية الأولى 


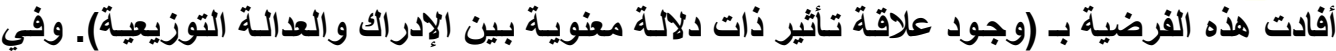

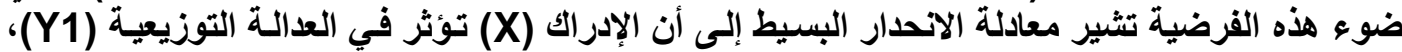

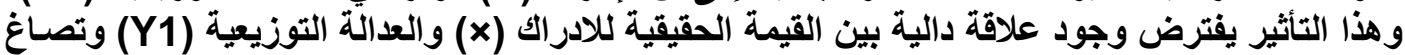

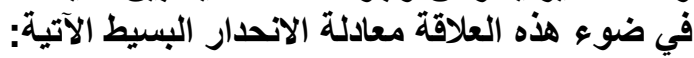
$Y 1=a+\beta X$

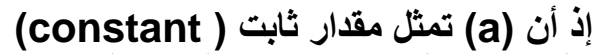

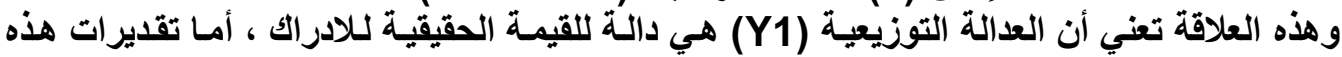

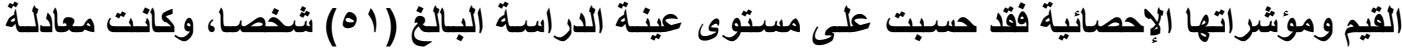

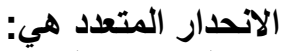

الجدول ( • 1 ) تحليل التباين للعلاقة بين الادراك والك والعدالة التوزيعية

\begin{tabular}{|c|c|c|c|c|c|}
\hline مستوى المعنوية & قيمة (F) المحسوبة & متوسط المربعات & مجموع المربعات & دالحرية & مصدر التباين \\
\hline$\because \cdots 0$ & $\Lambda .0 \wedge 1$ & $1 . V \mu$. & $1 . V \%$. & $T$ & الانحدار \\
\hline & & O.Y.Y & Q.AVV & $\xi 9$ & الخطاً \\
\hline & & & 11.7 .7 & 0. & المجموع \\
\hline
\end{tabular}

وفي إطار هذه الصياغة فان جدول تحليل التباين أسفر عن نتائج جرى في ضوئها تحليل التباين بين

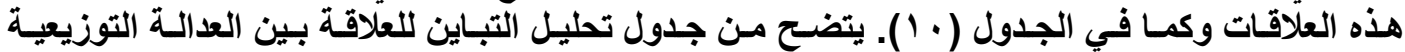

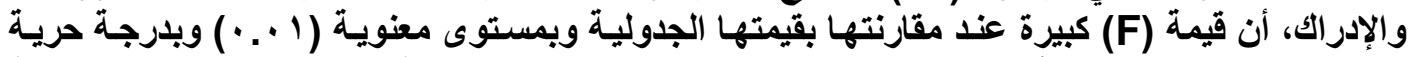

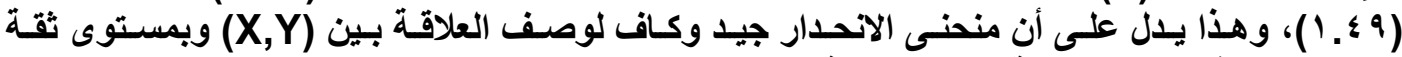

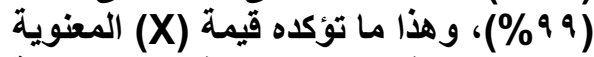

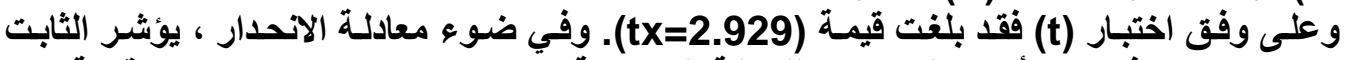

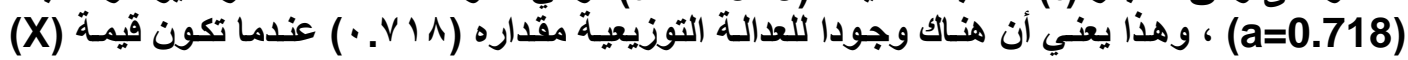
تساوي صفرا.

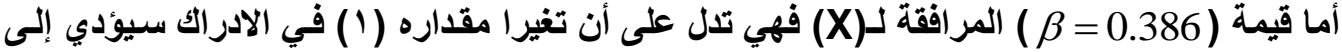

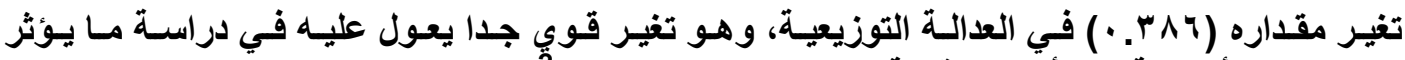

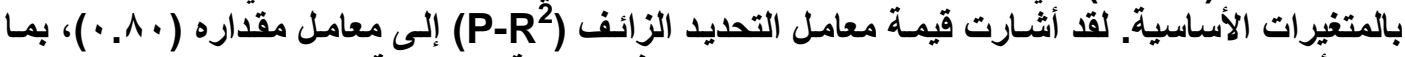

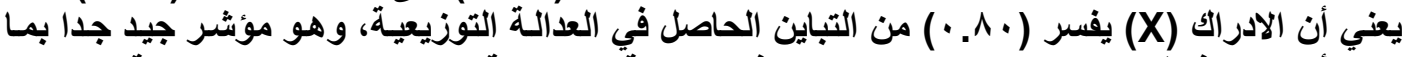

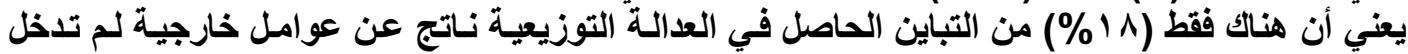

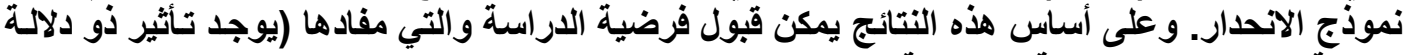

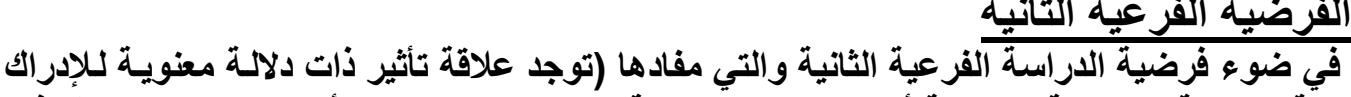

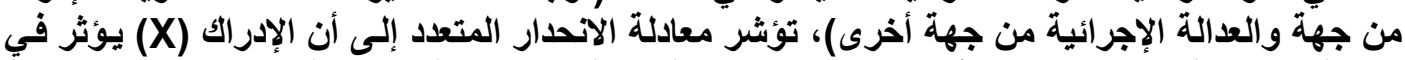

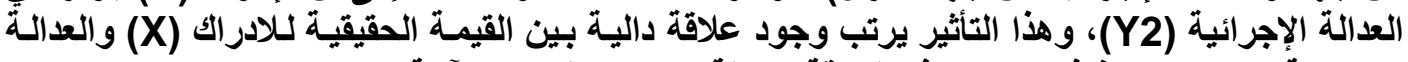

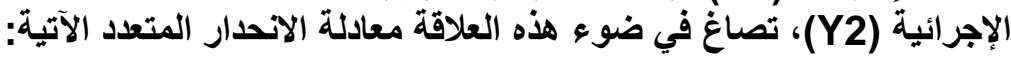
$Y 2=a+\beta X$ (a) تمثل مقدار ثابت (a) (a) إذ (constant) 


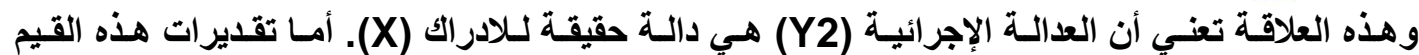

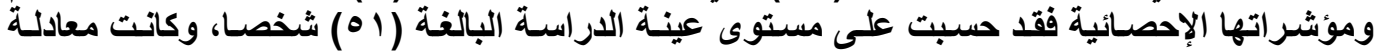

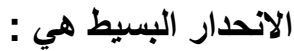

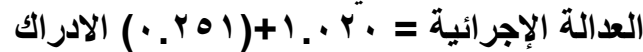

وفي إطار هذه المعادلة يبين جدول تحليل التباين مستوى المعنوية المبين في الجدول (1 (1)، وكما يأتي:

الجدول (1') تحليل التباين للعلاقة بين الادراك والعدالة الإجرائية

\begin{tabular}{|c|c|c|c|c|c|}
\hline مستوى المعنوية & قالمحسوبة (F) & متوسط المربعات & مجموع المربعات & درجة الحرية & مصدر التباين \\
\hline \multirow[t]{3}{*}{$\because \times 7$} & Y.Yq & $1.0 \leq$. & $1.0 \leq$. & 1 & الاتحدار \\
\hline & &..$\leqslant 7 V$ & $r Y . q \cdot V$ & $\leqslant 9$ & الخطأ \\
\hline & & & $Y \leqslant . \leqslant \leqslant V$ & 0 . & المجموع \\
\hline
\end{tabular}

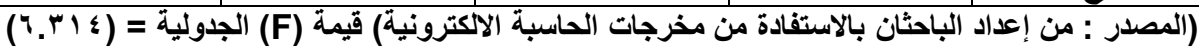

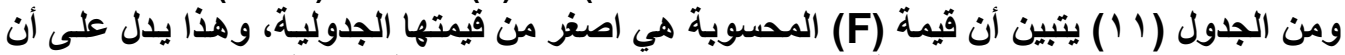

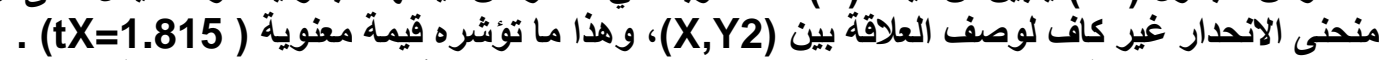

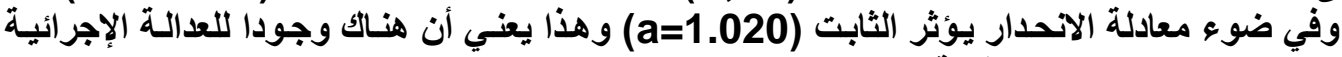

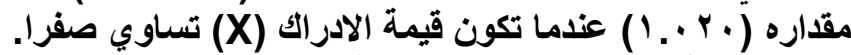
اما قيمة (X=0.251

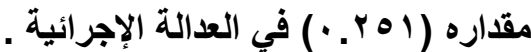

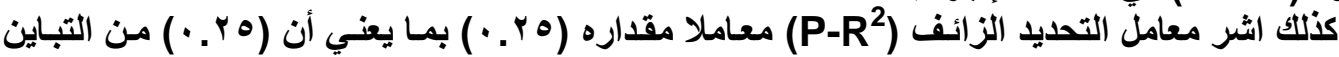

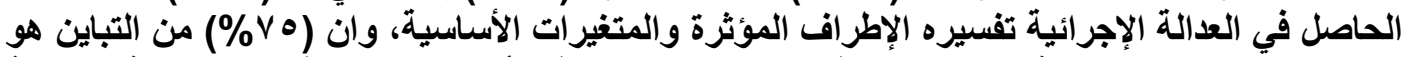

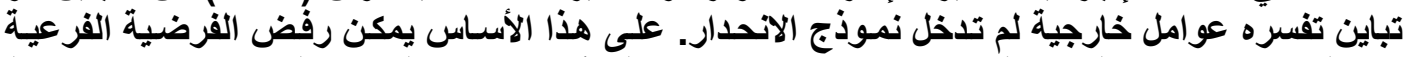

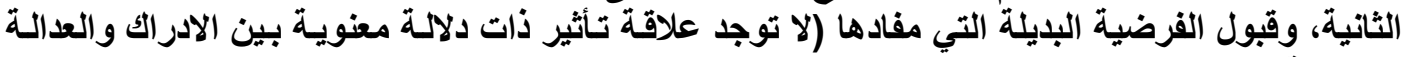

ب: الإجرضية الفية الفرعية الثالثة

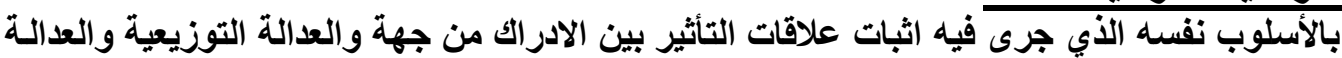

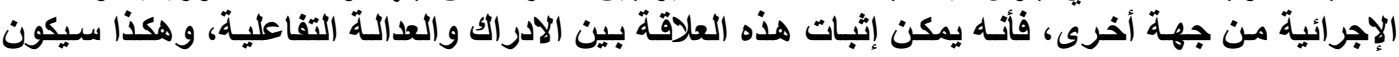

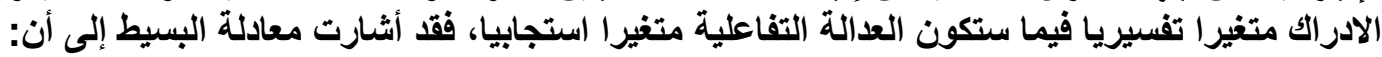

$$
Y 3=a+\beta X
$$

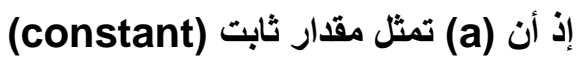

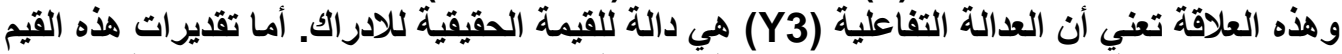

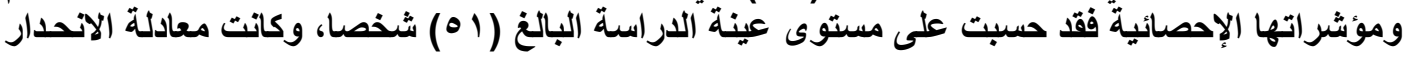

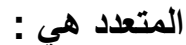

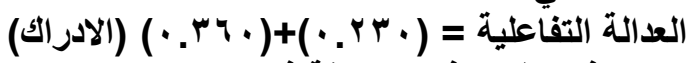

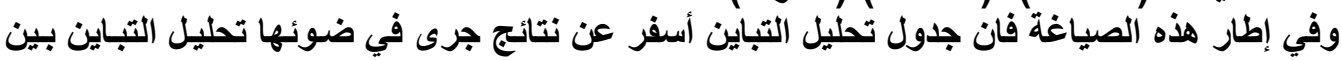

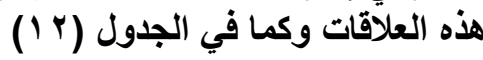

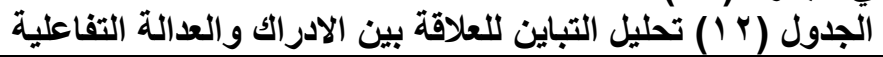

\begin{tabular}{|c|c|c|c|c|c|}
\hline مستوى المعنوية & قالمحسوبة (F) & متوسط المربعات & مجموع المربعات & درجة الحرية & مصدر التباين \\
\hline$\therefore \cdot 1$ & $V . Y V A$ & $r . v \circ q$ & r.v०q & 1 & الانحدار \\
\hline & & .017 & YO.r. T & $\leqslant 9$ & الخطأ \\
\hline & & & r9..70 & 0. & المجمو \\
\hline
\end{tabular}

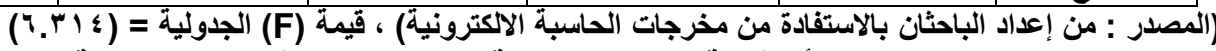

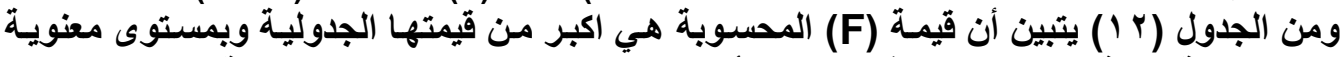

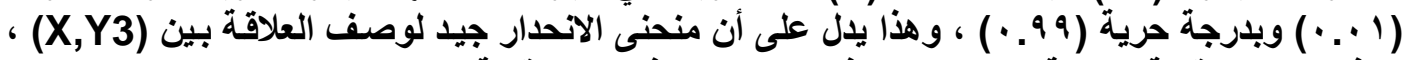

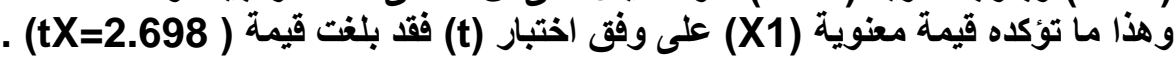




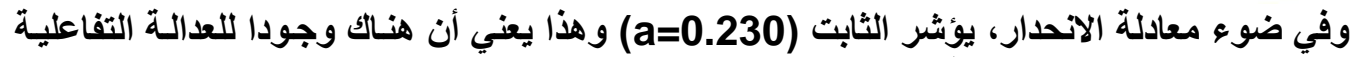

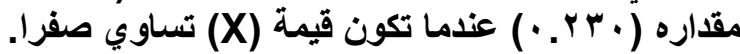

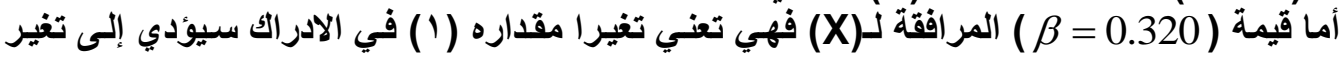

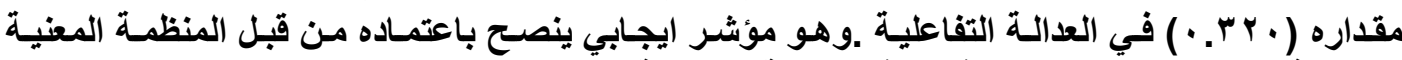

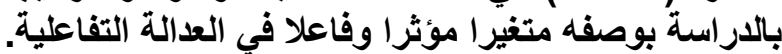
اشر معامل التحديد الزائف (P-R

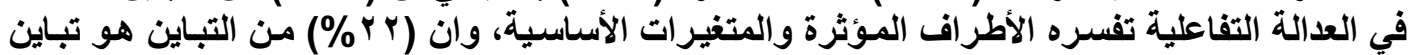

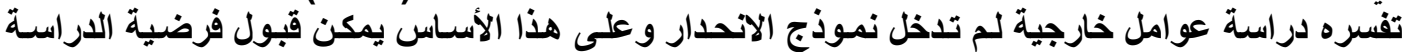

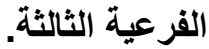

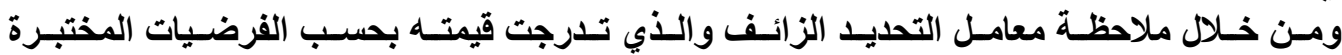

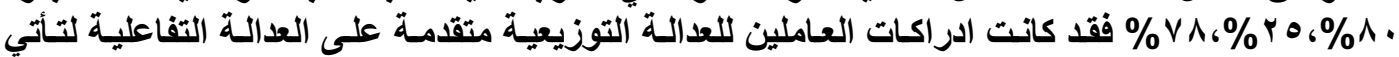

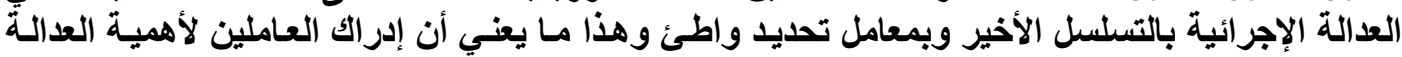

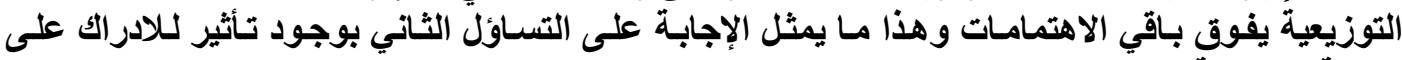
العدالة التفاعلية. ب: الفرضية الرئيسة الثة الثانية

بعد الانتهاء من اثبات الفرضية الفياتية الفرضيات الفرعية الثلاث لابد من اختبار الفرضية الرئيسة التي اشتقت منها

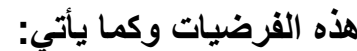

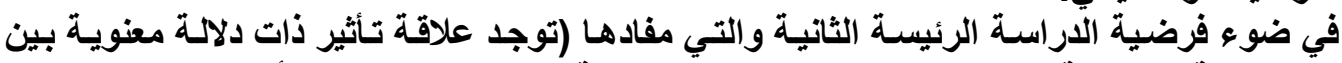

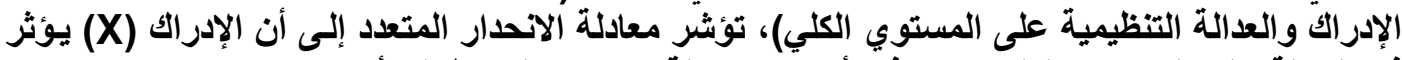

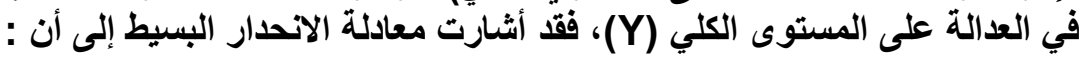

$$
Y=a+\beta X
$$

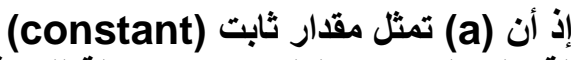

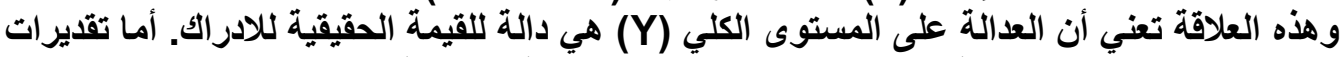

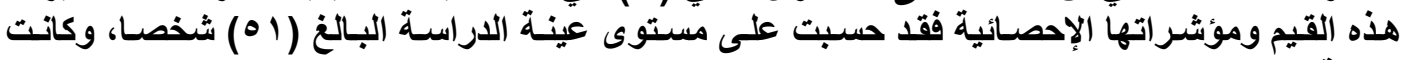

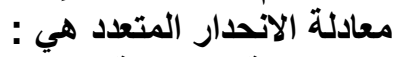

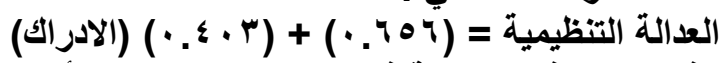

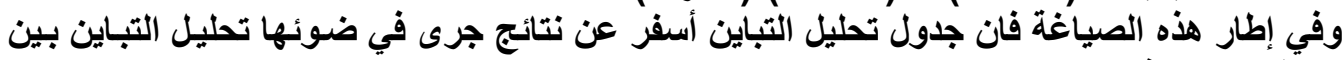

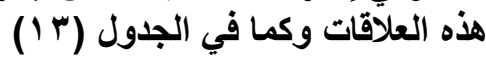
الجدول (T) أ) تحليل التباين للعلاقة بين الادراك والك والعدالة التنظيمية على المستوى الكلي

\begin{tabular}{|c|c|c|c|c|c|}
\hline مستّوى المغنوية & ألمحسة (F) & متوسط المربعات & مجموع المربعات & الحرجية & مصدر التباين \\
\hline$\because \cdots r$ & $9 . \varepsilon \wedge Y$ & $Y . Y \leq 0$ & $r . r \leqslant 0$ & 1 & الانحدار \\
\hline & &.$Y M V$ & 11.7 .1 & $\leqslant 9$ & الخطأ \\
\hline & & & $1 T . \wedge \leq 7$ & 0. & المجموع \\
\hline
\end{tabular}

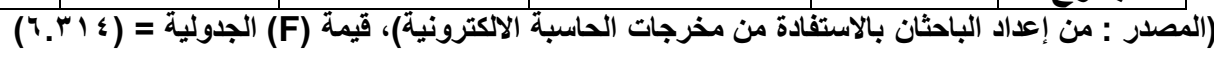

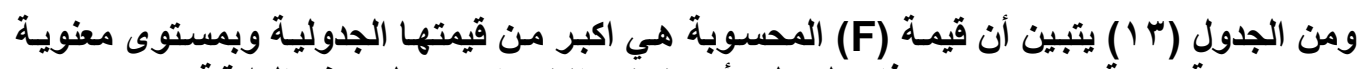

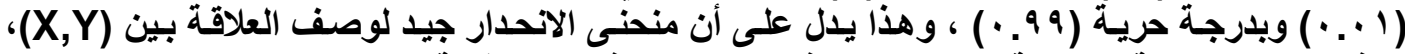

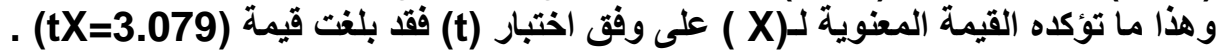

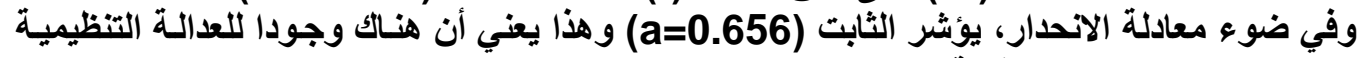

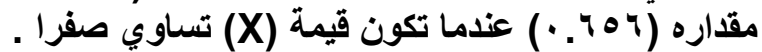

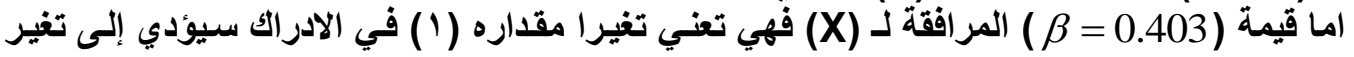

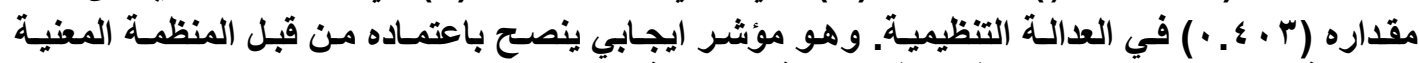

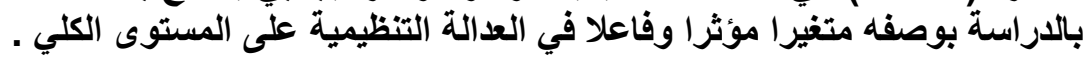




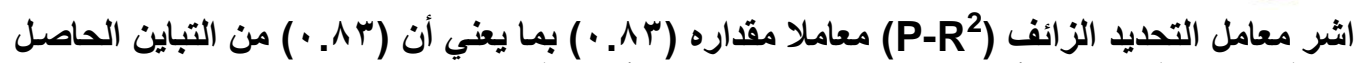

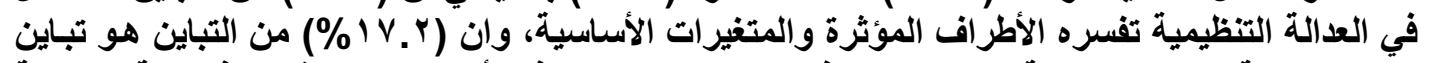

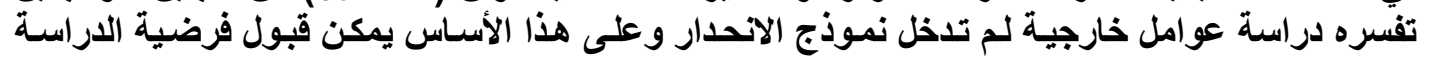

ولغزض الإجابة على التساؤل الرابع للاراسة وبعد قياس تأثير الادراك في العدالة التظيميسة بأبعادها الرئيسة الثانية .

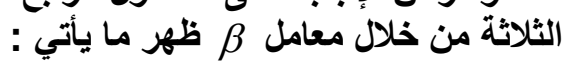

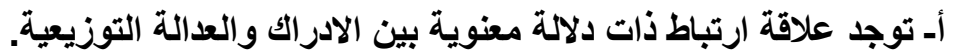

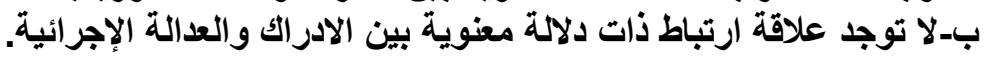

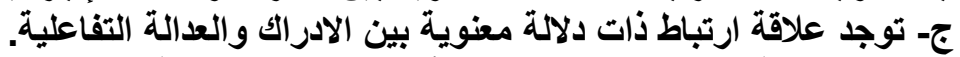

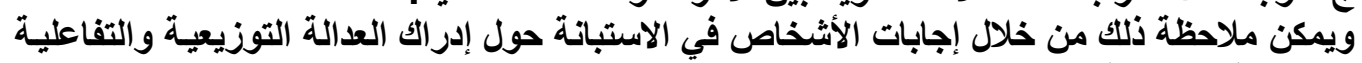
ضمن المنظمة المبحوثة. 


\section{أ- الاستنتاجات}

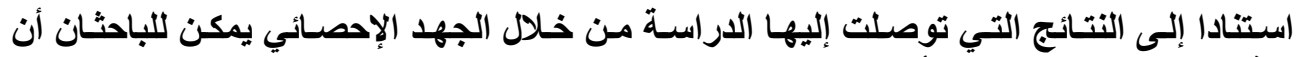
يخرجا بجملة من الاستنتاجات وكما يأتي: التئ

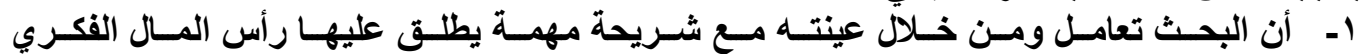

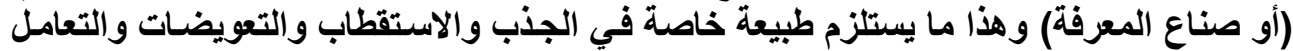
العلائقي وتنمية رأس المال الاجتماعي التنظيمي.

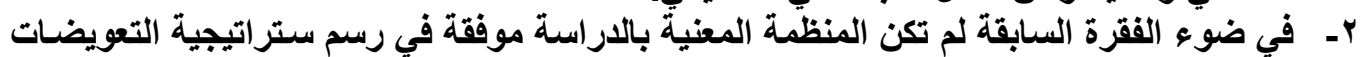

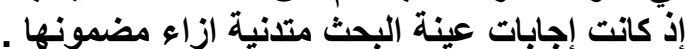

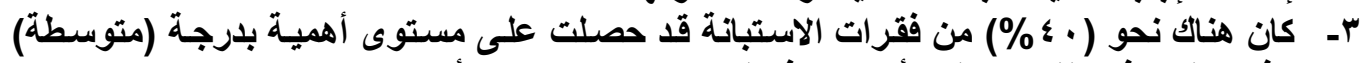

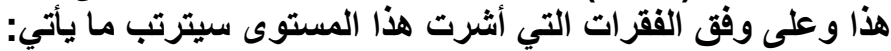

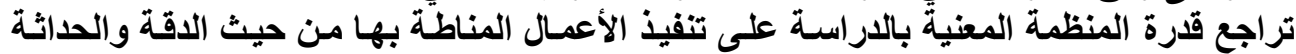

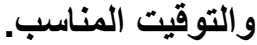

ب. حاجة المعنيين بالعينة إلى إدراك صورة الثخص المقابل المقابل وكما في واقع الحال ومـن خلال التعامل

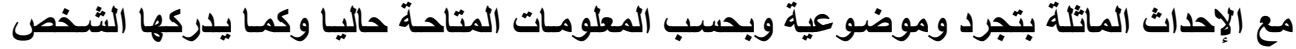

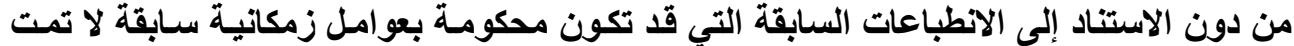

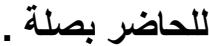
ج. تراجـع تفاعل المبحـوثين مـع بعضـهم في الوصـول ومـن خـلال تبـادل الآراء إلـى تكوين قواعد

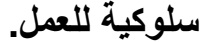
د. أن العاملين يكلفون بأعمال غير مناسبة لقدراتهم سواء أكان ذلك بالسلبي أم الايجابي.

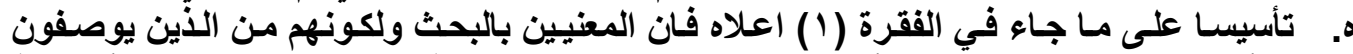

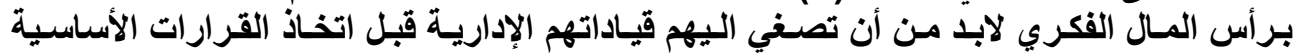

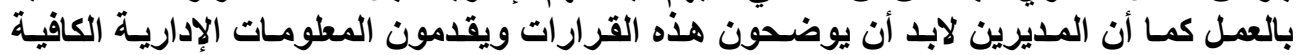

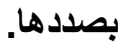

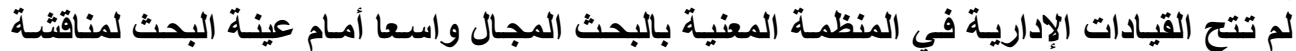

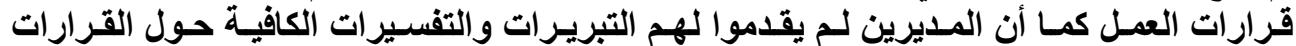

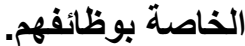

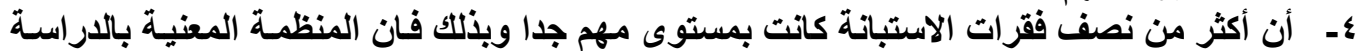

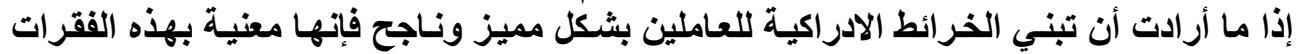

هـ وإذا مأ كاتت الفقرات السابقة قد تحققت من جراء ما افرزه الجهات الجهـ الإحصائي فان ملاحظات الباحثة

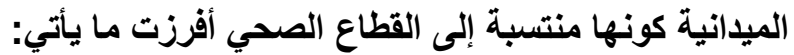

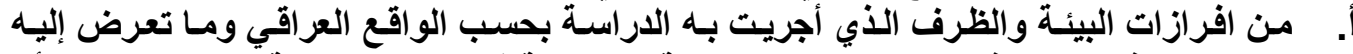

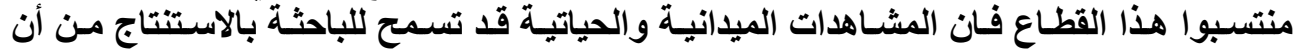

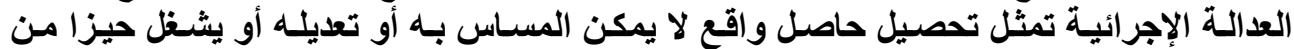

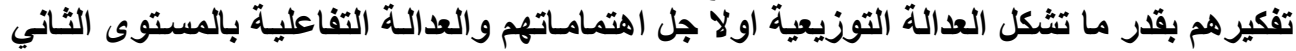

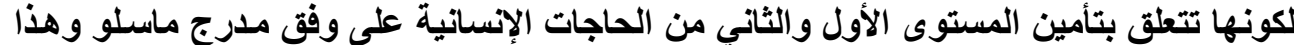

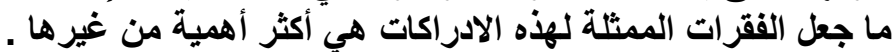

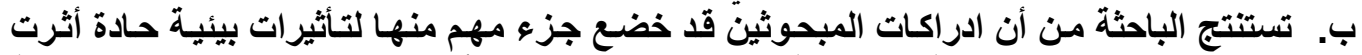

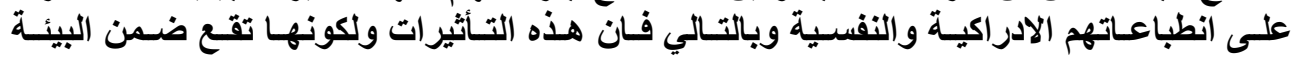

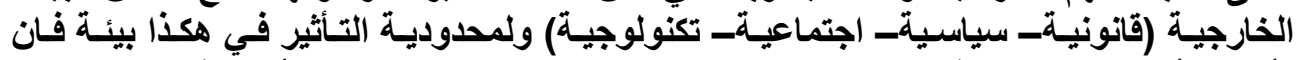

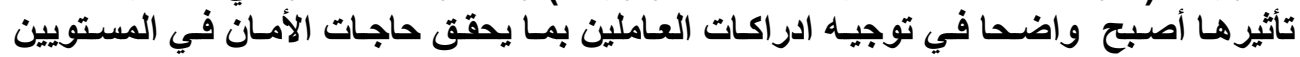

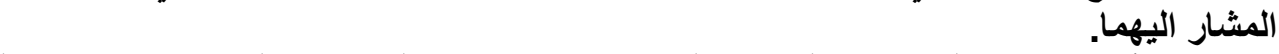

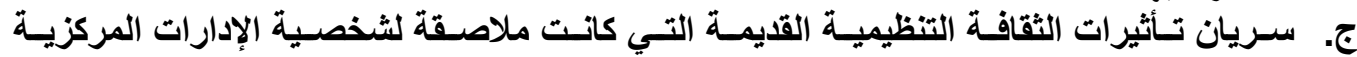

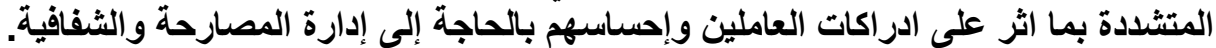

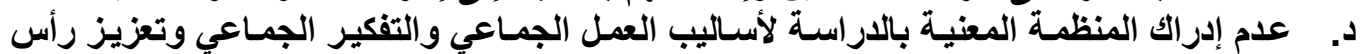

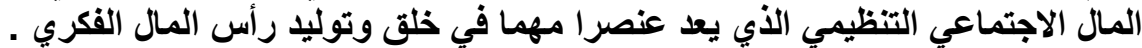

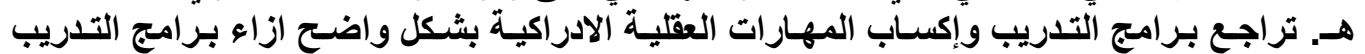

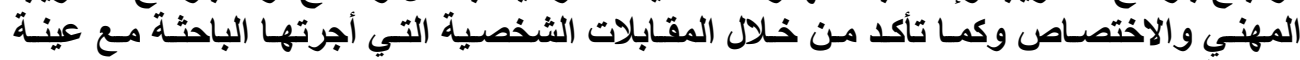




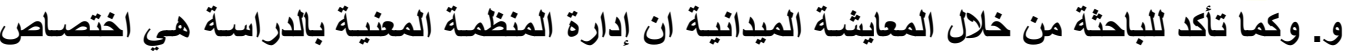

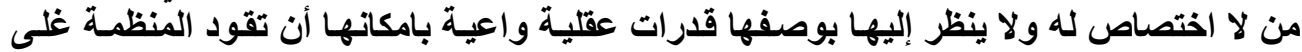

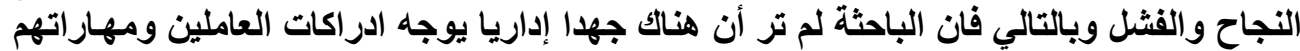

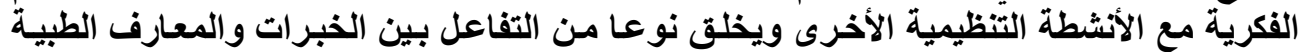

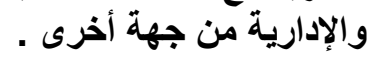

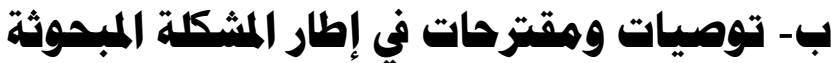

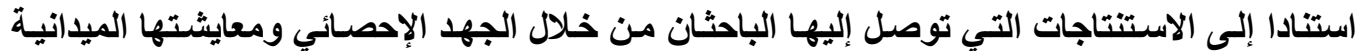
يمكن إجمال التوصيات بما يأتي: التئي

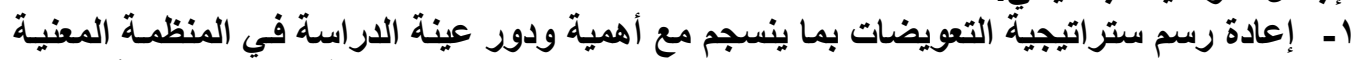

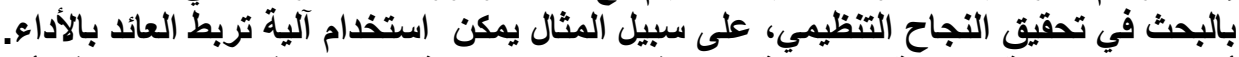

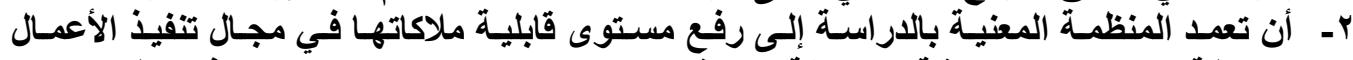

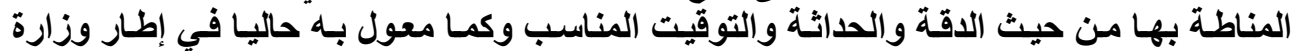

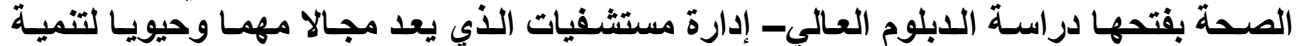

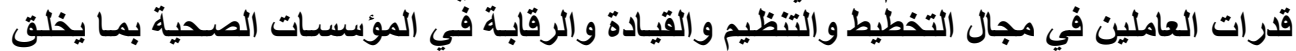

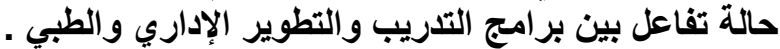

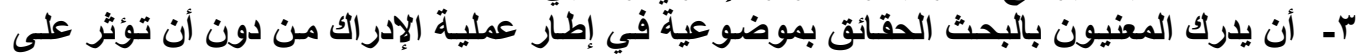
ادراكاتهم هذه هالة الصح أو الو هالة الخطأ.

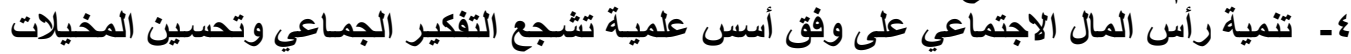

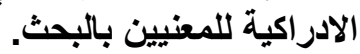

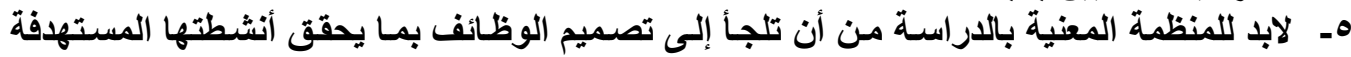

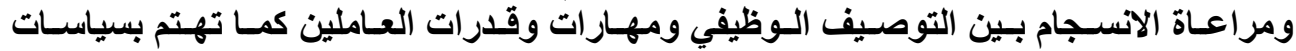

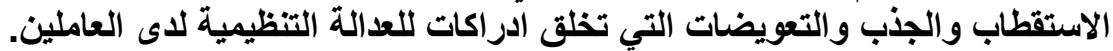

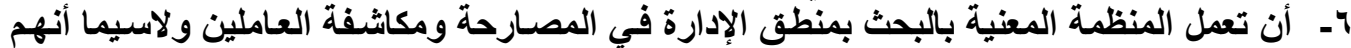

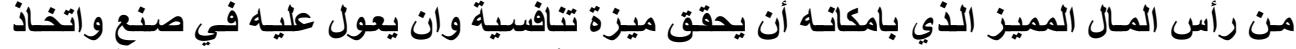

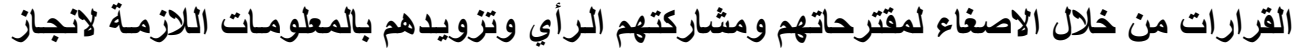

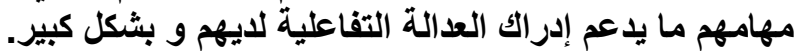

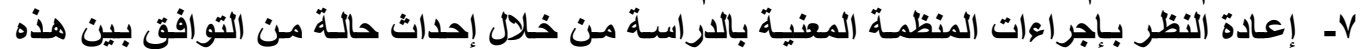

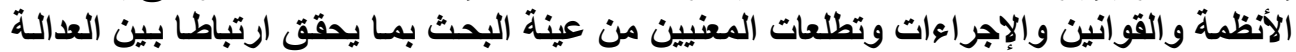

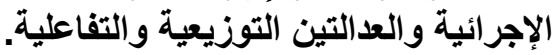

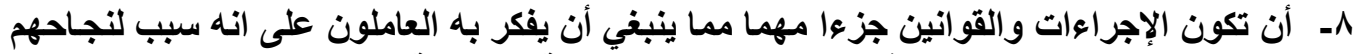

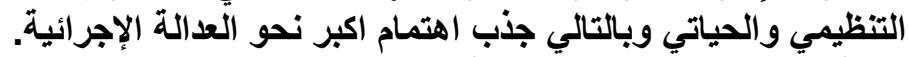

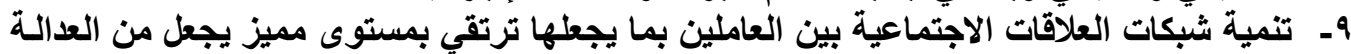

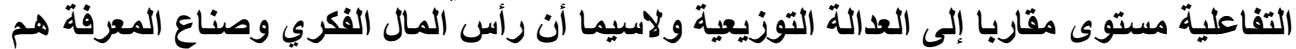

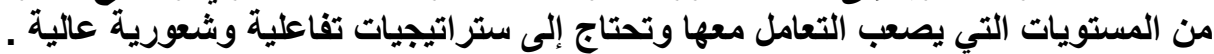

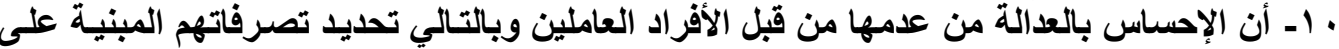

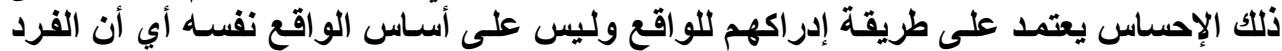

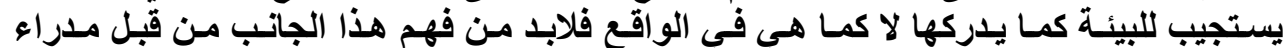

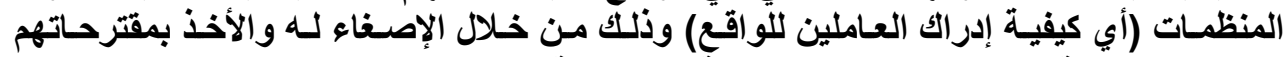

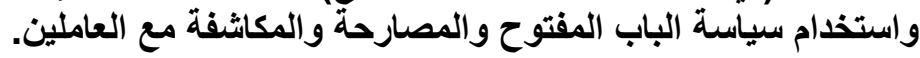




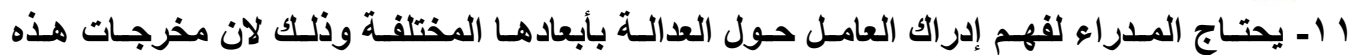

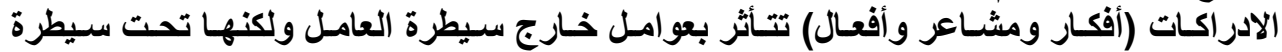

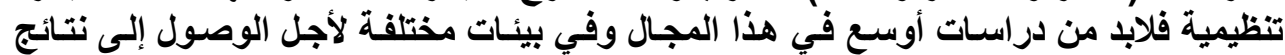

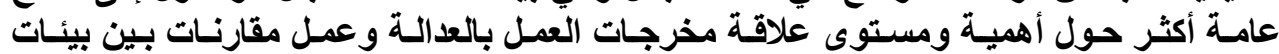

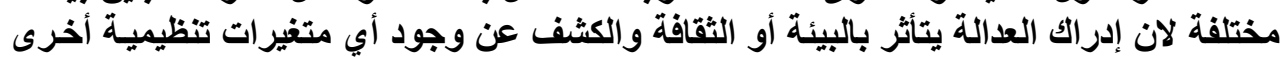

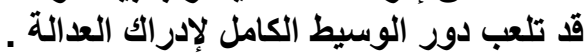

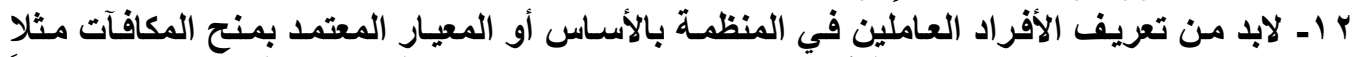

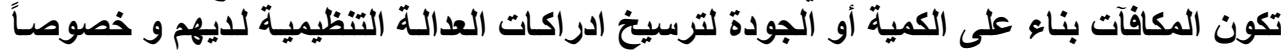

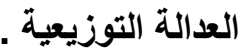

ب ا- هناك مكافآت مادية ومعنوية فلابد من تحديد وجهات نظر العاملين حولها كونهم يدركون نوعيات

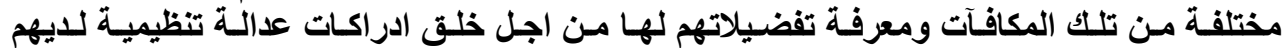
وخصوصاً العدالة التفاعليّة.

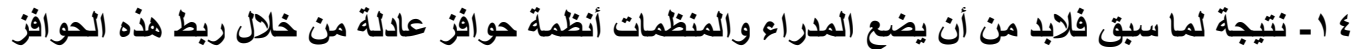

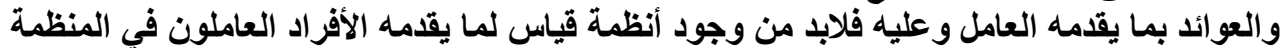

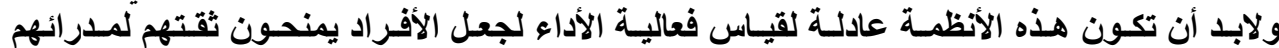

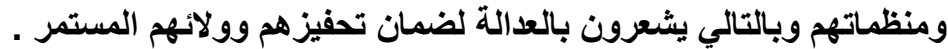

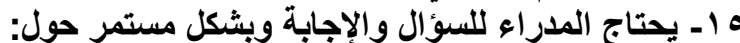

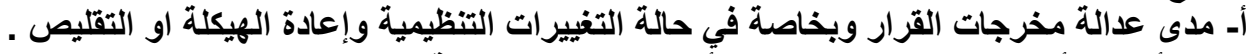

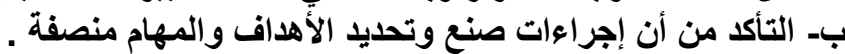

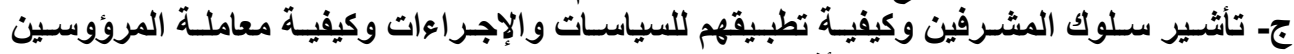
و التابعين لقرار اتهم وسلطاتهم و وأفعالهُ .

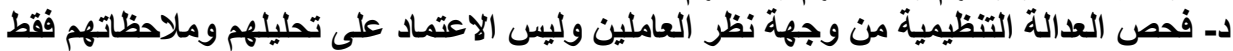

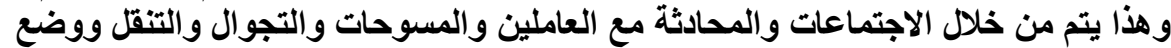

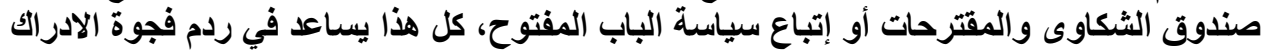

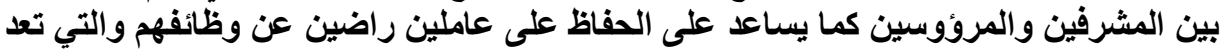

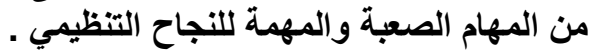




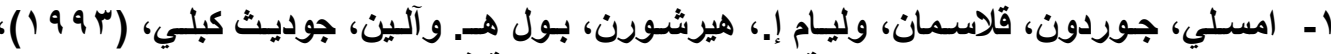

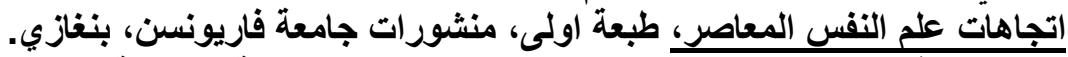

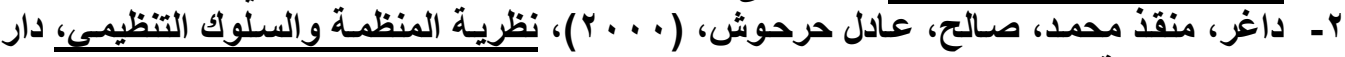

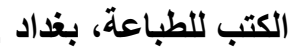

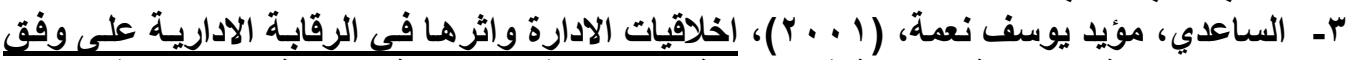

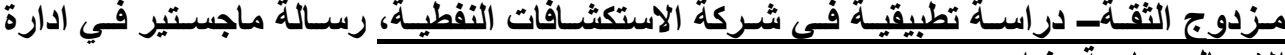

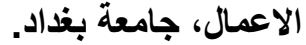

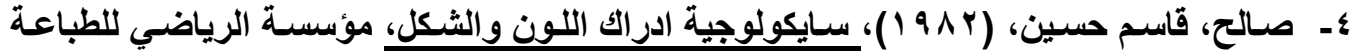

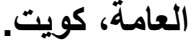

هـ العميان، محمود سلمان، ( ؟ . . ب)، السلوك التظيمى في منظمـات الاعمـال، الطبعة الثانية، دار

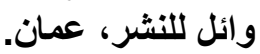

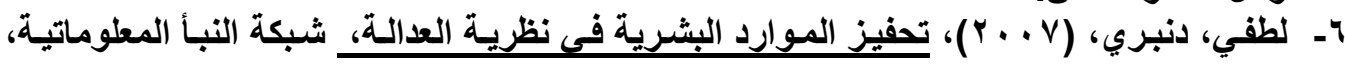
. www.annabaa.org

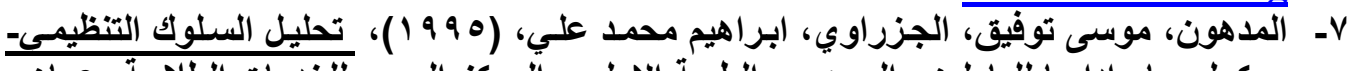

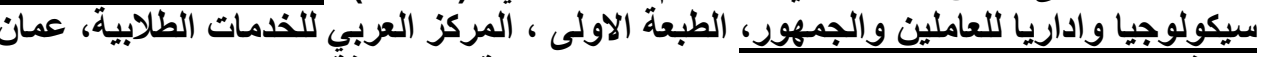

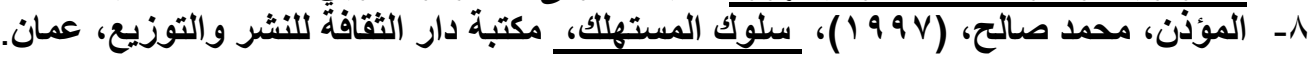

ثانيا: الاجنبية

1. 13-Champoux, Joseph E., (2000), organizational behavior: Essential Tenets for a new millennium, south- western college publishing - an international Thomson publishing company-ITP.

2. 14-Daft, Richard L., Noe, Raymond A., (2001), Organizational behavior , Harcourt college publishing, New York .

3. 15-Hellriegel, Don, Slocum, Jr., John W., woodman, Richard W., (2001), Organizational behavior, Ninth edition, south - western college publishing,

4. 16-Heresy, Paul, Blanchard, Kenneth H. , Johnson, Dewey E. , (2001), Management of organizational behavior- Leading Human resources, eighth edition , prentice-Hall , Inc., New Jersey.

5. 17-Ivancevich, John M., Matteson, Michael T. , (2002), organizational behavior and management, sixth edition, MCGraw-Hill higher education Irwin.

6. 18-Kreitner, Robert, Kinick, Angelo, (1992), organizational behavior, $2^{\text {nd }}$ edition, Irwin .

7. 19-Luthans, Fres, (1973), organizational behavior - amodern behavioral approach to management, to sho printing Co., Tokyo .

8. 20-Morgan, Clifford T., King, Richard A., Robinson, Nancy M., (1979), Introduction to Psychology, Sixth edition, MCGraw - Hill international book company, Tosho printing Co., Ltd. Tokyo. 
9. 21-Robbins, Stephen P., (2000), Essentials of organizational behavior, prntice Hall, New Jersey .

10. 22- Rowe, Alan J., Mason, Richard O., Dickel, Karl E. , Mann, Richard B., Mockler , Robert J., (1994), Strategic Management - am ethological approach, Addison -Wesley piublishing company, Inc.

11. 23- Schermerhorn , Jr. m John R. , Hunt , James G. , Osborn , Richard N. (1998), Basic organizational behavior, John Wley \& Sons , Inc. , New York.

12. Bradley, Lisa M., (2008), Perceptions of justice when selecting internal and external job candidates, personnel review, vol.35, number 1 .

13. 25-Campbell, Lisa, Finch, Edward , (2008), Customer satisfaction and organizational justice, facilities, vol.26, number 7/8.

14. 26-Eberlin, Richard, Tatum, B. Charles, (2008), organizational justice and decision making, management decision, vol.43, number 7/8.

15. 27-Fernandes, Cedwyn, Awameleh, Raed, (2008), Impact of organizational justice in an expatriate work environment, management research news, vol.31, number 11.

16. 28-Kivimaki, M., Elovainio, M., Vahtera, J., Ferrie, JE, (2003), organizational justice and health \& employees : perspective cohort study, occupational and environment medicine, 60 .

17. 29-Lilly, Juliana D. , Virick , Meghna , (2008), the effect of personality on perceptions of justice, journal of managerial psychology, vol.21, number 5.

18. 30-Peltola, Erja Wiili, Kivimaki , Mika , Elovainio, Mark , \& Virtanen, Marianna, (2007), organizational justice and employee perceptions on hospital management, vol.21, number .3.

19. 31-Sanders, Mark N.K., Thornhill, Adrian, (2008), organizational justice, Trust and the management of change an expliration, personnel review, vol.36, number .3.

20. 32-Suliman, Abubakr Mohyeldin Tahir , (2008), Links between justice, Satisfaction and performance in the workplace, journal of management development, vol.26, number.4.

21. 33-Tatum, B. Charles, Eberlin , Richard , Kottraba, Carin , Bradberry, Travis, (2008), Leadership, decision making, and organization justice, management _decision , vol,43, number.10.

22. 34-Teo, Thompson S.H., Lim, Virien K.G., (2008) .The effects of perceived justice on satisfaction and behavioral intentions on case of computer purchase, international journal of retail \& distribution management, vol.29, number.2.

23. 35-Wang, Yuan, (2008), Trust, procedural justice and Decision- making style: A study collective and private enterprises in the context of China's reform,vol.34, number .12. 